\title{
EFFECTS OF SUPPLEMENTAL HYDRATION ON PHYSIOLOGY AND BEHAVIOR OF NORTHERN PACIFIC RATTLESNAKES (CROTALUS OREGANUS OREGANUS)
}

\author{
A Thesis \\ presented to \\ the Faculty of California Polytechnic State University, \\ San Luis Obispo
}

\author{
In Partial Fulfillment \\ of the Requirements for the Degree \\ Master of Science in Biological Sciences
}

by

Griffin Dale Capehart

December 2015 
(C) 2015

Griffin Dale Capehart

ALL RIGHTS RESERVED 
TITLE:

AUTHOR:

DATE SUBMITTED:

COMMITTEE CHAIR:

COMMITTEE MEMBER:

COMMITTEE MEMBER:
Effects of supplemental hydration on physiology and behavior of Northern Pacific rattlesnakes (Crotalus oreganus oreganus)

Griffin Dale Capehart

December 2015

Emily Taylor, Ph.D.

Associate Professor of Biology

Clinton Francis, Ph.D.

Assistant Professor of Biology

John D. Perrine, Ph.D.

Associate Professor of Biology 


\begin{abstract}
Effects of supplemental hydration on physiology and behavior of Northern Pacific rattlesnakes (Crotalus oreganus oreganus)
\end{abstract}

\title{
Griffin Dale Capehart
}

Hydration is a critical element for many physiological processes in vertebrates, such as protein production, innate immunity, and behavioral processes such as daily activity and thermoregulation. Few studies have directly assessed the effect of hydration on these animals in nature. While it seems intuitive that drought is stressful to animals, studies examining drought are typically observational and fail to assess how the hydration state of these animals influences their physiology and behavior. We tested for an effect of hydration on several physiological and behavioral parameters in Northern Pacific rattlesnakes (Crotalus oreganus oreganus) by experimentally manipulating hydration levels in the field. Two treatment groups were created: one of these received supplemental hydration twice a month from May to September (hydrated) while the other did not (control). Pregnant females were brought to the lab before parturition to collect data on litter characteristics. We radio-tracked snakes to examine any effects on movement, measured SVL and mass of each snake throughout the study for assessment of body condition, and collected blood samples for stress hormone physiology. Finally, we used intra-coelomic temperature data loggers to track body temperature data for each individual snake every two hours.

Our results suggest that supplemental water and thus hydration has a significant effect on reproduction as all four hydrated females gave birth to a litter, while no control females gave birth. We saw no effect on movement parameters; however, males had larger home ranges and moved a larger total distance than females, regardless of hydration status. Interestingly, body condition was significantly higher in hydrated snakes, suggesting that hydrated individuals were acquiring more food than control snakes. We saw no effect on stress hormone physiology. There was no influence of hydration on any behavioral parameters such as time spent above or below ground, or time spent in a particular body position. Finally, there was a significant interaction of treatment group and sex on seasonal body temperature. Hydrated females had higher mean body temperatures than all other treatment group and sex combinations. However, all hydrated females were also pregnant, which confounds this result. Similar results were seen when body temperature was analyzed by time of day. Females overall had higher body temperature than males.

These results suggest that hydration may have a profound influence on reproduction and has the potential to affect body condition and thermoregulation. The lack of an effect on movement and stress physiology should not be overlooked, however. This study is the first to experimentally manipulate hydration in free-ranging rattlesnakes and one of the few to manipulate hydration in vertebrates. More studies are needed to support a pivotal role of hydration in physiology and behavior of reptiles and we encourage the use of experimental field manipulations to answer these questions. 


\section{ACKNOWLEDGMENTS}

This thesis would not have been possible without the overwhelming support and contributions of many people. My advisor and committee chair, Dr. Emily Taylor, provided me with extremely helpful advice, ideas, constructive criticism, and taught me so much about herpetology and physiology in general. Also, her patience with me as a young, inexperienced and often clueless graduate student was much appreciated. Tony Frazier's advice and support was invaluable and the many hours spent talking about snakes and the like has allowed me to maintain the necessary focus and drive to complete this thesis. Thanks to Mike DeLea for putting up with me and providing me with advice in the lab and field. I would also like to thank Natalie Claunch for her patience with me as a lab mate and providing me with feedback on drafts. Her assistance as a lab mate for the past year has been instrumental in this process. Many thanks to our collaborator, Ignacio Moore, who has graciously performed radioimmunoassay for our lab over the years. Additionally, I would like to thank my other committee members, Dr. Clint Francis and Dr. John Perrine for their feedback and assistance. Many undergraduates were essential for data collection: Gillian Larson, TJ Traber, Alex Harrison, Liz Saldo, Nikki Murphey, Jeff Warshauer, Scott Wong, Kate Vanderslice, Greg Reading, Abby Nemeth, and Matt Kane. My fellow graduate students also deserve an acknowledgement because of their continual support and help with classes, teaching, and research. Finally, I would like to thank California Polytechnic State University and California State Parks and John Sayers for funding and support of this project. 


\section{TABLE OF CONTENTS}

Page

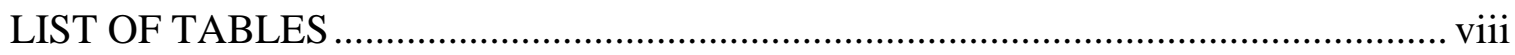

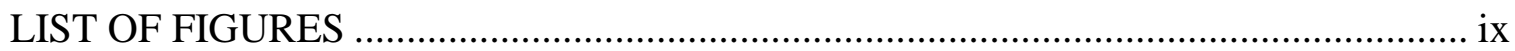

CHAPTER

GENERAL INTRODUCTION .............................................................................

1. EFFECTS OF SUPPLEMENTAL HYDRATION ON

REPRODUCTION, MOVEMENT, BODY CONDITION, AND

STRESS HORMONE PHYSIOLOGY OF NORTHERN PACIFIC

RATTLESNAKES (CROTALUS OREGANUS OREGANUS) ....................

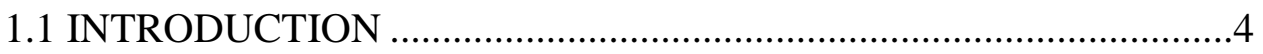

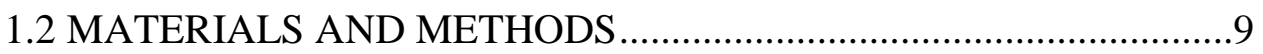

1.2.1 Study Animal and Site ....................................................

1.2.2 Experimental Manipulation of

Hydration ......................................................................... 10

1.2.3 Reproduction ..............................................................12

1.2.4 Home Range and Activity Patterns.....................................13

1.2.5 Body Condition ................................................................

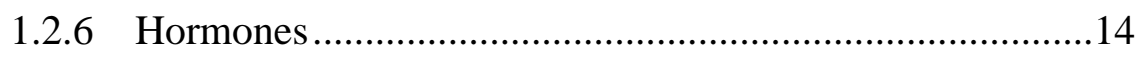

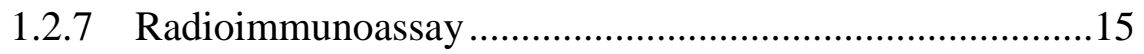

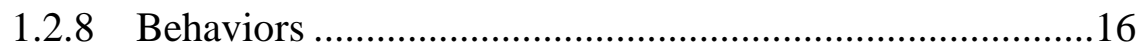

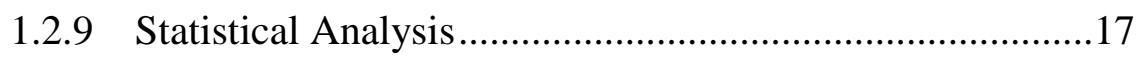

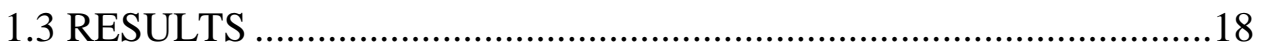

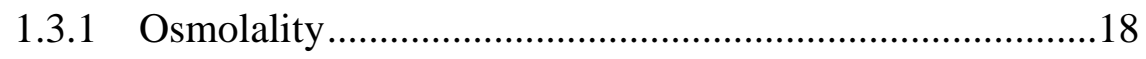

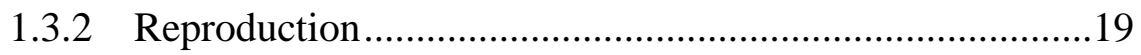


1.3.3 Home Range..............................................................19

1.3.4 Body Condition .......................................................20

1.3.5 Hormones .................................................................21

1.3.6 Behavior ..........................................................21

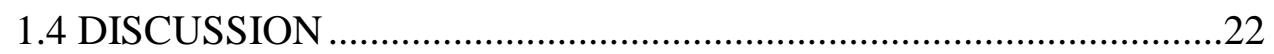

2. EFFECT OF SEX, REPRODUCTIVE STATE, AND HYDRATION ON THERMOREGULATION IN FREE-RANGING NORTHERN PACIFIC RATTLESNAKES (CROTALUS OREGANUS OREGANUS)..31

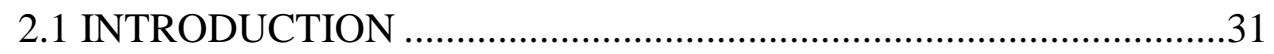

2.2 MATERIALS AND METHODS ...................................................33

2.2.1 Study Animal and Site ............................................33

2.2.2 Experimental Manipulation of

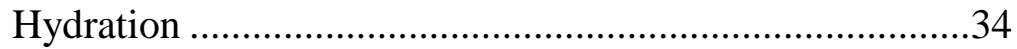

2.2.3 Thermal Biology .....................................................36

2.2.4 Statistical Analysis ....................................................36

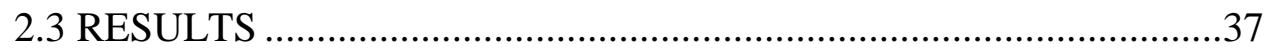

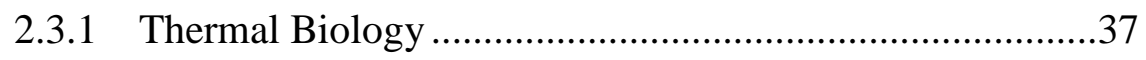

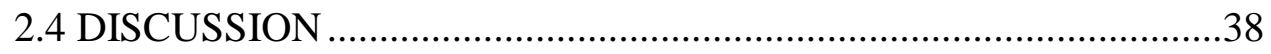

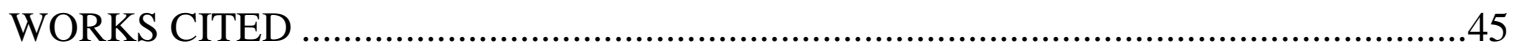

APPENDICES

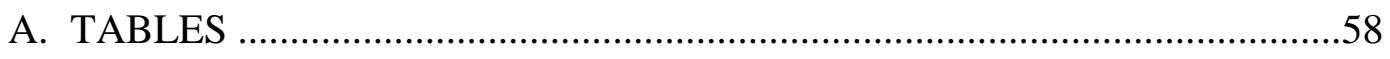

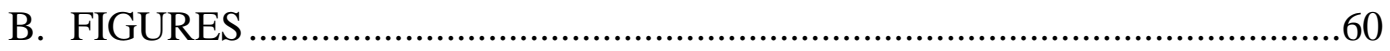

C. SUPPLEMENTARY FIGURES ....................................................... 81 


\section{LIST OF TABLES}

Table

Page

1. Descriptive characteristics of reproductive female Northern Pacific Rattlesnakes (Crotalus oreganus oreganus), all of which received supplemental hydration.

2. Means \pm SE of Northern Pacific Rattlesnakes (C. o. oreganus) for $100 \%$ and $95 \%$ minimum convex polygon (MCP) activity ranges (ha), total distance moved (m), and rate of movement ( $\mathrm{m} /$ day) for the entire study period ranging from $3 / 25 / 14$ 10/19/14. Note: Most snakes were tracked for a smaller period of time; however, all locations were recorded between the two previously mentioned dates

3. Effects of treatment group (hydrated and control), time (initial and end of study), and their interaction on body condition index (BCI) of $C$. o. oreganus. $\mathrm{P}<0.05$ designated by bold italics; $0.05<\mathrm{P}<0.10$ designated by italics. For unadjusted BCI and $\mathrm{BCI}$ adjusted for $10 \mathrm{~g}$ and $5 \mathrm{~g}$ of water weight, final BCI was higher for hydrated snakes, but this was marginally non-significant. In general, BCI was similar between treatment groups at the beginning of study, while hydrated snakes had higher BCI by the end of the study.... 


\section{LIST OF FIGURES}

Figure

Page

1. Map of study site highlighting two locations where the study took place. Both sites were located within Montaña de Oro, indicated by star on inset map....

2. Plasma osmolality of hydrated (water-supplemented) Crotalus o. oreganus was significantly lower than in control snakes, indicating that experimental water supplementation was successful. Numbers in bars are sample sizes, and error bars represent 1 SEM

3. $100 \%$ Minimum Convex Polygon (MCP) areas for C. o. oreganus. Males had larger home ranges than females, however, this result was driven by an outlier male. Additionally, a single female displayed an unusually large home range. A separate analysis was performed without these individuals, which found no significant difference between the sexes. Note the variability in home range size. Numbers at the base of bars are sample sizes and error bars represent 1 SEM

4. Snout-vent-length (SVL) of C. o. oreganus individuals is plotted against the area of the 100\% Minimum Convex Polygon (MCP) area or home range. Larger snakes had larger home ranges. Note that male home ranges are very similar to female home ranges and that only a few males had extensive home range sizes. There are two obvious outliers: one female and one male (circled). These snakes exerted large leverage on the home range analysis. Removal of these individuals caused the difference in home range size between the sexes to disappear. There was no effect of hydration on home range size

5. Snout-vent-length (SVL) of C. o. oreganus individuals is plotted against the area of the 95\% Minimum Convex Polygon (MCP) area or home range. Larger snakes had larger home ranges. Note that male home ranges are very similar to female home ranges and that only a few males had extensive home range sizes. There are two obvious outliers: one female and one male (circled). These snakes exerted large leverage on the home range analysis. Removal of these individuals caused the difference in home range size between the sexes to disappear. There was no effect of hydration on home range size. Only one snake experienced a large reduction in home range size from the calculation of $100 \% \mathrm{MCP}$ to $95 \% \mathrm{MCP}$

6. Total distance moved (TDM) of $C$. o. oreganus males and females. Males moved a larger total distance than females. Males moved $257 \mathrm{~m}$ more than females on average. The removal of the outlier female which moved a further total distance than all but one male did not influence the results. Numbers in bars are sample sizes and error bars are 1 SEM

7. Snout-vent-length (SVL) of individual C. o. oreganus is plotted against its total distance moved. Longer snakes moved larger total distances. Note the female 
which moved a larger total distance than all but one male (circled). Despite this, males still moved a larger total distance, overall

8. Snout-vent-length (SVL) of individual C. o. oreganus is plotted against the average distance moved per day. Longer snakes typically moved larger distances, with a few exceptions. The female with an abnormally large home range and total distance moved also had large daily movements (solid circle). Additionally, one smaller male $(\mathrm{SVL}=70)$ had larger movements than all but two males (dotted circle) ...67

9. Body condition index (BCI) for C. o. oreganus taken at the beginning and end of the study period. There was a significant main effect of hydration where hydrated snakes had significantly higher BCI than control snakes. There was a marginally non-significant interaction between time (initial or final) and treatment group with hydrated snakes having higher final BCI than control snakes. After adjusting for water weight, this difference was non-significant. Hydrated snakes BCI was still significantly higher than control snakes. The overall difference between the treatment groups appears to be driven by the increased BCI in hydrated snakes and the decrease in BCI in control snakes at the end of the study. Note the similarity in initial BCI.

10. Mean corticosterone (CORT) concentrations of $C$. o. oreganus for baseline or stressed samples, sex, and treatment groups (control or hydrated). Stressed CORT concentration was consistently higher than baseline CORT regardless of treatment group or sex. There were no effects of hydration or sex on CORT physiology. Error bars are 1 SEM

11. Frequency of time spent by C. o. oreganus in different body positions. Snakes spent a significantly larger amount of time in a moderate coil than in any other body position. This is expected in an ambush forager that does not make frequent movements. Bars that do not share a letter are significantly different. Error bars are 1 SEM

12. Frequency of time spent above or below ground by C. o. oreganus. Snakes spent a significantly larger portion of time on the surface than below ground. There were no effects of treatment group or sex on time spent on the surface. Error bars are 1 SEM

13. Mean $\mathrm{T}_{\mathrm{b}}$ of $C$. o. oreganus during spring, summer, and fall averaged across treatment groups and sexes $(\mathrm{N}=16) . \mathrm{T}_{\mathrm{b}}$ in the summer was significantly warmer than in the spring, but not from the fall. Note that $T_{b}$ is always lower than the max air temperature

14. Mean $\mathrm{T}_{\mathrm{b}}$ of C. o. oreganus during spring, summer, and fall. Hydrated females had significantly higher mean $\mathrm{T}_{\mathrm{b}}$ than both hydrated and control males, but not control females. This is most likely due to the fact that all hydrated females were pregnant. Note the large variance in $\mathrm{T}_{\mathrm{b}}$ of hydrated females and that the control 
15. Mass of individual C. o. oreganus is plotted against mean $\mathrm{T}_{\mathrm{b}}$. Mass was significant as a covariate in the analysis of seasonal mean $\mathrm{T}_{\mathrm{b}}$ with larger snakes having lower mean $\mathrm{T}_{\mathrm{b}}$

16. Mean variance of male and female $C$. o. oreganus in spring, summer, and fall. Variance was significantly higher in spring, regardless of sex or treatment group. Bars that do not share a letter are significantly different from each other. Numbers in bars are sample sizes and error bars are 1 SEM

17. Mass of individual C. o. oreganus is plotted against variance in seasonal $\mathrm{T}_{\mathrm{b}}$. Mass was a significant covariate in the analysis of seasonal variance in $T_{b}$ with heavier snakes having more variance

18. Mean $\mathrm{T}_{\mathrm{b}}$ of hydrated and control $C$. o. oreganus at four different times of day. The effect of hydration was dependent on the time of day. After noon, hydrated and control groups did not differ. However, between 0:00-10:00 hydrated and control groups differed in mean $\mathrm{T}_{\mathrm{b}}$. Bars that do not share a letter are significantly different. Error bars are 1 SEM

19. Mean $\mathrm{T}_{\mathrm{b}}$ of C. o. oreganus at four different times of day. Hydrated females show the highest mean $\mathrm{T}_{\mathrm{b}}$ regardless of time of day, however this was marginally nonsignificant. Note that all hydrated females were pregnant. Error bars are 1 SEM ....

20. Mean $\mathrm{T}_{\mathrm{b}}$ of male and female C. o. oreganus at four different times of day. Females had significantly higher $\mathrm{T}_{\mathrm{b}}$, regardless of the time of day. Error bars are 1 SEM

21. Variance in $\mathrm{T}_{\mathrm{b}}$ of male and female $C$. o. oreganus at four different times of day. The effect of sex on variance in $\mathrm{T}_{b}$ was dependent on the time of day. Means that do not share a letter are significantly different. Variance for males spiked in the middle of the day, while for females it drops. This suggests that the pregnant females in this group were maintaining a narrow temperature range; however, this difference was not significant. Error bars are 1 SEM

22. Initial BCI of individual C. o. oreganus is plotted against baseline and stressed CORT concentrations. Higher body conditions corresponded to lower CORT concentrations regardless of whether the sample came from before or after an acute stressor. Hydrated females are not included in this figure. ANCOVA: Sample $\mathrm{F}_{1,9.8}=$ 263.69, $\mathrm{p}<0.001$; Initial body condition $\mathrm{F}_{1,5.82}=17.83, \mathrm{p}=0.006$.

23. Plasma osmolality of individual $C$. o. oreganus is plotted against CORT concentration. There was a slight positive relationship and higher plasma osmolality corresponded to higher CORT concentrations. This relationship was not significant as a linear regression, but when included as a covariate with CORT as an ANCOVA 
it was significant (Sample $\mathrm{F}_{1,9.8}=263.69, \mathrm{p}<0.001$; plasma osmolality

$\left.\mathrm{F}_{1,5.81}=11.12, \mathrm{p}=0.016\right)$

24. Cloacal $\mathrm{T}_{\mathrm{b}}$ of individual C. o. oreganus is plotted against baseline and stressed CORT concentration. As temperatures rose, so did CORT concentrations. This was not significant on its own as a linear regression but was significant as a covariate with CORT in an ANCOVA (Sample $\mathrm{F}_{1,9.8}=263.69$, $\mathrm{p}<0.001$;

Cloacal $\mathrm{T}_{\mathrm{b}} \mathrm{F}_{1,6.1}=8.77, \mathrm{p}=0.025$ ). 


\section{GENERAL INTRODUCTION}

The effects of abiotic factors such as season and climate on biological communities have been examined by many scientific investigators. These ecosystem attributes play roles in the timing of reproductive behavior and migrations, food availability, and most importantly, survival. For example, with the onset of spring comes a change in weather and day length, which coincides with a burst of primary productivity, migrating songbirds, and large gatherings of breeding amphibians. Changes in season and climate have a wide range of effects. Primary productivity is reduced during severe heat and drought (Ciais et al., 2005); bird assemblages peak near water sources (Bock \& Bock, 1999; Bock, 2015); and rainfall stimulates amphibians to emerge from hibernation and migrate to breeding ponds (Blanchard, 1930; Martof, 1953). The common theme in all of these scenarios is water. Water influences a wide range of physiological processes and behaviors from the structure of DNA and protein folding to the massive migration that takes place every year on the African savanna where immense herds of Wildebeest (Connochaetes taurinus) follow the rains in search of fresh grazing opportunities (Albiser et al., 2001; Chaplin, 2001; Boone et al., 2006; Holdo et al., 2009).

An animal's hydration state is broadly defined as the amount of water present in the animal's system. Hydration state is obviously influenced by the amount of water in an environment. In the Sonoran Desert of Arizona, the seasonal monsoons provide a brief reprieve from the extreme heat and dryness and cause a burst of activity in everything from soil microbes, to birds and Gila Monsters (Heloderma suspectum) (Cable \& Huxman, 2004; Bock \& Bock, 1999; Davis \& DeNardo, 2010, respectively). Despite the 
obvious influence of hydration on animal physiology and behavior, very few studies have attempted to quantify these effects. This is surprising considering that climate change researchers predict drought to increase in severity in the $21^{\text {st }}$ century (Cook et al., 2004; Burke et al., 2006; Seager \& Vecchi, 2010). The central coast of California is currently (as of summer 2015) in an exceptional drought (droughtmonitor.unl.edu), considered California's worst in 1200 years (Griffin \& Anchukaitis, 2014). Physiologists know very little about how animals are responding to the current drought, or how they respond to drought in general. The current study was conceived in an effort to examine how the physiology and behavior of animals experiencing drought differ from animals with the pressures of drought removed. To achieve this goal, we experimentally manipulated hydration in free-ranging Northern Pacific rattlesnakes (Crotalus oreganus oreganus) by providing a subset of snakes with supplemental hydration. We chose rattlesnakes as a model organism because of their ability to respond and acclimate to changes in the environment (Andrade et al., 2004; McCue, 2007; Lutterschmidt et al., 2009). Additionally, multiple experiments on rattlesnakes have revealed that these reptiles are very robust to experimental manipulation in the field (Taylor et al., 2005; Brown et al., 2009; Holding et al., 2014), making us more confident that the observed physiology and behavior is natural.

To date, no studies have specifically addressed how rattlesnakes respond to drought. There are no studies directly asking this question. We decided to fill this gap by asking how some of the basic life-history characters of rattlesnakes are affected by a change in hydration state. We collected data on reproduction, movement parameters, body condition, hormones, and finally thermal biology. Our relatively non-invasive 
methodology allowed us to gather data on all of these variables simultaneously. We also collected snout-vent-length (SVL) and mass each time a snake received a water treatment, which allowed us to compare body condition between hydrated and control individuals, as well as during different time periods of the study. Stress reactivity data was also collected at the end of the study period. We collected blood samples before and after a standardized stressor to observe the effects on the stress hormone corticosterone (CORT). Finally, it is standard procedure to implant temperature data loggers in rattlesnakes for almost any study because they are easy to use and inexpensive. We used these to observe thermoregulatory patterns, which influence nearly every aspect of a reptile's day-to-day activity.

In summary, a relatively simple experimental design morphed into a multi-faceted study that culminated in this thesis. In Chapter 1 , the effects of hydration and sex on the reproduction, movement, body condition, and stress hormone physiology of rattlesnakes are presented. Chapter 2 focuses on the effects of hydration and sex on the thermal biology of these rattlesnakes. Major tables and figures are included within the chapters, and I provide additional figures in an Appendix for reference. 


\section{Chapter 1: Effects of supplemental hydration on reproduction, movement, body condition, and stress hormone physiology of Northern Pacific rattlesnake (Crotalus oreganus oreganus)}

\subsection{INTRODUCTION}

Hydration is a crucial component of the overall homeostatic balance an organism must maintain for survival. The ability of an animal to acquire water and use it efficiently is subject to strong selection in nature, especially in dry climates. Scientists have documented a recent increase in drought severity and predict this trend to continue (Burke et al., 2006; Carnicer et al., 2011), further emphasizing the importance of waterconservation strategies. Many studies have examined a wide range of dehydration effects from protein production to innate immunity, but most of these studies took place under controlled laboratory settings (Chew, 1961; Shoemaker, 1964; Denny \& Dawson, 1975; Churchill \& Storey, 1995; Moeller et al., 2013). The lack of field studies highlights an area of research in need of more attention. Greene (2005) emphasized the importance of studying organisms in nature. He stresses that organisms exemplify topics such as genetics, development, morphology, physiology, behavior, and are also the fundamental unit of a population, community, or ecosystem. Thus, our understanding of organisms in nature spans the entire biological hierarchy of complexity. It follows that our current, clinical understanding of dehydration may not encompass the intricacies of how wild animals are affected by dehydration. Additionally, studying animals in-situ more 
accurately depicts the nature in which these animals respond to drought, whereas in the lab individuals may not behave in an ecologically and socially relevant manner.

It is generally agreed upon that drought is stressful to animals. Drought affects animal behavior and dietary niche breadth, which is mostly a response to the altered plant community (Folks et al. 2014). Whooping cranes' (Grus americana) over-winter survival is reduced during drought (Butler et al. 2014). In Africa, species that are adapted to a semi-arid climate still experience reductions in fecundity following a drought (Talbot \& Talbot, 1963). Finally, in a species of water snake (Seminatrix pygaea), larger snakes had lower survival during drought years (Winne et al. 2010). This could be due to differences in resource requirements of larger and smaller snakes. Larger animals require more food than smaller animals, and in times of low prey density (i.e. during a drought) these energy requirements cannot be met. Thus, the smaller snakes are selected for as a result of lower resource requirements. These studies suggest that drought's effects are universal and that diverse arrays of taxa are vulnerable.

Reproduction requires significant energy expenditure, which typically differs between the sexes. Generally, females invest more energy into the production of offspring than males (Herron \& Freeman, 2014). In viviparous snakes, a large portion of energy is allocated to vitellogenesis, or yolk production (Van Dyke \& Beaupre, 2011). This process occurs during late fall and spring in rattlesnakes (Taylor \& DeNardo, 2010). Water content of yolk is relatively high, with estimates of $>70 \%$ on the first day of incubation in the lizard Amphibolurus barbatus (Packard et al., 1985). Due to the high water content of the yolk, it can be hypothesized that a drought may affect the number or size of offspring a female is capable of producing, simply because she cannot allocate 
enough water to yolk production. Mallard ducks (Anas platyrhynchos) exhibited a shorter nesting period, unsuccessful re-nesting attempts, and a smaller average clutch size during dry years (Krapu et al., 1983). In birds, the amount of water and energy invested into an egg is fixed after eggs are laid. However, placental lecithotrophic reptiles can compensate for deficits in water or ion content of the yolk via the placenta (Stewart et al., 1990). This suggests that viviparous reptiles may be able to respond to changes in water availability when reproducing. On the contrary, if a female has to divert her own body water toward developing offspring, she runs the risk of dehydrating herself beyond her physiological limit. For example, water deprivation during pregnancy had no effect on litter size or mass in Vipera aspis; however, pregnant females lost $89 \%$ greater mass than nonreproductive females when water-deprived (Dupoué et al., 2015). This suggests that females compromise their own water balance for benefit to their offspring. It may be more beneficial to forego reproduction, for example by resorbing developing follicles, in order to survive to reproduce another year. These ideas have not been tested, as to date there have been no direct assessments of the effects of hydration on reptile reproduction.

During a drought, animals may move more frequently and/or for longer distances in search of water or food. Spatial ecology may therefore change depending on water availability in the environment. For example, many aquatic turtle species make large terrestrial movements in search of suitable nesting habitat, overwintering sites, better foraging grounds, or mating opportunities (Gibbons, 1986). These movements are limited by the amount of rainfall, with more movement occurring during periods of higher rainfall (Roe \& Georges, 2008). For amphibians, less water in the environment equates to a higher desiccation risk. For example, invasive cane toads (Rhinella marina) moved 
more under wet conditions when they were far from a water source, and moved less under dry conditions, typically following straight lines (Tingley \& Shine, 2011). Amphibians, being extremely vulnerable to desiccation, may be heavily influenced by rainfall in terms of movement. Reptiles, on the other hand, do not require direct access to bodies of water for survival. Instead of searching for water during drought, many species are more likely to remain stationary in an effort to conserve energy and water. For example, drought significantly reduced movements of the desert tortoise, Gopherus agassizii, and the Australian scincid lizard, Tiliqua rugosa (Duda et al., 1999; Kerr \& Bull, 2006, respectively). Evaporative water loss (EWL) increases with movement (Gans et al., 1968; Heatwole \& Veron, 1977; Seidel, 1978). Reptiles that decrease their movements may be doing so in an effort to minimize EWL.

Effects of dehydration on spatial ecology may also be tied to body condition. Drought results in decreases in primary productivity (Ciais et al., 2005; Peñuelas at al., 2007; Zhao \& Running, 2010). More productive ecosystems can support more trophic levels, and vice versa (Mittelbach, 2012). If primary consumer populations of rodents, a favorite prey source for large snake species like rattlesnakes, are negatively affected by drought, then body condition of their predators may also decrease (Sperry \& Weatherhead, 2008). Several aquatic snake species drastically declined in number and appeared to cease reproductive activities during a severe drought in the southeastern U.S. (Willson et al., 2006). This decline was partially attributed to lack of prey, which would cause a decline in body condition of snakes surviving the drought. These studies suggest that prey abundance may mediate the effect of drought on a predator species' body condition. This effect may also manifest itself if an animal foregoes movement in an 
effort to maintain a lower preferred body temperature. As body temperature increases, so does evaporative water loss, which has been shown to be true for multiple taxa (Amphibians: Buttemer, 1990; Amey \& Grigg, 1995; Reptiles: Bentley \& SchmidtNielsen, 1966; Cohen, 1975; Mammals: Zhu et al., 2008; Zhu et al., 2010; Birds: Batholomew et al. 1962; Wolf \& Walsberg, 1996). In a drought, animals will be actively working to minimize water loss and if that means moving less and avoiding foraging grounds, then body condition may decrease as a result of delayed foraging.

All of the previously mentioned traits may be affected by the stress of a drought. None of them are a direct measure of stress, however. Corticosterone (CORT) is a steroid hormone that is often used to quantify stress in vertebrates (Amphibians \& Reptiles: Moore \& Jessop, 2003; Mammals: Touma et al., 2004; Palme et al., 2005; Birds: Hau et al., 2010). CORT levels can be related to a multitude of life-history traits including spatial ecology (Bodnoff et al., 1995; Pravosudov, 2003), reproduction (Love et al., 2004; Cease et al., 2007), body condition (Belthoff \& Dufty, 1998; Moore et al., 2000), and thermal biology (Frigerio et al., 2004; Preest \& Cree, 2008). If any of these traits are affected by drought, then there may be a signature in CORT levels. Hurricane Rita and the subsequent drought significantly elevated plasma osmolality and CORT levels in alligators from Louisiana (Lance et al., 2010). It is not clear whether the drought was the direct cause for the elevated CORT, because the marsh was also inundated with seawater from the hurricane. This is the most likely cause for the high plasma osmolality, which could result in severe stress.

Drought presents an unpredictable and severe environmental stressor.

Rattlesnakes are excellent model organisms for physiological studies such as these 
because they are highly responsive to changes in the environment (de Andrade et al., 2004; McCue, 2007; Lutterschmidt et al., 2009). Despite this trend, no studies to date have directly assessed the ability of rattlesnakes to cope with drought and dehydration. We hypothesize that hydration affects the spatial ecology, reproduction, and body condition of Northern Pacific rattlesnakes (Crotalus oreganus oreganus). Additionally, we hypothesize that thermoregulation and hormones are associated with varying hydration levels. In order to test these hypotheses, we manipulated hydration in freeranging C. o. oreganus. We predicted hydrated snakes to a) have a higher proportion of reproductive individuals, b) have larger home ranges, c) have higher body condition, and d) have elevated CORT levels than control snakes.

\subsection{MATERIALS AND METHODS}

\subsubsection{Study Animal and Site}

Twenty-one adult $C$. o. oreganus were captured from Montaña de Oro State Park in Los Osos, San Luis Obispo County, California. Snakes were captured by visual encounter surveys at two sites within the park. The majority of the snakes ( $8 \mathrm{M}, 7 \mathrm{~F})$ were captured at the Bluff Trail. The Bluff Trail and surrounding vicinity is dominated by Coyote Bush (Baccharis pilularis), Poison Oak (Toxicodendron diversilobum), and California Sage (Artemisia californica). The remaining snakes (4 M, 2 F) were captured at the Sandspit, 2 miles north of the Bluff Trail (Fig. 1). The Sandspit is a sand dune complex with numerous vegetation islands, dominated by California Sage, Black Sage (Salvia mellifera), and invasive Ice Plant (Carpobrotus edulis). Collection and handling 
of rattlesnakes was carried out under California Department of Fish and Wildlife Scientific Collecting Permit \#SC-12963 and a California State Parks Permit. Use and treatment of snakes was conducted under California Polytechnic State University Institutional Animal Care and Use Committee Protocol \#1403.

Snakes were transported to California Polytechnic State University for radio transmitter implantation. Each snake was housed individually in a 28 " by 24 " by 12 " vision cage (Model V221, LLL Reptile and Supply Company) with a heat pad and hide box (no food or water was provided). Snakes were anesthetized via isoflurane inhalation (Vet One, MWI, USA) and implanted intra-coelomically with a 4-5g SB-2 radio transmitter (Holohil Systems Ltd. Carp, Ontario, Canada) and a 3.25g temperature data logger (model DS1921G, Maxim Integrated, San Jose, California). Snakes were allowed to recuperate for 1-2 days and then released at their site of capture. Snout-vent-length (SVL) and mass were recorded at the time of surgery and approximately every three weeks thereafter for each snake.

\subsubsection{Experimental Manipulation of Hydration}

Snakes were randomly assigned to one of two experimental groups. Treatments were balanced between the sexes. The first group (hydrated treatment) received an experimental hydration procedure twice per month, with the first treatments occurring on 17 May 2014 and every other week thereafter. Not all snakes had been added to the study at this point, therefore some treatments began later in the summer. The second group (control) received a sham procedure. The hydrated group consisted of 4 females and 6 males for a total of 10 snakes. The control group consisted of 5 females and 6 males for a 
total of 11 snakes. Three snakes died during the study; one apparently due to consumption of an overly large meal that she was incapable of digesting due to insufficient energy reserves, another due to predation, and a third to an infection. Two females from the control group died, leaving a total of three control female snakes. One control male died mid-way during the study, so his data were still used for home range analysis and thermal biology. This left five snakes in the control male group.

In early April 2014, prior to beginning treatments, blood samples were obtained from each snake to acquire initial values for blood osmolality (see below). Snakes were coaxed into a clear plastic tube for safe handling, and blood samples were obtained via caudal venipuncture. An intragastric tube procedure was used to introduce water into the esophagus and stomach of each snake in the hydrated group (Davis and Denardo 2009). While secure in the tube, a $52 \mathrm{~cm}$ tomcat urinary catheter rinsed with deionized water was introduced into the snake's mouth and down its esophagus, until the catheter was approximately $1 / 4$ of the way down the snake's body, in the stomach. The snake was then held upright while a $50 \mathrm{ml}$ syringe with plunger removed was affixed to the exposed end of the catheter. Twenty-five (25) ml of Millipore water (about 5-15\% of each snake's body mass) was then poured directly into the syringe and allowed to drain into the snake's esophagus and stomach. Snakes in the control group received the same treatment without the introduction of water. After being removed from the snake, the catheter was cleaned with a dry towel to remove any debris from the snake's esophagus that remained on the outside of the catheter. It was then flushed with water and then with ethanol to remove any debris inside the catheter. It was then stored in ethanol until the next treatment. Treatments occurred twice a month with snakes receiving $5.7 \pm 0.5$ (mean \pm 1 
SEM) total treatments for an average duration of $3.9 \pm 0.2$ months. At the end of the study, we again took a blood sample to measure osmolality. Samples were returned to the lab within 4 hours and immediately centrifuged. Plasma was separated from red blood cells and stored at $-2^{\circ} \mathrm{C}$ for $2-3$ days until plasma osmolality was determined with a freezing point depression osmometer (model 3320, Advanced Instruments, Inc., Norwood, Massachusetts).

\subsubsection{Reproduction}

In August, we used portable ultrasound (Ibex Pro model, E.I. Medical Imaging, Loveland, Colorado, U.S.A.) to examine female snakes for pregnancy. Ultrasound images were acquired using a curved linear transducer at a frequency of $6 \mathrm{MHz}$. When developing fetuses were detected and parturition appeared imminent (e.g., little yolk reserves, Taylor and DeNardo 2005), the snake was brought to the lab and housed individually until parturition in the same cages previously described with a heat pad and hide box but no water until after parturition. If they were in the lab during a treatment week, they were given their supplemental water. Females gave birth 2-4 weeks after they were brought to the lab. Within a day after parturition, SVL and mass of the mother and all viable and non-viable offspring were recorded. Non-viable offspring included those offspring that were stillborn or underdeveloped as well as yolk plugs ("slugs"). SVL of the viable neonates was measured with the squeeze-box method (Quinn and Jones, 1974). Sex of neonates was recorded when possible. Relative clutch mass was calculated as the clutch mass divided by the mother's post-parturient mass (Taylor and DeNardo 2005) and 
was calculated with and without non-viable offspring. Females were released with their neonates at their site of capture within a week after parturition.

\subsubsection{Home Range and Activity Patterns}

Snakes were tracked 4-6 times per month on average. Collectively, snake locations were recorded from 17 May 2014 to 2 November 2014 using a Garmin eTrex Legend H model GPS (Garmin Ltd.). All snake locations were uploaded to the DNRGPS application for Windows (Minnesota Department of Natural Resources) to convert the data to $(\mathrm{x}, \mathrm{y})$ coordinates for use in geographic information system (GIS) software. ArcMap 9.3 (ESRI, Redlands, California) was used for all spatial analysis. The Home Range Tools extension for ArcGIS (Rodgers et. al 2007) was used to calculate $100 \%$ and 95\% minimum convex polygon (MCP) home range sizes, which are frequently used for studies on rattlesnakes (Hyslop et. al, 2014; Putman et. al 2013). Total distance moved was calculated by measuring the cumulative distance between each consecutive location using the measure tool. The average rate of movement in m/day was calculated by dividing the total distance moved by the total number of days tracked. This metric may underestimate actual movement because we did not track snakes every day. However, rattlesnakes are relatively sedentary and this method provides a rough estimate of movement. Snakes were tracked an average of $18.7 \pm 1.7$ times throughout the duration of the study for an average of $139 \pm 10$ days. 


\subsubsection{Body Condition}

Body condition was calculated by regressing log-transformed body mass and logtransformed SVL and using the residuals as a body condition index (BCI) (Cease et. al 2007). Initial and final BCI were calculated using body mass and SVL measurements taken at the start and end of the study. Because body condition uses mass, we also attempted to control for the water mass added from our experimental water supplementation. We took each individual snake's final mass and subtracted $25 \mathrm{~g}$ to obtain a mass representative of the snake without the most recent water supplement. This new mass was then used to calculate a BCI. Because snakes might not be expected to retain the entire $25 \mathrm{~g}$ of water from the most recent treatment, we repeated this process by subtracting $20 \mathrm{~g}, 15 \mathrm{~g}, 10 \mathrm{~g}$ and $5 \mathrm{~g}$ from final mass to obtain six different measures of BCI.

\subsubsection{Hormones}

At the end of the experiment, we evaluated baseline CORT levels and stress reactivity of each snake. Snakes were captured and bled via caudal venipuncture for a baseline sample. Time-to-bleed (min) was recorded as well as cloacal temperature $\left({ }^{\circ} \mathrm{C}\right)$. After the first blood sample was collected, snakes were placed into a pillowcase and secured in an opaque plastic bucket for one hour to induce standardized handling stress (Holding et al., 2014). After this time, snakes were bled a second time. Samples were then returned to the lab within 4 hours and immediately centrifuged. Plasma was separated from red blood cells and stored at $-2^{\circ} \mathrm{C}$ for $2-3$ days and then stored at $-20^{\circ} \mathrm{C}$ until radioimmunoassay. We used radioimmunoassays of CORT to quantify stress 
reactivity, which is defined as the increase in CORT from baseline following an acute stressor (in this case handling stress) (Holding et al., 2014).

\subsubsection{Radioimmunoassay}

Radioimmunoassay methods and language are adapted from Holding (2011). Plasma samples were sent to Virginia State University (Blacksburg, VA) for radioimmunoassay. Corticosterone (CORT) was measured after extraction and chromatographic separation procedures (Wingfield and Farner, 1975; Taylor et al. 2004, Lind et al. 2010). When plasma steroid concentrations were predicted to be high, we used $20 \mu \mathrm{l}$ of plasma (post-stress), and when steroid concentrations were predicted to be low (<10 min after capture) we used $50 \mu$ of plasma (Taylor et al. 2004, Lind et al. 2010). Samples were equilibrated overnight with 2,000 cpm of tritiated steroid to determine individual extraction efficiency. Extractions were done in $5 \mathrm{ml}$ of distilled dichloromethane with the dichloromethane phase removed and dried in a bath warmed by a stream of nitrogen gas, and re-suspended in $10 \%$ ethyl acetate in isooctane. All samples were transferred to diatomaceous earth (Celite, Sigma) columns for chromatographic separation and removal of neutral lipids and isolation of individual steroids. Neutral lipids and other steroids were discarded via elution with $2 \mathrm{ml}$ of isooctane. CORT was eluted with $2.5 \mathrm{ml}$ of $50 \%$ ethyl acetate in isooctane. Samples were then dried in a $40^{\circ} \mathrm{C}$ water bath under nitrogen gas and subsequently re-suspended in $600 \mu l$ phosphate buffered saline, and maintained overnight at $4^{\circ} \mathrm{C}$.

Extraction efficiency for CORT was determined from $100 \mu \mathrm{l}$ of the sample, and $200 \mu \mathrm{l}$ of the sample was allocated to each of two duplicates for the assay. Mean recovery 
for CORT was $78.6 \%$. Serial dilutions for the standard curve was performed in triplicate (CORT curve range $=2000-4 \mathrm{pg})$. Samples were incubated overnight in $100 \mu \mathrm{l}$ of antiserum (T: T-3003, Wien Laboratories, Succasunna, NJ; CORT: Esoterix Endocrinology, Calabasas Hills, CA) and $100 \mu \mathrm{l}$ of tritiated steroid. Separation of unbound steroid was done using dextran-coated charcoal; bound steroid was then decanted into scintillation vials. A liquid scintillation counter was used to count samples and final concentrations were corrected for extraction efficiency. Intra-assay coefficient of variation $(\mathrm{CV})$ for CORT was $20 \%$.

\subsubsection{Behaviors}

Basic qualitative data were collected on detectability and body position.

Detectability was recorded as whether a snake was visible or not upon first approach. We also analyzed the frequency of snakes observed above ground and below ground. Body positions included tight coil, moderate coil, loose coil, and elongated. Snakes were considered to be in a tight coil when greater than $25 \%$ of its body was under coils, while a moderate coil was less than $25 \%$ coverage. A loose coil occurred when all of the snake's body was visible, but the snake was still in a coiled position. Elongated snakes included any snake that could not be considered coiled. It was also noted whether or not snakes had recently fed by observation of a noticeable food bulge during tracking or palpation when snakes were captured. We also recorded whether they rattled, fled, or tongue-flicked upon first approach; however, these behaviors were so rare that statistical analysis was not possible. 


\subsubsection{Statistical Analysis}

All statistical tests were performed in Minitab 16 (Minitab Inc. 2010) and JMP (SAS Institute Inc. 2013). ANOVA was the main test used to determine the effect of hydration on movement parameters, thermal biology, body condition, hormones, and behaviors. The General Linear Model (GLM) function was used to tailor these models.

All terms were included in the model and were systematically eliminated as nonsignificant terms were identified (see below). T-tests were used when only a single term was deemed significant and only two groups were of interest. All variables were subject to tests of normality and for the homogeneity of variances. When these assumptions were violated, transformations were applied to the variable in question.

The effects of hydration treatment and sex on plasma osmolality were modeled using ANOVA. Mass and the number of water treatments received by each snake were used as covariates. Osmolality was also analyzed using linear regression analysis to observe the relationship between the number of treatments and osmolality. Home range sizes measured using $100 \%$ and $95 \%$ MCPs were analyzed as an ANCOVA with SVL and total number of locations as covariates. Treatment group, sex and the interaction between treatment and sex were included in the model. Total distance moved and distances moved per day were analyzed in the same way. We used a mixed model ANOVA to examine the effect of treatment, time (initial or end of study), and the interaction between the treatment and time on BCI. Snake ID was included as a random factor. We performed this analysis for un-adjusted BCI and for each of the BCI adjusted for possible added water mass. We also used linear regression to elucidate any relationships between $\mathrm{BCI}$ and osmolality or CORT. The effect of treatment group, 
sample (baseline or stressed) and the interaction between treatment and sample on CORT was modeled with an ANCOVA with cloacal $\mathrm{T}_{\mathrm{b}}$, initial body condition, time-to-bleed, and plasma osmolality as covariates. Due to CORT's complex interactions with many life-history traits, we also used linear regression to examine potential relationships with home range and activity patterns, osmolality, and thermal biology. Pregnant females were not included in the CORT analysis because we did not calculate a BCI for these individuals. Behaviors were analyzed as frequencies. We took the number of times each individual snake was visible and divided that by the total number of observations to obtain a proportion. We did the same procedure for whether the snake was above or below ground and body position to acquire proportions of tightly, moderately, loosely coiled, and elongated positions. These proportions were then arcsine-square root transformed. We used ANOVA to determine if treatment group or sex had an effect on the amount of time spent visible or the amount of time spent in a particular body position.

\subsection{RESULTS}

\subsubsection{Osmolality}

Plasma osmolality was significantly lower in hydrated snakes (mean $=261.7$ $\mathrm{mOsm} / \mathrm{kg}$ ) than in control snakes (mean $=306.8 \mathrm{mOsm} / \mathrm{kg}$ ) at the end of the study (GLM: $F_{1,14}=16.74, p=0.002$, Fig. 2). There was no significant effect of sex on plasma osmolality $\left(\mathrm{F}_{1,14}=1.38, \mathrm{p}=0.265\right)$ and the interaction between treatment group (control or hydrated $)$ and sex was also non-significant $\left(\mathrm{F}_{1,14}=0.12, \mathrm{p}=0.732\right)$. Neither mass nor the number of treatments co-varied with plasma osmolality. 


\subsubsection{Reproduction}

All four hydrated females gave birth during the study while no control females gave birth. All females gave birth to at least one viable offspring and one unviable offspring (e.g. stillborn, under-developed, or a yolk plug). Three hydrated females each produced two non-viable offspring. Of these non-viable offspring, one was either malformed or under-developed while the other was a yolk plug. The fourth hydrated female produced only one viable and one non-viable offspring, which was a yolk plug. A summary of reproductive data for all four snakes can be found in Table 1.

\subsubsection{Home Range}

Home range size was not significantly affected by treatment group (ANCOVA: 100\% MCP: $\mathrm{F}_{1,14}=0.98, \mathrm{p}=0.339 ; 95 \%$ MCP: $\left.\mathrm{F}_{1,14}=0.42, \mathrm{p}=0.527\right)$. Males had larger $100 \%$ MCP home ranges than females $\left(\mathrm{F}_{1,14}=4.65, \mathrm{p}=0.049\right.$; Fig. 3$)$, but not $95 \% \mathrm{MCP}$ home ranges $\left(\mathrm{F}_{1,14}=3.40, \mathrm{p}=0.086\right)$; and the interaction between treatment and sex did not significantly affect home range size $\left(100 \% \mathrm{MCP}: \mathrm{F}_{1,14}=1.08, \mathrm{p}=0.316 ; 95 \% \mathrm{MCP}\right.$ : $\left.\mathrm{F}_{1,14}=0.92, \mathrm{p}=0.355\right)$. However, $\mathrm{SVL}$ was a significant covariate for both $100 \% \mathrm{MCP}$ $\left(\mathrm{F}_{1,14}=16.61, \mathrm{p}=0.002\right.$, Fig. 4$)$ and $95 \% \operatorname{MCP}\left(\mathrm{F}_{1,14}=11.19, \mathrm{p}=0.005\right.$, Fig. 5), indicating that larger snakes had larger home range sizes. Two snakes displayed relatively large home ranges and appeared to exert large leverage, thus a separate analysis was performed that excluded these individuals. This caused the difference in home range size between the sexes to disappear $\left(100 \% \mathrm{MCP}: \mathrm{F}_{1,12}=1.55, \mathrm{P}=0.237 ; 95 \%\right.$ MCP: $\mathrm{F}_{1,12}$ $=0.73, \mathrm{P}=0.409)$. 
Hydration had no effect on total distance moved $\left(\mathrm{F}_{1,14}=0.60, \mathrm{P}=0.45\right)$, nor did it interact with sex to affect movement $\left(\mathrm{F}_{1,14}=1.23, \mathrm{P}=0.27\right)$. Males moved a larger total distance than females (ANCOVA: $F_{1,14}=8.87, p=0.01$, Fig. 6), and SVL was significant as a covariate $\left(\mathrm{F}_{1,14}=23.69, \mathrm{p}<0.001, \mathrm{Fig} .7\right)$. Distance moved per day was not affected by treatment group, sex, or the interaction between sex and treatment (treatment group: $\mathrm{F}_{1,14}=0.05, \mathrm{p}=0.83 ;$ Sex: $\mathrm{F}_{1,14}=1.22, \mathrm{p}=0.29 ;$ treatment group by sex: $\mathrm{F}_{1,14}=2.95, \mathrm{p}=$ 0.11). SVL co-varied with distance moved per day, with larger snakes moving longer distances $\left(\mathrm{F}_{1,14}=8.10, \mathrm{p}=0.013\right.$, Fig. 8). One female moved an unusually large total distance $(1572 \mathrm{~m})$, which substantially increased the mean total distance moved for females (overall mean $=408 \mathrm{~m}$; mean with outlier female removed $=214 \mathrm{~m})$. However, removal of this individual from the analyses of total distance moved and distance moved per day did not affect the results.

\subsubsection{Body Condition}

A $t$-test of the initial BCI values revealed that there was no difference between hydrated and control snakes at the beginning of the study $(t=-2.45, \mathrm{p}=0.25)$. A repeated-measures ANOVA indicated that overall, hydrated snakes had significantly higher BCI than control snakes $\left(\mathrm{F}_{1,22}=6.96, \mathrm{p}=0.015\right)$. The interaction, however, between the treatment group and time (initial or end of study) was marginally nonsignificant $\left(\mathrm{F}_{1,22}=3.72, \mathrm{p}=0.067\right.$, Fig. 9). Conversely, a $t$-test of the final BCI values indicated that hydrated snakes were in better body condition at the end of the study than control snakes $(t=-3.10, \mathrm{p}=0.009)$. Final BCI adjusted for $25 \mathrm{~g}$ of water provided similar results with hydrated snakes' BCI higher than control snakes' regardless of when 
the measurement was taken $\left(\mathrm{F}_{1,22}=4.70, \mathrm{p}=0.041\right)$. The interaction between treatment group and time was non-significant $\left(\mathrm{F}_{1,25}=2.12, \mathrm{p}=0.160\right)$. Once again, a $t$-test of final BCI values adjusted for $25 \mathrm{~g}$ of water indicated that hydrated snakes were in better body condition than control snakes at the end of the study $(t=-2.45, \mathrm{p}=0.03)$. Sex was consistently non-significant so it was not included in the model. See Table 3 for a complete summary of the BCI analysis.

\subsubsection{Hormones}

Stressed CORT concentrations were significantly higher than baseline concentrations $\left(F_{1,9.8}=263.69, p<0.001\right.$, Fig. 10). There was no effect of sex or hydration treatment on any aspect of CORT physiology. Initial BCI was significant as a covariate, with higher BCI corresponding to lower CORT concentrations $\left(\mathrm{F}_{1,5.82}=17.83\right.$, $p=0.006$, Fig. 22). Osmolality was also a significant covariate, with higher osmolalities corresponding to higher CORT concentrations $\left(\mathrm{F}_{1,5.81}=11.17, \mathrm{p}=0.016\right.$, Fig. 23). Finally, cloacal $\mathrm{T}_{\mathrm{b}}$ was also a significant covariate, with higher cloacal $\mathrm{T}_{\mathrm{b}}$ corresponding to higher $\operatorname{CORT}\left(\mathrm{F}_{1,6.1}=8.77, \mathrm{p}=0.025\right.$, Fig. 24$)$. Time-to-bleed was non-significant as a covariate.

\subsubsection{Behavior}

The arcsine-square root transformation improved the normality of both variables; however, only frequency of time spent above or below ground was transformed sufficiently to fit the normal distribution. There were no significant differences between hydrated and control snakes or between the sexes in frequency above or below ground, or frequency found in a particular body position. All snakes spent significantly more time in 
a moderate coil than any other body position (ANOVA: $F_{3,75}=27.08, p<0.001$, Fig. 11). Snakes spent a significantly larger portion of time above ground than below ground $\left(\mathrm{F}_{1,37}\right.$ $=73.62, \mathrm{P}<0.001 ;$ Fig. 12).

\subsection{DISCUSSION}

This study is the first to manipulate hydration in free ranging snakes. We hypothesized that hydration would affect physiology and behavior and this was partially supported. Small sample sizes limited our statistical power and we emphasize our results as suggestive rather than definitive. Plasma osmolality of hydrated snakes was significantly lower than control snakes, as expected. This suggests that snakes receiving supplemental hydration were absorbing the water into circulation. Our results suggest that females were using this water for reproduction. We observed a clear relationship between supplemental hydration and the production of a litter as all four hydrated females gave birth while no control females produced a litter. We saw no effect of hydration on movement patterns; however, we did see an increase in BCI of hydrated snakes at the end of the study. This suggests that increased BCI was not related to movement, which is in contrast to the results of Davis and DeNardo (2009). Finally, we did not see any differences in CORT physiology between hydrated and control groups but initial BCI was a significant covariate with CORT concentration with higher initial BCI corresponding to lower CORT. This suggests that BCI at the beginning of the active season may determine how a snake responds physiologically at the end of the active season, depending on energy intake. 
Our prediction that a larger proportion of hydrated females would give birth was supported, as all four hydrated females gave birth to a litter while no control females produced offspring. We randomly assigned snakes to treatment groups, which helps to assure that any differences between groups are due to the treatment applied. However, with the small sample sizes of females in each group, it is possible that the observed difference between groups is due to chance. Most species of female rattlesnakes begin vitellogenesis in the fall or early spring, several months before the time when we began supplementally hydrating snakes. So, if indeed the effect is due to hydration, we suggest that some of the control snakes resorbed their follicles (Keenlyne, 1978; Kofron, 1979; Sinervo \& Licht, 1991; Bonnet et al., 2008), presumably due to a deficit in water, whereas hydrated snakes continued to develop follicles and reproduced. There are very few manipulative studies focusing on reproduction in rattlesnakes, making it difficult to determine if this is the only possible mechanism for the difference observed between hydrated and control snakes in this study. In one of the few experimental studies on female rattlesnakes, supplemental feeding significantly increased the incidence of pregnancy in a population of free-ranging Western diamond-backed rattlesnakes (Crotalus atrox) in Arizona (Taylor et al., 2005). Hydration should be very important for reproduction too, but long-term supplemental hydration experiments are needed to understand how water affects reproduction. Water comprises a large proportion of yolk, ranging from $\sim 50 \%-80 \%$ in birds and oviparous reptiles (Ballinger \& Clark, 1973; Carey et al., 1980; Packard et al., 1985). In viviparous reptiles, water content rises dramatically from $40-50 \%$ in oviductal eggs to $70-80 \%$ in neonates (Stewart \& Castillo, 1984; Stewart, 1989; Stewart et al., 1990). If conditions are poor, it would be beneficial for a female to 
conserve water by decreasing her clutch or litter size by resorption of eggs or follicles, but no studies have directly tested this ability in squamates. Sinervo \& Licht (1991) documented a complete resorption of follicles and cessation of reproduction in Uta stansburiana after experimental reduction in clutch size. This suggests that female squamates are capable of resorbing follicles in response to environmental perturbations. This ability to resorb follicles may also play a role in the reproductive cycle of rattlesnakes. Most rattlesnakes reproduce every other year (Rahn, 1942; Fitch, 1949; Glissmeyer, 1951) and are capital breeders, relying on stored energy for reproduction (Diller \& Wallace, 1984; Macartney \& Gregory, 1988). It is unlikely that the energy available during a summer when a female is pregnant limits reproduction in rattlesnakes because of their reliance on stored energy. The previous year's energy intake is used for the production of offspring. Water availability however, has the potential to directly influence reproduction in the current year because rattlesnakes do not store water in an accessory organ. Any water allocated toward yolk production or the resultant offspring must come from the female's tissues, which may result in a dramatic increase in plasma osmolality and severe dehydration. If supplemental hydration increases reproductive frequency long-term, then it can be concluded that dehydration physiologically limits some aspect of reproduction in rattlesnakes.

The average clutch size in this study is smaller than those reported for other members of the western rattlesnake complex (Crotalus oreganus spp.). Fitch (1949) reported an average clutch size of 9.9 in the Sierra Nevada where females ranged from 300-400 g. Two studies in Idaho reported clutch sizes of 8.3 and 5.5, with reproducing females weighing greater than $400 \mathrm{~g}$ in southern Idaho and averaging $192 \mathrm{~g}$ in northern 
Idaho, respectively (Diller, 1981; Diller \& Wallace, 1984). Snakes in our study had an average clutch size of 2.5 and average body mass of $210 \mathrm{~g}$. The discrepancy in the clutch size is most likely related to average size of the females, as larger females tend to have larger clutches (Diller \& Wallace, 1984). A more likely explanation may lie in the impacts of drought already experienced by the rattlesnakes in this study. It is possible that the small clutch size is the result of the accumulated effects of dehydration from previous years. A reduction in clutch size was observed in the lizard Sceloporus virgatus during a drought (Abell, 1999). Snakes at the present study site had been under drought pressures for several years at the time of this study. Therefore, any reproductive snake is likely to have a smaller litter due to drought effects already experienced.

We predicted that hydrated snakes would make larger movements and have larger home ranges, yet there were no differences in movement parameters between hydrated and control snakes. The only differences were between the sexes. It appears that hydration does not directly influence the movements of rattlesnakes at this site. Many rattlesnake species diverged in the warm deserts of North America (Douglas et al., 2006) and currently occupy much of the American Southwest (Klauber, 1956; Campbell \& Lamar, 2004), a testament to their adaptability and tolerance for dry climates. It is possible that they are able to make large seasonal movements despite varying levels of hydration. Rattlesnakes are sit-and-wait foragers and they feed infrequently (Klauber, 1956). This low-energy budget may allow for movement even during times of drought. Female rattlesnakes typically have smaller home ranges than males (Adams, 2005; Waldron et al, 2006; Parker \& Anderson, 2007; Putman et al., 2013), because males make long-distance movements in search of mates (King \& Duvall, 1990). Therefore, it is 
not surprising that hydrated and control females had similar home range sizes, because they typically do not occupy large home ranges in the first place. The lack of a difference between hydrated and control males in this study suggests that snake movements are unaffected by drought and further emphasizes the effect of sex. Home ranges at this site were relatively small compared to other published home range data for the C. oreganus complex (see Adams, 2005; Waldron et al, 2006; Parker \& Anderson, 2007; Putman et al., 2013 for data) suggesting that snakes at Montaña de Oro do not move large enough distances to be affected by dehydration. Our study site is bounded on one side by the ocean, which may partially explain the small home ranges. Additionally, vegetation may limit movement. Sparse vegetation and open habitats may limit movement because predators are more apt to see potential prey. Perhaps snakes that possess larger home ranges than those found at Montaña de Oro are restricted in their movements by drought, but more research is needed to support this hypothesis.

Regarding the effect of hydration on body condition, our prediction that final BCI of hydrated snakes would be higher than that of control snakes was not supported. A repeated-measure ANOVA reported that overall, hydrated snakes had significantly higher body condition than control snakes. However, the interaction between treatment group and time (initial or end of study) was not significant. $T$-tests indicated no difference between the groups at the beginning of the study, but hydrated snakes had significantly higher body condition than control snakes at the end of the study. After adjusting body condition for water weight, hydrated snakes still possessed an overall higher BCI than control snakes when analyzed as a repeated-measure ANOVA. Once again, a $t$-test showed significantly higher BCI in hydrated snakes at the end of the study. It appears that 
our water supplement provided some benefit to the hydrated group of snakes, possibly by allowing them to remain on the surface more and have better hunting success. Surface activity may increase as a result of hydration because hydrated snakes can afford to lose more water via evaporative water loss when on the surface maintaining a higher preferred $T_{b}$. We did not see any difference between hydrated and control groups in proportion of time spent on the surface, however. Whether the elevated BCI in hydrated snakes was due to increased intake of food remains to be seen because hydrated snakes were not observed more often with food bulges and only six snakes were ever observed with obvious food bulges. Since rattlesnakes do not possess a bladder like Gila Monsters (Heloderma suspectum) or Gopher Tortoises (Gopherus agassizii), it is possible water is stored in an organ such as the stomach, lymph sacs, or folds of skin (Dunson, 1970; Louw \& Holm, 1972; Smits, 1986). Stored water would potentially result in a pseudoelevated body condition, but also provide the benefits of additional hydration. However, the water-storage capabilities of rattlesnakes have not been well studied and more research is needed to determine the physiology of water storage in these reptiles.

Our prediction that CORT would be higher in control snakes was not supported. The only significant difference was between baseline and stressed samples, with no interaction with treatment group, indicating that baseline CORT and stress reactivity were not affected by hydration. However, it is interesting to note that initial body condition and CORT concentration were significantly and negatively correlated, meaning that fatter snakes had lower CORT. Snakes with lower CORT and corresponding higher body condition were not relying on energy reserves as much as snakes with higher CORT. This relationship between high CORT and low body condition is well supported in the 
literature (Moore et al., 2000; Romero \& Wikelski, 2001). The lack of a difference in CORT concentration at the end of the study suggests that control snakes were no more stressed than hydrated snakes. These results should not be interpreted as evidence for the lack of an effect of the drought on this population, however. Considering the positive trend between plasma osmolality and CORT seen in this study, one could hypothesize that hydration state has the potential to influence the stress levels of an individual. Water deprivation produced elevated CORT in mice (Roberts et al., 2011) and chickens (Árnason et al., 1986). It is possible that CORT tracks with hydration levels in snakes to provide constant feedback on the environment; however, we have no other data on the hormonal profiles of dehydrated snakes. We did not see any differences in baseline or stressed CORT between experimental groups in this study. This could mean 1) that these snakes are not water-stressed or 2) that they have established a new CORT baseline in response to drought. The term for this process of achieving stability through a change in the environment is allostasis (McEwen \& Wingfield, 2003). Arid-adapted species such as rattlesnakes may cope using an allostatic mechanism, which would explain the similarity in CORT between hydrated and control groups. Rattlesnakes experiencing regular drought may require a higher level of environmental stress to trigger the release of CORT. Bradshaw and Rice (1981) found a similar result in Varanus gouldii where differences in hydration were not related to CORT.

Finally, our analysis of snake behaviors yielded typical results for rattlesnakes. Tongue-flicking and rattling behaviors were exceptionally rare upon approach. The large proportion of time spent coiled reflects their ambush-style foraging and relative inactivity. Additionally, snakes spent a significantly larger proportion of time on the surface. We did 
not see any differences between treatment groups or sexes in either analysis, suggesting that hydration does not influence snake behavior. Rattlesnakes are known to be robust to frequent handling stress (Holding et al., 2014), so it is unlikely that handling these rattlesnakes once every two weeks masked an effect of hydration on behavior. Our results differ from those of Davis and DeNardo (2009) who found supplemental hydration to increase surface activity of Gila Monsters. This may be due to differences in climate and habitat. Gila Monsters in the Sonoran Desert deal with much higher temperatures than the rattlesnakes in the current study, which forces them to remain underground. However, snakes studied in a warmer climate on the Carrizo Plain spent similar amounts of time on the surface as the snakes in the present study (Holding et al., 2014). This provides further evidence that hydration does not influence snake behavior.

Our data indicate that hydration's effect on rattlesnake physiology and behavior is complex. The mixed effects seen in this study suggest that there are many hidden factors at play that need to be teased apart for better understanding of how hydration state influences rattlesnakes. The positive influence seen on pregnancy deserves a much closer look to provide more support to the hypothesis that hydration is a limiting factor for reproduction in snakes. Movement parameters and the effect of hydration should also be further investigated because the effect of sex and population clearly influence movement more strongly than short-term supplemental hydration. Hydration influenced body condition, but the exact mechanism and strength of the relationship is unclear. Finally, differences in hydration were not related to CORT. Our study fills a gap in the literature regarding the effects of drought on free-ranging reptiles and indicates the usefulness of supplemental hydration studies for understanding these effects. Future studies should 
focus on the physiological mechanisms that allow rattlesnakes to cope with such prolonged dry conditions. 


\section{Chapter 2: The effect of sex, reproductive state, and hydration on thermoregulation in free-ranging Northern Pacific rattlesnakes (Crotalus oreganus oreganus)}

\subsection{INTRODUCTION}

Temperature is one of the most important factors influencing the physiology of reptiles (Huey \& Stevenson, 1979; Huey, 1982; Angilletta et al., 2002). As ectotherms, reptiles rely on environmental temperatures to remain active and perform necessary metabolic functions in order to survive. Thermoregulation is involved in virtually every aspect of a reptile's life, from development to death. For example, many species exhibit temperature-dependent sex determination, where the thermal environment of the developing embryo determines the offspring's sex (see Shine, 1999 for review). Thermal environment of the developing embryo may also influence other aspects of offspring phenotype such as size and growth rates (Shine \& Harlow, 1993; Shine \& Downes, 1999; Andrews et al., 2000). During adult life, thermoregulation is related to behavior and physiological characters such as foraging efficiency (Avery et al., 1982; Ayers \& Shine, 1997; Blouin-Demers \& Weatherhead, 2001), reproductive activity (Schwarzkopf \& Shine, 1991; Isaac \& Gregory, 2004; Crane \& Greene, 2008), and metabolism (Paladino et al., 1990; McCue \& Lillywhite, 2002; Ladyman et al., 2003).

Thermoregulation has direct influences on hydration state of an organism. For example, as body temperature increases, so does evaporative water loss (EWL) (Amphibians: Buttemer, 1990; Amey \& Grigg, 1995; Reptiles: Bentley \& SchmidtNielsen, 1966; Cohen, 1975; Mammals: Zhu et al., 2008; Zhu et al., 2010; Birds: Batholomew et al. 1962; Wolf \& Walsberg, 1996). This presents a unique challenge to 
ectotherms and small endotherms. Ectotherms such as reptiles behaviorally thermoregulate to obtain a preferred body temperature (Cowles \& Bogert, 1944; Bogert, 1949) and if an animal is dehydrated, maintaining a preferred body temperature may come at a cost to water conservation. Lab experiments provide data in support of lower preferred body temperature in dehydrated reptiles (Crowley, 1987; Lorenzon et al., 1999; Ladyman \& Bradshaw, 2003). Despite the large body of literature and the importance of thermoregulation in reptilian life histories and physiology, few studies have experimentally manipulated hydration. Those that have manipulated hydration provide inconsistent results. For example, growth rates in the lab of supplementally hydrated Sceloporus graciosus did not differ from control lizards (Sears \& Angilletta, 2003). This contrasts with the findings of Stamps \& Tanaka (1981) who found that growth rates of Anolis aeneus differed between water-supplemented and control groups. Sears and Angilletta (2003) attribute these differences to study design: S. graciosus was held at constant temperature in the lab, whereas A. aeneus was allowed to thermoregulate in the field and thus grow faster. Davis and DeNardo (2009) provided one of the first in-depth looks at supplemental hydration in the field with Gila Monsters (Heloderma suspectum). They found hydrated Gila Monsters to be more surface active than control individuals, suggesting that supplemental hydration influences thermoregulation and activity. It is clear that water intake influences thermoregulation, but more studies are needed to understand how different taxa respond to varying hydration levels in the field and will prove increasingly important as drought is predicted to increase in severity and the climate to continue on a drying trajectory (Cook et al., 2004; Burke et al., 2006; Seager \& Vecchi, 2010). 
Northern Pacific rattlesnakes (Crotalus oreganus oreganus) are members of the Western rattlesnake clade (C. oreganus spp.) that range from British Columbia south to Baja California and west to Colorado. Drought is a fundamental feature of the western U.S. and in the last four years California has experienced what may be the most severe drought of the last 1200 years (Griffin \& Anchukaitis, 2014). Rattlesnakes are highly plastic animals that are very responsive to changes in the environment (de Andrade et al., 2004; McCue, 2007; Lutterschmidt et al., 2009). Klauber (1956) references the ability of rattlesnakes to take advantage of favorable weather and shield themselves from poor conditions, but there is very little known about how rattlesnakes respond to hydration, even in the form of seasonal rainfall. As ambush foragers, their movements may not be influenced much by hydration (see Chapter 1), but thermoregulatory behavior may be impacted. Hydration may allow snakes to maintain warmer body temperatures than dehydrated conspecifics that are attempting to minimize water loss. We proposed directly testing for a lower body temperature in dehydrated reptiles by experimentally manipulating hydration in a coastal population of northern Pacific rattlesnakes experiencing drought.

\subsection{MATERIALS AND METHODS}

\subsubsection{Study Animal and Site}

Twenty-one adult Northern Pacific Rattlesnakes (Crotalus oreganus oreganus) were captured from Montaña de Oro State Park in Los Osos, San Luis Obispo County, California at two sites within the park. Fifteen snakes ( 8 M, 7 F) were captured on or near 
a footpath called the Bluff Trail. Habitat at this site consists mainly of Coyote Bush (Baccharis pilularis), Poison Oak (Toxicodendron diversilobum), and California Sage (Artemisia californica). Six snakes (4 M, 2 F) were captured two miles north of the Bluff Trail at the Sandspit (Fig. 1), a coastal dune scrub community comprised mainly of California Sage, Black Sage (Salvia mellifera), and invasive Ice Plant (Carpobrotus edulis). Collection and handling of rattlesnakes was permitted by California Department of Fish and Wildlife Scientific Collecting Permit \#SC-12963 and a California State Parks permit. Use and treatment of snakes was conducted under California Polytechnic State University Institutional Animal Care and Use Committee Protocol \#1403.

Radio transmitter implantation surgery was conducted at California Polytechnic State University. Individual snakes were housed in a 28 " by 24 " by 12 " vision cage (Model V221, LLL Reptile and Supply Company) with a heat pad and hide box (no water provided). Inhaled isoflurane was used to anesthetize snakes (Vet One, MWI, USA) during surgery. Snakes were implanted intra-coelomically with a 4-5g SB-2 radio transmitter (Holohil Systems Ltd. Carp, Ontario, Canada) and a 3.25g temperature data logger (model DS1921G, Maxim Integrated, San Jose, California). Snakes were released at their site of capture after 1-2 days of recuperation in the lab. Snout-vent-length (SVL) and mass were recorded every $3.27 \pm 0.37$ weeks for each snake.

\subsubsection{Experimental Manipulation of Hydration}

Assignment to treatment groups was random and balanced between the sexes. One group received supplemental hydration twice per month and will be hereafter referred to as "hydrated" The other group received a sham procedure and will be 
hereafter referred to as "control." Three snakes died during the study. Two females from the control group died, leaving a total of three control female snakes. However, two of these females were too small to receive both radio and transmitter and temperature data logger. This left us with a single control female with a temperature data logger. One control male died mid-way during the study, so this data was still used. Final sample sizes are $10(6 \mathrm{M}, 4 \mathrm{~F})$ for the hydrated group and $6(5 \mathrm{M}, 1 \mathrm{~F})$ for controls.

The first round of supplemental hydration took place on 17-18 May 2014. Safe handling of snakes was permitted by coaxing them into a clear plastic tube. We introduced water into the esophagus and stomach of each snake in the hydrated group by using an intragastric tube procedure (Davis and DeNardo 2009). We inserted a $52 \mathrm{~cm}$ tomcat urinary catheter rinsed with deionized water into the mouth and esophagus until it was nearly $1 / 4$ of the length of the snake's body. While held upright, a syringe with plunger removed was attached to the catheter and $25 \mathrm{ml}$ of deionized water was allowed to drain into the snake's stomach. We chose $25 \mathrm{ml}$ because it represented $5-15 \%$ of each snake's body mass. Control snakes received the same procedure only no water was given. After each treatment, the catheter was cleaned with a dry towel to remove any debris from the previous snake or otherwise. We also forcefully flushed the inside of the catheter with water and ethanol to remove any accumulated debris inside the catheter. It was then stored in ethanol until the next treatment. Treatments occurred twice a month with snakes receiving $5.7 \pm 0.5$ total treatments for an average duration of $3.9 \pm 0.2$ months. 


\subsubsection{Thermal Biology}

The temperature data loggers implanted into the snakes were programmed to record body temperature $\left(\mathrm{T}_{\mathrm{b}}\right)$ every two hours. If the mass of the radio transmitter and the iButton exceeded 5\% of the snake's mass, we did not implant an iButton. Two of our control females fell into this category. We analyzed the data separately on hourly and seasonal scales. The hourly data were broken up into four time intervals: midnight to $4 \mathrm{~h}$, 6h-10h, 12h-16h and 18h-22h; representing a period where snakes were cool, warming, at peak temperatures, and cooling, respectively. We also examined the data seasonally by breaking them into three time periods: the end of spring (20 April - 14 May: corresponding to early activity), summer (15 May - 9 August: mating) and the beginning of fall (10 August - 4 October: post-mating period). We also used air temperature data downloaded from the National Oceanic and Atmospheric Administration's (NOAA) National Climatic Data Center collected at the Morro Bay Fire Department weather station (ID - GHCND:USC00045866) located $9.5 \mathrm{~km}$ NE of the study site. These temperatures are included in figures regarding thermal data for visual comparison.

\subsubsection{Statistical Analysis}

We analyzed the thermal data with a repeated measures design. Hourly block or season was used as the within-subjects factor, ID was included as a random factor, and sex was included as a fixed factor. Hourly and seasonal means as well as the variance of the mean were analyzed. We predicted hydrated snakes to have higher mean body temperature and more variance in body temperature than control snakes, especially during summer and mid-day when air temperatures are highest. Tukey's post-hoc tests 
were used to find any significant differences between model effects. Alpha was set at 0.05 for significance.

\subsection{RESULTS}

\subsubsection{Thermal Biology}

In the full model examining the effects of season, treatment group, and sex on mean $\mathrm{T}_{\mathrm{b}}$, season had a significant effect with post-hoc tests revealing that snakes during the summer had higher $T_{b}$ than in spring (Mixed Model: $F_{2,28.35}=8.05, p=0.002$, Fig. 13). There was a significant interaction between treatment group and sex with hydrated females having significantly higher $\mathrm{T}_{\mathrm{b}}$ than both hydrated and control males, but not the single control female $\left(\mathrm{F}_{1,10.29}=5.09, \mathrm{P}=0.047\right.$, Fig. 14). Mass was marginally nonsignificant as a covariate and showed a trend for larger snakes to have lower $\mathrm{T}_{\mathrm{b}}\left(\mathrm{F}_{1,10.98}=\right.$ $3.640, p=0.083$, Fig. 15). Season interacted with sex to influence the variance $\left(F_{2,24.06}=\right.$ 4.90, $\mathrm{p}=0.016$, Fig. 16). Post-hoc tests revealed that males in the fall had variance significantly lower than females during the fall and both males and females in the spring; males in the summer also had significantly lower variance than both males and females in the spring; and females in the summer and fall had variance significantly lower than females in the spring. Mass was a significant covariate with larger snakes having more variance in $\mathrm{T}_{\mathrm{b}}\left(\mathrm{F}_{1,11.2}=9.96, \mathrm{P}=0.009\right.$, Fig. 17).

When analyzing the thermal data by time of day, the effect of the treatment group was dependent on the time of day $\left(\mathrm{F}_{3,42}=5.07, \mathrm{p}=0.004\right.$, Fig. 18) while the interaction between treatment group and sex was marginally non-significant $\left(\mathrm{F}_{1,12}=4.15, \mathrm{P}=0.064\right.$, 
Fig. 19). Sex was significant as a main effect with higher $T_{b}$ in females than in males $\left(F_{1,12}=13.02, p=0.004\right.$, Fig. 20$)$. In terms of hourly variance, there was a significant interaction between the time of day and $\operatorname{sex}\left(\mathrm{F}_{3,42}=13.94, \mathrm{p}<0.001\right.$, Fig. 21). Neither mass nor body condition co-varied with the analysis of mean $\mathrm{T}_{\mathrm{b}}$ or variance in $\mathrm{T}_{\mathrm{b}}$, therefore they were not included in the model as covariates.

\subsection{DISCUSSION}

Our prediction of higher $\mathrm{T}_{\mathrm{b}}$ in hydrated snakes was supported. Hydrated snakes had elevated $T_{b}$ over control snakes. Hydrated females showed the highest $T_{b}$ whereas all the other groups exhibited similar temperature profiles. However, it is crucial to note that all four hydrated females in this study were pregnant (see Chapter 1), whereas no control snakes were pregnant. This confounds our result that hydration influences $T_{b}$ and could suggest that pregnant females maintain higher $\mathrm{T}_{\mathrm{b}}$ than males and non-pregnant females.

We expected hydration to significantly alter thermoregulatory patterns by allowing hydrated snakes to maintain higher $\mathrm{T}_{\mathrm{b}}$ than controls because they would be able to afford to lose water via EWL. Our results mirror those of Ladyman \& Bradshaw (2003) where dehydrated tiger snakes (Notechis scutatus) selected lower preferred and maximum body temperatures. However, desert iguanas (Dipsosaurus dorsalis) did not change thermoregulatory behavior following a dehydration of $80 \%$ initial body weight (Dupré \& Crawford, 1985). This species is known to have the highest recorded body temperatures of any vertebrate (Bennett \& Dawson, 1972). Dipsosaurus dorsalis is an herbivore and its diet is $80-90 \%$ water (Dupré \& Crawford, 1985). It is unlikely that 
rattlesnakes are acquiring prey items that are $80-90 \%$ water because rodents, a typical food source for rattlesnakes, have body water contents that range from $60-75 \%$ total body water as a percentage of body weight (Fleharty et al., 1973; Holleman \& Dietrich, 1973). In addition, they most certainly do not experience the body temperatures observed in Dipsosaurus. In fact, snakes in this study never achieved body temperatures greater than $36^{\circ} \mathrm{C}$. It is also possible that the need to thermoregulate overrides the need to conserve water in reptiles. Conversely, evaporative water loss (EWL) may not be an issue for these snakes despite the overall paucity of water in the environment. For example, the coastal study site in which these rattlesnakes were found is relatively cool during the summer months. Average daily maximum temperatures in May, June, July, and August averaged $24,22.1,25.1$, and $25^{\circ} \mathrm{C}$, respectively. This is low compared to the maximum temperatures inland at the Carrizo Plain, which averages $27.1,32.1,34.7$, and $33.5^{\circ} \mathrm{C}$ (data from ncdc.noaa.gov). The cooler temperatures on the coast may explain why there were no differences in thermoregulatory behavior between hydrated and control snakes. It is important to note that other factors such as humidity and wind speed may also influence EWL in reptiles (Foley \& Spotila, 1978; Kobayashi et al., 1983). This study highlights the need for research that examines the thermoregulatory response of dehydrated rattlesnakes to different environmental conditions.

We found that hydrated females displayed the highest $\mathrm{T}_{\mathrm{b}}$; however, this result was confounded with pregnancy. Pregnancy's influence on thermoregulation in squamates is not clear. For example, Charland \& Gregory (1990) found that pregnant and nonpregnant females of Crotalus viridis had similar mean plateau $\mathrm{T}_{\mathrm{b}}$, but also that pregnant females maintained a significantly lower variance in temperature. Gier et al. (1989) found 
a similar result in C. oreganus oreganus. On the contrary, Graves \& Duvall (1993) found that gravid females maintained higher body temperatures than non-gravid females. A study on C. horridus in the eastern U.S. also found that females maintained higher temperatures during pregnancy than non-gravid conspecifics (Gardner-Santana \& Beaupre, 2009). Furthermore, Sanders and Jacob (1981) report lower $T_{b}$ s in pregnant female copperheads (Agkistrodon contortrix). Pregnant females in this study thermoregulated at higher temperatures than conspecifics regardless of the time of day. However, their $\mathrm{T}_{\mathrm{b}}$ varied more between the hours of 0:00 and 10:00, and between 18:00 and 22:00. In the middle of the day (12:00-16:00), pregnant females had lower variance than other snakes. This suggests that pregnant females maintain a more narrow temperature range during the warmest part of the day, while they are less precise during the cooler parts of the day.

Variation in $T_{b}$ may be a result of different thermoregulatory strategies used by snakes. Different life-history stages may exhibit specific thermoregulatory profiles and behaviors. For example, Schwarzkopf \& Shine (1991) suggest that more variable $T_{b}$ S in pregnant females may be a result of basking attempts even on cloudy days. It is more difficult to obtain higher $T_{b} S$ on cloudy days, or other sub-optimal weather conditions (i.e. windy, foggy, early or late in the day), which are common at coastal locations such as Montaña de Oro. Perhaps pregnant females at Montaña de Oro attempt to bask in these conditions to acquire the maximum amount of heat possible. In the process, they may be exposed to more variation in environmental temperature, whereas snakes that remain in a retreat at these times have a more stable $\mathrm{T}_{\mathrm{b}}$. Additionally, there may be an effect of geographical location. For example, the Carrizo Plain has a higher mean maximum 
$\left(29.7^{\circ} \mathrm{C}\right)$ and minimum $\left(22.7^{\circ} \mathrm{C}\right)$ air temperature from April to October than the current coastal study site (mean max: $23.8^{\circ} \mathrm{C}$; mean min: $18.7^{\circ} \mathrm{C}$ ) (data from ncdc.noaa.gov). Inland females may be able to more precisely thermoregulate and maintain a higher $T_{b}$ than coastal females because of these observed differences in weather. Huey and Slatkin (1976) suggest that precise thermoregulation occurs typically in low-cost situations. Perhaps pregnant females have higher variation in $\mathrm{T}_{\mathrm{b}}$ in the morning and late evening because it is costly to thermoregulate at those times.

The inconsistencies of thermal biology in pregnant rattlesnakes require clarification. Why do some snakes show elevated $\mathrm{T}_{\mathrm{b}}$ during pregnancy while others do not? There is little objection that temperature during incubation affects offspring phenotype (reviewed in Booth, 2006; Shine \& Harlow, 1993; Shine \& Downes, 1999; Wapstra, 2000; Wapstra et al., 2004). These studies have not shown a clear relationship between incubation temperature and offspring phenotype, but rather only that a relationship exists. Perhaps there is a trade-off between the timing of parturition and offspring phenotype. More time spent developing means higher quality offspring for some species (Shine \& Olsson, 2003). This is because the embryo has more time to differentiate and develop key morphological and physiological features. On the contrary, if a pregnant female maintains $T_{b}$ higher than the optimum for her embryos, she may give birth earlier but at the expense of her offspring. Detrimental effects to offspring have been observed at temperatures higher than the optimum in Sceloporus jarrovi (Mathies \& Andrews, 1997). The most compelling evidence for this sort of relationship was found in Podarcis muralis. Higher incubation temperatures resulted in earlier hatching, but smaller, slower-growing, and slower-sprinting individuals (van Damme et al., 1992). This species 
is found in a Mediterranean climate similar to our study species, suggesting that female northern Pacific rattlesnakes may be under similar environmental pressures. Additionally, females may be under pressure to balance offspring quality with the timing of parturition, given the environmental circumstances. Coastal California does not provide optimal conditions for incubation (nor does any location) because it is generally cooler. One would expect observed $\mathrm{T}_{b} \mathrm{~S}$ to be similar among all snakes at a site with a cooler temperature regime such as coastal California if these temperatures are sub-optimal for activity and physiological processes; however, non-pregnant snakes in this study (males included) had significantly lower mean $\mathrm{T}_{\mathrm{b}}$ than pregnant snakes.

The discrepancy in $T_{b}$ between males and females raises an interesting question. If snakes are capable of acquiring higher $\mathrm{T}_{b} \mathrm{~S}$ as indicated by the pregnant females, then why do non-pregnant snakes remain at lower temperatures? One hypothesis is that there is a trade-off between thermoregulation and EWL in pregnant females with respect to offspring development. Higher temperatures are thought to speed embryonic development via an increase in metabolism (Shine, 1983; Van Damme et al., 1992; Braña $\& \mathrm{Ji}, 2000$; Ladyman et al., 2003). If a pregnant female were to maintain lower $\mathrm{T}_{b} \mathrm{~S}$ than those seen in this study, then she may not be able to reach parturition before fall temperatures begin to drop, especially in a coastal environment where maximum temperatures are relatively cool. Despite the cooler temperature regime, any increase in $T_{b}$ has the consequence of increased EWL. Snakes may have been maintaining these lower $T_{b} \mathrm{~s}$ in an attempt to minimize EWL during drought conditions. This hypothesis relies on the assumption that EWL rates have a larger influence on thermoregulation than does plasma osmolality, because hydrated snakes in this study had significantly lower 
plasma osmolality than controls yet no difference in thermoregulatory behavior was observed.

The increased $\mathrm{T}_{\mathrm{b}}$ of pregnant females in this study suggests supplemental hydration might eliminate the risks of EWL to pregnant females, which could allow them to thermoregulate properly and thus give birth. Males and control females did not need to elevate their $\mathrm{T}_{\mathrm{b}}$ because they did not require an increased metabolism. Van Dyke and Beaupre (2011) claimed that the metabolic costs of pregnancy are not significantly higher than those of a non-pregnant snake. However, this experiment maintained the ambient temperature at $30^{\circ} \mathrm{C}$ during respirometry. It has been demonstrated that pregnant female rattlesnakes typically do not maintain their $T_{b}$ the same as males (see above). It is well known that an increase in temperature corresponds to an increase in metabolism and respiratory exchange (Ege \& Krogh, 1914; Krogh, 1916; reviewed in Clarke \& Fraser, 2004). Therefore, even if the metabolic costs are no different when a constant temperature is maintained, an elevated $\mathrm{T}_{\mathrm{b}}$ should increase metabolism and provide the necessary benefits to developing embryos. This additional metabolic cost of developing embryos may have been allowed by supplemental hydration. Without hydration, females may resorb developing embryos, a phenomenon that has been observed in viviparous snakes (Bonnet et al., 2008). If a control snake in this study were to reproduce, the costs of EWL associated with maintaining elevated $\mathrm{T}_{\mathrm{b}}$ may be too great, even fatal. By resorbing follicles or embryos early in the season, females can survive to reproduce another year. This plasticity in reproduction and ability to "choose" when to reproduce could account for variation in the reproductive cycle of rattlesnakes. 
The results of this study highlight an area of research that requires more attention. It is also the first to attempt to answer questions about the effects of hydration on thermoregulation in rattlesnakes. The synergistic effects of the environment that influence an ectotherm's thermoregulation have been overlooked. Hydration's influence on thermoregulation was not obvious in this study, however, the apparent effect on reproduction begs for further investigation. It is possible that these females reproduced only because they were able to maintain higher $\mathrm{T}_{b} \mathrm{~s}$ as a result of supplemental hydration. Lab and field studies that examine how pregnant females thermoregulate regularly and in a dehydrated state will elucidate the determinants of litter production in reptiles during drought. 


\section{WORKS CITED}

Abell, A. J. 1999. Variation in clutch size and offspring size relative to environmental conditions in the lizard Sceloporus virgatus. Journal of Herpetology 33:173-180.

Adams, J. P. 2005. Home range and behavior of the timber rattlesnake (Crotalus horridus). M.S. Thesis. Marshall University

Albiser, G., A. Lamiri, and S. Premilat. 2001. The A-B transition: Temperature and base composition effects on hydration of DNA. International Journal of Biological Macromolecules 28:199-203.

Amey, A. P., and G. C. Grigg. 1995. Lipid-reduced evaporative water loss in two arboreal hylid frogs. Comparative Biochemistry and Physiology 111A:283-291.

Andrews, R. M., T. Mathies, and D. A. Warner. 2000. Effect of incubation temperature on morphology, growth, and survival of juvenile Sceloporus undulatus. Herpetological Monographs 14:420-431.

Angilletta, M. J., P. H. Niewiarowski, and C. A. Navas. 2002. The evolution of thermal physiology in ectotherms. Journal of Thermal Biology 27:249-268.

Árnason, S. S., G. E. Rice, A. Chadwick, and E. Skadhauge. 1986. Plasma levels of arginine vasotocin, prolactin, aldosterone and corticosterone during prolonged dehydration in the domestic fowl: effect of dietary $\mathrm{NaCl}$. Journal of Comparative Physiology B 156:383-397.

Avery, R. A., J. D. Bedford, and C. P. Newcombe. 1982. The Role of thermoregulation in lizard biology: predatory efficiency in a temperate diurnal basker. Behavioral Ecology and Sociobiology 11:261-267.

Ayers, D. Y., and R. Shine. 1997. Thermal influences on foraging ability: body size, posture and cooling rate of an ambush predator, the python Morelia spilota. Functional Ecology 11:342-347.

Ballinger, R. E., and D. R. J. Clark. 1973. Energy content of lizard eggs and the measurement of reproductive effort. Journal of Herpetology 7:129-132.

Bartholomew, G. A., J. W. Hudson, and T. R. Howell. 1962. Body temperature, oxygen consumption, evaporative water loss and heart rate in the Poor-will. The Condor 64:117-125.

Belthoff, J. R., and A. M. Dufty Jr. 1998. Corticosterone, body condition and locomotor activity: a model for dispersal in screech-owls. Animal Behaviour 55:405-415. 
Bennett, A. F., and W. R. Dawson. 1972. Aerobic and anaerobic metabolism during activity in the lizard Dipsosaurus dorsalis. Journal of Comparative Physiology 81:289-299.

Bentley, P. J., and K. Schmidt-Nielsen. 1966. Cutaneous water loss in reptiles. Science 151:1547-1549.

Blanchard, F. N. 1930. The stimulus to the breeding migration of the spotted salamander, Ambystoma maculatum (Shaw). The American Naturalist 64:154-167.

Blouin-Demers, G., and P. J. Weatherhead. 2001. An experimental test of the link between foraging, habitat selection and thermoregulation in black rat snakes Elaphe obsoleta obsoleta. Journal of Animal Ecology 70:1006-1013.

Bock, C. E., and J. H. Bock. 1999. Response of winter birds to drought and shortduration grazing in southeastern Arizona. Conservation Biology 13:1117-1123.

Bock, C. E. 2015. Abundance and variety of birds associated with point sources of water in southwestern New Mexico, U. S. A. Journal of Arid Environments 116:53-56.

Bodnoff, S. R., A. G. Humphreys, J. C. Lehman, D. M. Diamond, G. M. Rose, and M. J. Meaney. 1995. Enduring effects of chronic corticosterone treatment on spatial learning, synaptic plasticity, and hippocampal neuropathology in young and midaged rats. The Journal of Neuroscience 15:61-69.

Bogert, C. M. 1949. Thermoregulation in reptiles, a factor in evolution. Evolution 3:195211.

Bonnet, X., S. Akoka, R. Shine, and L. Pourcelot. 2008. Disappearance of eggs during gestation in a viviparous snake (Vipera aspis) detected using non-invasive techniques. Acta Herpetologica 3:129-137.

Boone, R. B., S. J. Thirgood, and J. G. C. Hopcraft. 2006. Serengeti wildebeest migratory patterns modeled from rainfall and new vegetation growth. Ecology 87:1987-1994.

Booth, D. T. 2006. Influence of incubation temperature on hatchling phenotype in reptiles. Physiological and Biochemical Zoology 79:274-281.

Bradshaw, S. D., and G. E. Rice. 1981. The effects of pituitary and adrenal hormones on renal and postrenal reabsorption of water and electrolytes in the lizard, Varanus gouldii (Gray). General and Comparative Endocrinology 44:82-93.

Braña, F., and X. Ji. 2000. Influence of incubation temperature on morphology, locomotor performance, and early growth of hatchling wall lizards (Podarcis muralis). Journal of Experimental Zoology 286:422-433. 
Brown, J. R., C. a. Bishop, and R. J. Brooks. 2009. Effectiveness of short-distance translocation and its effects on western rattlesnakes. Journal of Wildlife Management 73:419-425.

Burke, E. J., S. J. Brown, and N. Christidis. 2006. Modeling the recent evolution of global drought and projections for the twenty-first century with the Hadley Centre climate model. Journal of Hydrometeorology 7:1113-1125.

Butler, M. J., K. L. Metzger, and G. Harris. 2014. Whooping crane demographic responses to winter drought focus conservation strategies. Biological Conservation 179:72-85.

Buttemer, W. 1990. Effect of temperature on evaporative water loss of the Australian tree frogs Litoria caerulea and Litoria chloris. Physiological Zoology 63:1043-1057.

Cable, J. M., and T. E. Huxman. 2004. Precipitation pulse size effects on Sonoran Desert soil microbial crusts. Oecologia 141:317-324.

Campbell, J.A. and W.W. Lamar. 2004. The venomous reptiles of the western hemisphere, two vols. Ithaca: Cornell University Press.

Carey, C., H. Rahn, and P. Parisi. 1980. Calories, water, lipid and yolk in avian eggs. The Condor 82:335-343.

Carnicer, J., M. Coll, M. Ninyerola, X. Pons, G. Sánchez, and J. Peñuelas. 2011. Widespread crown condition decline, food web disruption, and amplified tree mortality with increased climate change-type drought. Proceedings of the National Academy of Sciences of the United States of America 108:1474-1478.

Cease, A. J., D. I. Lutterschmidt, and R. T. Mason. 2007. Corticosterone and the transition from courtship behavior to dispersal in male red-sided garter snakes (Thamnophis sirtalis parietalis). General and Comparative Endocrinology 150:124131.

Chaplin, M. F. 2001. Water: Its importance to life. Biochemistry and Molecular Biology Education 29:54-59.

Charland, M. B., and P. T. Gregory. 1990. The influence of female reproductive status on thermoregulation in a viviparous snake, Crotalus viridis. Copeia 1089-1098.

Chew, R. M. 1961. Water metabolism of desert-inhabiting vertebrates. Biological Reviews 36:1-31.

Churchill, T. A., and K. B. Storey. 1995. Metabolic effects of dehydration on an aquatic frog, Rana pipiens. The Journal of Experimental Biology 198:147-154. 
Ciais, P., M. Reichstein, N. Viovy, A. Granier, J. Ogée, V. Allard, M. Aubinet, N. Buchmann, C. Bernhofer, A. Carrara, F. Chevallier, N. De Noblet, a D. Friend, P. Friedlingstein, T. Grünwald, B. Heinesch, P. Keronen, A. Knohl, G. Krinner, D. Loustau, G. Manca, G. Matteucci, F. Miglietta, J. M. Ourcival, D. Papale, K. Pilegaard, S. Rambal, G. Seufert, J. F. Soussana, M. J. Sanz, E. D. Schulze, T. Vesala, and R. Valentini. 2005. Europe-wide reduction in primary productivity caused by the heat and drought in 2003. Nature 437:529-533.

Clarke, A., and K. P. P. Fraser. 2004. Why does metabolism scale with temperature? Functional Ecology 18:243-251.

Cohen, A. 1975. Some factors affecting water economy in snakes. Comparative Biochemistry and Physiology 51A:361-368.

Cook, E. R., C. A. Woodhouse, C. M. Eakin, D. M. Meko, and D. W. Stahle. 2004. Longterm aridity changes in the western United States. Science 306:1015-1018.

Cowles, R. B., and C. M. Bogert. 1944. A preliminary study of the thermal requirements of desert lizards. Bulletin of the American Museum of Natural History 83:261-296.

Crane, A. L., and B. D. Greene. 2008. The Effect of reproductive condition on thermoregulation in female Agkistrodon piscivorus near the northwestern range limit. Herpetologica 64:156-167.

Crowley, S. R. 1987. The effect of desiccation upon the preferred body temperature and activity level of the lizard Sceloporus undulatus. Copeia 1:25-32.

Davis, J., and D. DeNardo. 2009. Water supplementation affects the behavioral and physiological ecology of Gila monsters (Heloderma suspectum) in the Sonoran Desert. Physiological and Biochemical Zoology 82:739-48.

Davis, J. R., and D. F. DeNardo. 2010. Seasonal patterns of body condition, hydration state, and activity of Gila Monsters (Heloderma suspectum) at a Sonoran Desert site. Journal of Herpetology 44:83-93.

de Andrade, D. V., G. J. Tattersall, S. P. Brito, R. Soncini, L. G. Branco, M. L. Glass, A. S. Abe, and W. K. Milsom. 2004. The ventilatory response to environmental hypercarbia in the South American rattlesnake, Crotalus durissus. Journal of Comparative Physiology B 174:281-291.

Denny, M., and T. Dawson. 1975. Effects of dehydration on body-water distribution in desert kangaroos. American Journal of Physiology 229:251-254.

Diller, L. V. 1981. Comparative ecology of Great Basin rattlesnakes (Crotalus viridis lutosus) and Great Basin gopher snakes (Pituophis melanoleucus deserticola) and 
their impact on small mammal populations in the Snake River Birds of Prey Natural Area. PhD Dissertation, University of Idaho.

Diller, L., and R. Wallace. 1984. Reproductive biology of the northern Pacific rattlesnake (Crotalus viridis oreganus) in northern Idaho. Herpetologica 40:182-193.

Douglas, M. E., M. R. Douglas, G. W. Schuett, and L. W. Porras. 2006. Evolution of rattlesnakes (Viperidae; Crotalus) in the warm deserts of western North America shaped by Neogene vicariance and Quaternary climate change. Molecular Ecology 15:3353-3374.

Duda, J. J., A. J. Krzysik, and J. E. Freilich. 1999. Effects of drought on desert tortoise movement and activity. The Journal of Wildlife Management 63:1181-1192.

Dunson, W. A. 1970. Some aspects of electrolyte and water balance in three estuarine reptiles, the diamondback terrapin, American and "salt water" crocodiles. Comparative Biochemistry and Physiology 32:161-174.

Dupoué, A., F. Brischoux, F. Angelier, D. F. DeNardo, C. D. Wright, and O. Lourdais. 2015. Intergenerational trade-off for water may induce a mother-offspring conflict in favour of embryos in a viviparous snake. Functional Ecology 29:414-422.

Dupré, R. K., and E. C. Crawford. 1985. Behavioral thermoregulation during dehydration and osmotic loading of the desert iguana. Physiological Zoology 58:357-363.

Ege, R., and A. Krogh. 1914. On the relation between the temperature and the respiratory exchange in fishes. Internationale Revue der gesamten Hydrobiologie und Hydrographie 7:48-55.

Fitch, H. S. 1949. Study of snake populations in central California. American Midland Naturalist 41:513-579.

Fleharty, E. D., M. E. Krause, and D. P. Stinnett. 1973. Body composition, energy content, and lipid cycles of four species of rodents. Journal of Mammalogy 54:426438.

Foley, R. E., and J. R. Spotila. 1978. Effect of wind speed, air temperature, body size and vapor density difference on evaporative water loss from the turtle Chrysemys scripta. Copeia 1978:627-634.

Folks, D. J., K. Gann, T. E. Fulbright, D. G. Hewitt, C. A. DeYoung, D. B. Wester, K. N. Echols, and D. A. Draeger. 2014. Drought but not population density influences dietary niche breadth in white-tailed deer in a semiarid environment. Ecosphere 5:115. 
Frigerio, D., J. Dittami, E. Möstl, and K. Kotrschal. 2004. Excreted corticosterone metabolites co-vary with ambient temperature and air pressure in male Greylag geese (Anser anser). General and Comparative Endocrinology 137:29-36.

Gans, C., Krakauer, T., \& Paganelli, C. V. 1968. Water loss in snakes: interspecific and intraspecific variability. Comparative Biochemistry and Physiology 27:747-761.

Gardner-Santana, L. C., and S. J. Beaupre. 2009. Timber rattlesnakes (Crotalus horridus) exhibit elevated and less variable body temperatures during pregnancy. Copeia 363368.

Gibbons, J. W. 1986. Movement patterns among turtles populations: applicability to management of the desert tortoise. Herpetologica 42:104-113.

Gier, P. J., R. L. Wallace, and R. L. Ingermann. 1989. Influence of pregnancy on behavioral thermoregulation in the northern Pacific rattlesnake Crotalus viridis oreganus. Journal of Experimental Biology 145:465-469.

Glissmeyer, H. R. 1951. Egg Production of the Great Basin rattlesnake. Herpetologica 7:24-27.

Graves, B. M., and D. Duvall. 1993. Reproduction, rookery use, and thermoregulation in free-ranging, pregnant Crotalus v . viridis. Journal of Herpetology 27:33-41.

Greene, H. W. 2005. Organisms in nature as a central focus for biology. Trends in Ecology and Evolution 20:23-27.

Griffin, D., and K. J. Anchukaitis. 2014. How unusual is the 2012-2014 California drought? Geophysical Research Letters 41:9017-9023.

Hau, M., R. E. Ricklefs, M. Wikelski, K. A. Lee, and J. D. Brawn. 2010. Corticosterone, testosterone and life-history strategies of birds. Proceedings of the Royal Society B 277:3203-3212.

Heatwole, H., and J. E. N. Veron. 1977. Vital limit and evaporative water loss in lizards (Reptilia, Lacertilia): a critique and new data. Journal of Herpetology 11:341-348.

Herron, J. C., Freeman, S. 2014. Evolutionary Analysis. $5^{\text {th }}$ ed. Pearson.

Holding, M. 2011. Short-distance translocation of the northern Pacific rattlesnake (Crotalus o. oreganus): Effects on volume and neurogenesis in the cortical forebrain, steroid hormone concentrations, and behaviors. M.S. Thesis, California Polytechnic State University.

Holding, M., J. Frazier, S. Dorr, S. Henningsen, I. Moore, and E. Taylor. 2014. Physiological and behavioral effects of repeated handling and short-distance 
translocations on free-ranging northern Pacific rattlesnakes (Crotalus oreganus). Journal of Herpetology 48:233-239.

Holdo, R. M., R. D. Holt, and J. M. Fryxell. 2009. Opposing rainfall and plant nutritional gradients best explain the wildebeest migration in the Serengeti. The American Naturalist 173:431-445.

Holleman, D. F., and R. a Dieterich. 1973. Body water content and turnover in several species of rodents as evaluated by the tritiated water method. Journal of Mammalogy 54:456-465.

Huey, R. B. 1982. Temperature, Physiology, and the Ecology of Reptiles. Pages 25-91 in. Biology of the Reptilia.

Huey, R. B., and M. Slatkin. 1976. Cost and benefits of lizard thermoregulation. The Quarterly Review of Biology 51:363-384.

Huey, R. B., and R. D. Stevenson. 1979. Integrating thermal physiology and ecology of ectotherms: A discussion of approaches. American Zoologist 19:357-366.

Hyslop, N. L., J. M. Meyers, R. J. Cooper, and D. J. Stevenson. 2014. Effects of body size and sex of Drymarchon couperi (eastern indigo snake) on habitat use, movements, and home range size in Georgia. The Journal of Wildlife Management 78:101-111.

Isaac, L. A, and P. T. Gregory. 2004. Thermoregulatory behaviour of gravid and nongravid female grass snakes (Natrix natrix) in a thermally limiting high-latitude environment. Journal of Zoology 264:403-409.

Keenlyne, K. D. 1978. Reproductive cycles in two species of rattlesnakes. American Midland Naturalist 100:368-375.

Kerr, G. D., and C. M. Bull. 2006. Movement patterns in the monogamous sleepy lizard (Tiliqua rugosa): Effects of gender, drought, time of year and time of day. Journal of Zoology 269:137-147.

King, M. B., and D. Duvall. 1990. Prairie rattlesnake seasonal migrations: episodes of movement, vernal foraging and sex differences. Animal Behaviour 39:924-935.

Klauber, L. M. 1956. Rattlesnakes: Their Habits, Life History and Influence on Mankind. University of California Press, Berkeley.

Kobayashi, D., W. J. Mautz, and K. a Nagy. 1983. Evaporative water loss: humidity acclimation in Anolis carolinensis lizards. Copeia 1983:701-704. 
Kofron, C. P. 1979. Reproduction of aquatic snakes in south-central Louisiana. Herpetologica 35:44-50.

Krapu, G. L., A. T. Klett, and D. G. Jorde. 1983. The effect of variable spring water conditions on Mallard reproduction. The Auk 100:689-698.

Krogh, A. 1916. The respiratory exchange of animals and man. Longmans, Green. Vol. 13

Ladyman, M., and D. Bradshaw. 2003. The influence of dehydration on the thermal preferences of the Western tiger snake, Notechis scutatus. Journal of Comparative Physiology B 173:239-46.

Ladyman, M., X. Bonnet, O. Lourdais, D. Bradshaw, and G. Naulleau. 2003. Gestation, thermoregulation, and metabolism in a viviparous snake, Vipera aspis: evidence for fecundity-independent costs. Physiological and Biochemical Zoology 76:497-510.

Lance, V. A., R. M. Elsey, G. Butterstein, P. L. Trosclair, and M. Merchant. 2010. The effects of Hurricane Rita and subsequent drought on alligators in Southwest Louisiana. Journal of Experimental Zoology 313A:106-113.

Lind, C. M., J. F. Husak, C. Eikenaar, I. T. Moore, and E. N. Taylor. 2010. The relationship between plasma steroid hormone concentrations and the reproductive cycle in the northern Pacific rattlesnake, Crotalus oreganus. General and Comparative Endocrinology 166:590-599.

Lorenzon, P., J. Clobert, A. Oppliger, and H. John-Alder. 1999. Effect of water constraint on growth rate, activity and body temperature of yearling common lizard (Lacerta vivipara). Oecologia 118:423-430.

Louw, G. N., and E. Holm. 1972. Physiological, morphological and behavioural adaptations of the ultrapsammophilous, Namib Desert lizard Aporosaura anchietae (Bocage). Madoqua 1:67-85.

Love, O. P., C. W. Breuner, F. Vézina, and T. D. Williams. 2004. Mediation of a corticosterone-induced reproductive conflict. Hormones and Behavior 46:59-65.

Lutterschmidt, W. I., D. I. Lutterschmidt, R. T. Mason, and H. K. Reinert. 2009. Seasonal variation in hormonal responses of timber rattlesnakes (Crotalus horridus) to reproductive and environmental stressors. Journal of Comparative Physiology B 179:747-57.

Macartney, J. M., and P. T. Gregory. 1988. Reproductive biology of female rattlesnakes (Crotalus viridis) in British Columbia. Copeia 47-57. 
Martof, B. 1953. Home range and movements of the green frog, Rana clamitans. Ecology 34:529-543.

Mathies, T., and R. M. Andrews. 1997. Influence of pregnancy on the thermal biology of the lizard, Sceloporus jarrovi: why do pregnant females exhibit low body temperatures? Functional Ecology 11:498-507.

McCue, M. D. 2007. Western diamondback rattlesnakes demonstrate physiological and biochemical strategies for tolerating prolonged starvation. Physiological and Biochemical Zoology 80:25-34.

McCue, M. D., and H. B. Lillywhite. 2002. Oxygen consumption and the energetics of island-dwelling Florida cottonmouth snakes. Physiological and Biochemical Zoology 75:165-178.

McEwen, B. S., and J. C. Wingfield. 2003. The concept of allostasis in biology and biomedicine. Hormones and Behavior 43:2-15.

Mittelbach, G. G. 2012. Community Ecology. Sinauer Associates.

Moeller, K. T., M. W. Butler, and D. F. Denardo. 2013. The effect of hydration state and energy balance on innate immunity of a desert reptile. Frontiers in Zoology 10:1-10.

Moore, I. T., J. P. Lerner, D. T. Lerner, and R. T. Mason. 2000. Relationships between annual cycles of testosterone, corticosterone, and body condition in male red-spotted garter snakes, Thamnophis sirtalis concinnus. Physiological and Biochemical Zoology 73:307-312.

Moore, I. T., and T. S. Jessop. 2003. Stress, reproduction, and adrenocortical modulation in amphibians and reptiles. Hormones and Behavior 43:39-47.

Packard, M. J., G. C. Packard, J. D. Miller, M. E. Jones, and W. H. N. Gutzke. 1985. Calcium mobilization, water balance, and growth in embryos of the agamid lizard Amphibolurus barbatus. Journal of Experimental Zoology 235:349-357.

Paladino, F. V., M. P. O'Connor, and J. R. Spotila. 1990. Metabolism of leatherback turtles, gigantothermy, and thermoregulation of dinosaurs. Nature 344:858-860.

Palme, R., S. Rettenbacher, C. Touma, S. M. El-Bahr, and E. Möstl. 2005. Stress hormones in mammals and birds: Comparative aspects regarding metabolism, excretion, and noninvasive measurement in fecal samples. Annals of the New York Academy of Sciences 1040:162-171.

Parker, J. M., and S. H. Anderson. 2007. Ecology and behavior of the midget faded rattlesnake (Crotalus oreganus concolor) in Wyoming. Journal of Herpetology 41:41-51. 
Peñuelas, J., P. Prieto, C. Beier, C. Cesaraccio, P. de Angelis, G. de Dato, B. A. Emmett, M. Estiarte, J. Garadnai, A. Gorissen, E. K. Láng, G. Kröel-dulay, L. Llorens, G. Pellizzaro, T. Riis-nielsen, I. K. Schmidt, C. Sirca, A. Sowerby, D. Spano, and A. Tietema. 2007. Response of plant species richness and primary productivity in shrublands along a north-south gradient in Europe to seven years of experimental warming and drought: reductions in primary productivity in the heat and drought year of 2003. Global Change Biology 13:2563-2581.

Pravosudov, V. V. 2003. Long-term moderate elevation of corticosterone facilitates avian food-caching behaviour and enhances spatial memory. Proceedings of the Royal Society B 270:2599-2604.

Preest, M. R., and A. Cree. 2008. Corticosterone treatment has subtle effects on thermoregulatory behavior and raises metabolic rate in the New Zealand common gecko, Hoplodactylus maculatus. Physiological and Biochemical Zoology 81:641650.

Putman, B., C. Lind, and E. Taylor. 2013. Does size matter? Factors influencing the spatial ecology of northern Pacific rattlesnakes (Crotalus oreganus oreganus) in central California. Copeia 2013:485-492.

Quinn, H., J.P. Jones. 1974. Squeeze box technique for measuring snakes. Herpetological Review 5:35

Rahn, H. 1942. The reproductive cycle of the prairie rattler. Copeia 4:233-240.

Roberts, E. M., G. R. Pope, M. J. F. Newson, S. J. Lolait, and A.-M. O’Carroll. 2011. The vasopressin $\mathrm{V} 1 \mathrm{~b}$ receptor modulates plasma corticosterone responses to dehydration-induced stress. Journal of Neuroendocrinology 23:12-19.

Rodgers, A. R., A.P., Carr, H.L. Beyer, L. Smith, J.G. Kie. 2007. HRT: home range tools for ArcGIS.

Roe, J. H., and A. Georges. 2008. Terrestrial activity, movements and spatial ecology of an Australian freshwater turtle, Chelodina longicollis, in a temporally dynamic wetland system. Austral Ecology 33:1045-1056.

Romero, L., and M. Wikelski. 2001. Corticosterone levels predict survival probabilities of Galapagos marine iguanas during El Nino events. Proceedings of the National Academy of Sciences of the United States of America 98:7366-7370.

Sanders, J. S., and J. S. Jacob. 1981. Thermal ecology of the copperhead (Agkistrodon contortrix). Herpetologica 37:264-270. 
Schwarzkopf, L., and R. Shine. 1991. Thermal biology of reproduction in viviparous skinks, Eulamprus tympanum: why do gravid females bask more? Oecologia 88:562-569.

Seager, R., and G.A. Vecchi. 2010. Greenhouse warming and the 21st century hydroclimate of southwestern North America. Proceedings of the National Academy of Sciences of the United States of America 107:21277-21282.

Sears, M., and M. Angilletta. 2003. Life-history variation in the sagebrush lizard: Phenotypic plasticity or local adaptation? Ecology 84:1624-1634.

Seidel, M. E. 1978. Terrestrial dormancy in the turtle Kinosternon flavescens: respiratory metabolism and dehydration. Comparative Biochemistry and Physiology Part A 61:1-4.

Shine, R. 1983. Reptilian viviparity in cold climates: testing the assumptions of an evolutionary hypothesis. Oecologia 57:397-405.

Shine, R. 1999. Why is sex determined by nest temperature in many reptiles? Trends in Ecology and Evolution 14:186-188.

Shine, R., and S. J. Downes. 1999. Can pregnant lizards adjust their offspring phenotypes to environmental conditions? Oecologia 119:1-8.

Shine, R., and P. Harlow. 1993. Maternal thermoregulation influences offspring viability in a viviparous lizard. Oecologia 96:122-127.

Shine, R., and M. Olsson. 2003. When to be born? Prolonged pregnancy or incubation enhances locomotor performance in neonatal lizards (Scincidae). Journal of Evolutionary Biology 16:823-832.

Shoemaker, V. H. 1964. The effects of dehydration on electrolyte concentrations in a toad, Bufo marinus. Comparative Biochemistry and Physiology 13:261-271.

Sinervo, B., and P. Licht. 1991. Hormonal and physiological control of clutch size, egg size, and egg shape in side-blotched lizards (Uta stansburiana) - Constraints on the evolution of lizard life histories. Journal of Experimental Zoology 257:252-264.

Smits, A. W. 1986. Accessory lymph sacs and body fluid partitioning in the lizard, Sauromalus hispidus. Journal of Experimental Biology 121:165-77.

Sperry, J. H., and P. J. Weatherhead. 2008. Prey-mediated effects of drought on condition and survival of a terrestrial snake. Ecology 89:2770-2776.

Stamps, J., and S. Tanaka. 1981. The influence of food and water on growth rates in a tropical lizard (Anolis aeneus). Ecology 62:33-40. 
Stewart, J., and R. Castillo. 1984. Nutritional provision of the yolk of two species of viviparous reptiles. Physiological Zoology 57:377-383.

Stewart, J. 1989. Facultative placentotrophy and the evolution of squamate placentation: quality of eggs and neonates in Virginia striatula. American Naturalist 133:111137.

Stewart, J. R., D. G. Blackburn, D. C. Baxter, and L. H. Hoffman. 1990. Nutritional provision to embryos in a predominantly lecithotrophic placental reptile, Thamnophis ordinoides (Squamata: Serpentes). Physiological Zoology 63:722-734.

Talbot, L. M., and M. H. Talbot. 1963. The wildebeest in western Masailand, East Africa. Wildlife Monographs 12:3-88.

Taylor, E. N., D. F. DeNardo, and D. H. Jennings. 2004. Seasonal steroid hormone levels and their relation to reproduction in the Western diamond-backed rattlesnake, Crotalus atrox (Serpentes: Viperidae). General and Comparative Endocrinology 136:328-37.

Taylor, E. N., and D. F. Denardo. 2005. Sexual size dimorphism and growth plasticity in snakes: an experiment on the Western diamond-backed rattlesnake (Crotalus atrox). Journal of Experimental Zoology 303A:598-607.

Taylor, E. N., M. A. Malawy, D. M. Browning, S. V. Lemar, and D. F. DeNardo. 2005. Effects of food supplementation on the physiological ecology of female western diamond-backed rattlesnakes (Crotalus atrox). Oecologia 144:206-213.

Taylor, E. N., and D. F. Denardo. 2010. Hormone and reproductive cycles in snakes. Pages 355-372 in. Hormones and Reproduction of Vertebrates, Vol. 3 Reptiles.

Tingley, R., and R. Shine. 2011. Desiccation risk drives the spatial ecology of an invasive anuran (Rhinella marina) in the Australian semi-desert. PLoS ONE 6:e25979.

Touma, C., R. Palme, and N. Sachser. 2004. Analyzing corticosterone metabolites in fecal samples of mice: A noninvasive technique to monitor stress hormones. Hormones and Behavior 45:10-22.

Van Damme, R., D. Bawens, F. Brana, and F. Rudolf. 1992. Incubation temperature differentially affects hatching time, survival, and hatchling performance in the lizard Podarcis muralis. Herpetologica 48:220-228.

Van Dyke, J. U., and S. J. Beaupre. 2011. Bioenergetic components of reproductive effort in viviparous snakes: costs of vitellogenesis exceed costs of pregnancy. Comparative Biochemistry and Physiology - Part A 160:504-515. 
Waldron, J. L., S. H. Bennett, S. M. Welch, M. E. Dorcas, J. D. Lanham, and W. Kalinowsky. 2006. Habitat specificity and home-range size as attributes of species vulnerability to extinction: a case study using sympatric rattlesnakes. Animal Conservation 9:414-420.

Wapstra, E. 2000. Maternal basking opportunity affects juvenile phenotype in a viviparous lizard. Functional Ecology 14:345-352.

Wapstra, E., M. Olsson, R. Shine, A. Edwards, R. Swain, and J. M. P. Joss. 2004. Maternal basking behaviour determines offspring sex in a viviparous reptile. Proceedings of the Royal Society B 271:S230-S232.

Willson, J. D., C. T. Winne, M. E. Dorcas, and J. W. Gibbons. 2006. Post-drought responses of semi-aquatic snakes inhabiting an isolated wetland: Insights on different strategies for persistence in a dynamic habitat. Wetlands 26:1071-1078.

Wingfield, J. C., and D. S. Farner. 1975. The determination of five steroids in avian plasma by radioimmunoassay and competitive protein-binding. Steroids 26:311321.

Winne, C. T., J. D. Willson, and J. W. Gibbons. 2010. Drought survival and reproduction impose contrasting selection pressures on maximum body size and sexual size dimorphism in a snake, Seminatrix pygaea. Oecologia 162:913-922.

Wolf, B., and G. Walsberg. 1996. Respiratory and cutaneous evaporative water loss at high environmental temperatures in a small bird. The Journal of Experimental Biology 199:451-457.

Zhao, M., and S. W. Running. 2010. Drought-induced reduction in global terrestrial net primary production from 2000 through 2009. Science 329:940-943.

Zhu, W. L., T. Jia, X. Lian, and Z. K. Wang. 2008. Evaporative water loss and energy metabolic in two small mammals, voles (Eothenomys miletus) and mice (Apodemus chevrieri), in Hengduan mountains region. Journal of Thermal Biology 33:324-331.

Zhu, W. L., L. Zhang, and Z. K. Wang. 2010. Thermogenic characteristics and evaporative water loss in the tree shrew (Tupaia belangeri). Journal of Thermal Biology 35:290-294. 


\section{APPENDICES}

Appendix A Tables

Table 1. Descriptive characteristics of reproductive female Northern Pacific Rattlesnakes (Crotalus oreganus oreganus), all of which received supplemental hydration.

\begin{tabular}{cccccccc}
\hline & $\begin{array}{l}\text { SVL } \\
(\mathrm{cm})\end{array}$ & Mass & $\begin{array}{l}\text { Viable/Non } \\
\text {-viable } \\
\text { offspring }\end{array}$ & $\begin{array}{l}\text { Post- } \\
\text { Parturien } \\
\text { t Mass }\end{array}$ & $\begin{array}{l}\text { Total } \\
\text { Clutch } \\
\text { Mass }\end{array}$ & $\begin{array}{l}\text { Live } \\
\text { Clutch } \\
\text { Mass }\end{array}$ & $\begin{array}{l}\text { Relative } \\
\text { Clutch Mass } \\
\text { total }\end{array}$ \\
\hline 61 & 48.8 & 140 & $2 / 2$ & 104.5 & 38 & 23.4 & 0.364 \\
44 & 58.3 & 265 & $4 / 2$ & 175 & 60.1 & 42.9 & 0.343 \\
53 & 56 & 226 & $3 / 2$ & 139 & 46 & 31.5 & 0.331 \\
26 & 47.7 & 183 & $1 / 1$ & 167 & 13 & 10 & 0.078 \\
\hline
\end{tabular}

Table 2. Means \pm SE of Northern Pacific Rattlesnakes (C. o. oreganus) for $100 \%$ and 95\% minimum convex polygon (MCP) activity ranges (ha), total distance moved (m), and rate of movement (m/day) for the entire study period ranging from 25 March 2014 19 October 2014. Note: Most snakes were tracked for a smaller period of time; however, all locations were recorded between the two previously mentioned dates.

\begin{tabular}{llllll}
\hline Group & $N$ & $100 \% \operatorname{MCP}(\mathrm{ha})$ & $95 \% \operatorname{MCP}(\mathrm{ha})$ & $\operatorname{TDM}(\mathrm{m})$ & Rate $(\mathrm{m} /$ day $)$ \\
\hline Control F & 3 & $0.99 \pm 0.73$ & $0.93 \pm 0.67$ & $689 \pm 448.6$ & $5.27 \pm 3.02$ \\
Hydrated F & 4 & $0.23 \pm 0.12$ & $0.22 \pm 0.12$ & $197.5 \pm 27.3$ & $1.53 \pm 0.24$ \\
Control M & 5 & $0.89 \pm 0.39$ & $0.89 \pm 0.39$ & $594.6 \pm 205.2$ & $6.07 \pm 2.17$ \\
Hydrated M & 7 & $2.40 \pm 1.33$ & $1.94 \pm 1.27$ & $715.7 \pm 227.3$ & $6.31 \pm 1.66$ \\
\hline
\end{tabular}


Table 3. Effects of treatment group (hydrated and control), time (initial and end of study), and their interaction on body condition index (BCI) of C. o. oreganus. $\mathrm{P}<0.05$ designated by bold italics; $0.05<\mathrm{P}<0.10$ designated by italics. For unadjusted BCI and BCI adjusted for $10 \mathrm{~g}$ and $5 \mathrm{~g}$ of water weight, final BCI was higher for hydrated snakes, but this was marginally non-significant. In general, BCI was similar between treatment groups at the beginning of study, while hydrated snakes had higher BCI by the end of the study.

\begin{tabular}{lcccccc} 
& \multicolumn{2}{c}{ Treatment Group } & \multicolumn{2}{c}{ Time } & \multicolumn{2}{c}{ Interaction } \\
\cline { 2 - 7 } & $\mathrm{F}_{1,25}$ & $\mathrm{P}$ & $\mathrm{F}_{1,25}$ & $\mathrm{P}$ & $\mathrm{F}_{1,25}$ & $\mathrm{P}$ \\
\hline Unadjusted & 6.96 & $\mathbf{0 . 0 1 5}$ & 0.022 & 0.883 & 3.72 & 0.067 \\
$25 \mathrm{~g}$ & 4.70 & $\mathbf{0 . 0 4 1}$ & 0.013 & 0.912 & 2.12 & 0.160 \\
$20 \mathrm{~g}$ & 5.13 & $\mathbf{0 . 0 3 4}$ & 0.014 & 0.906 & 2.41 & 0.135 \\
$15 \mathrm{~g}$ & 5.57 & $\mathbf{0 . 0 2 8}$ & 0.016 & 0.900 & 2.72 & 0.113 \\
$10 \mathrm{~g}$ & 6.03 & $\mathbf{0 . 0 2 3}$ & 0.018 & 0.895 & 3.04 & 0.095 \\
$5 \mathrm{~g}$ & 6.49 & $\mathbf{0 . 0 1 8}$ & 0.020 & 0.889 & 3.37 & 0.080 \\
\hline
\end{tabular}




\section{Appendix B Figures}

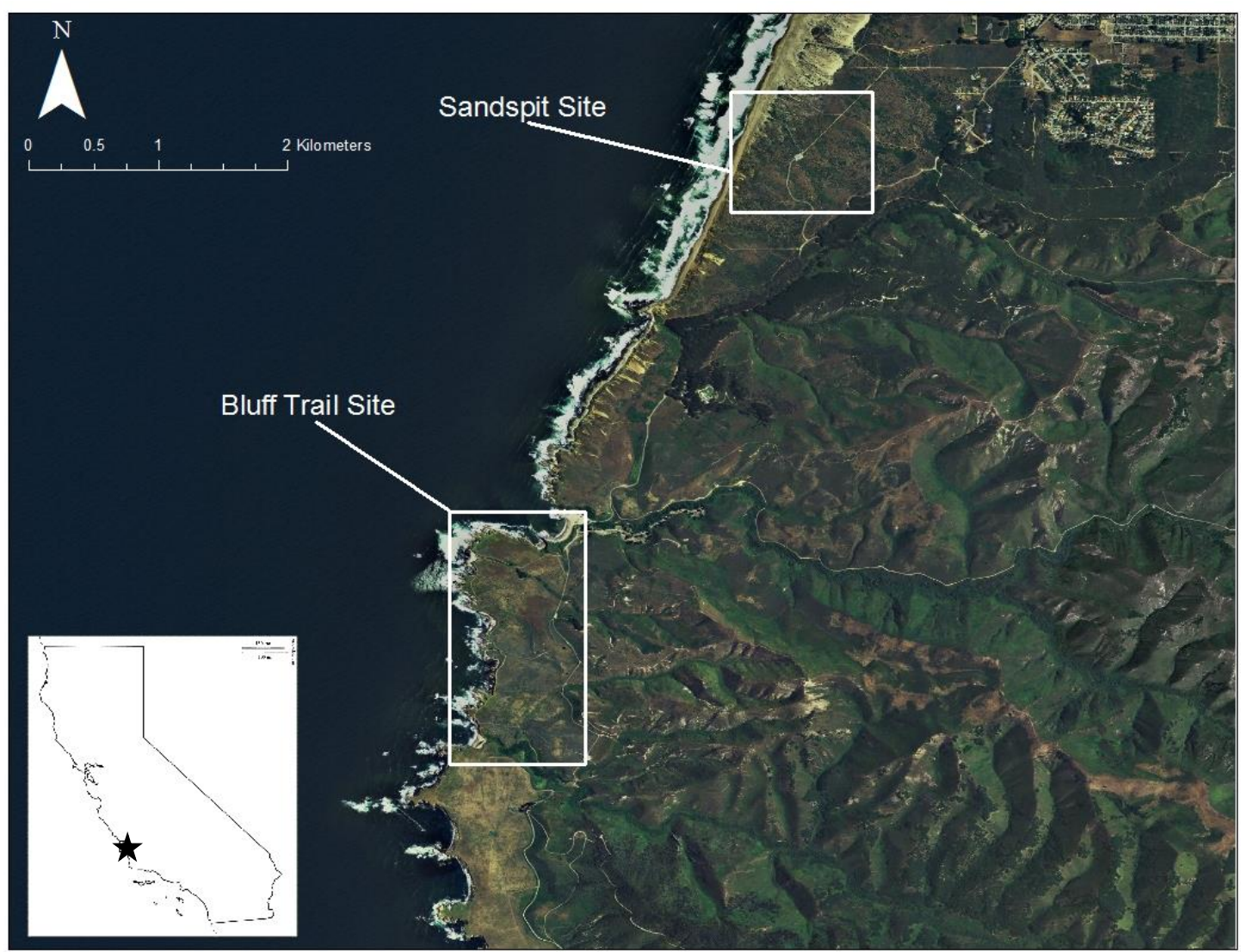

Figure 1. Map of study site highlighting two locations where the study took place. Both sites were located within Montaña de Oro, indicated by star on inset map. 


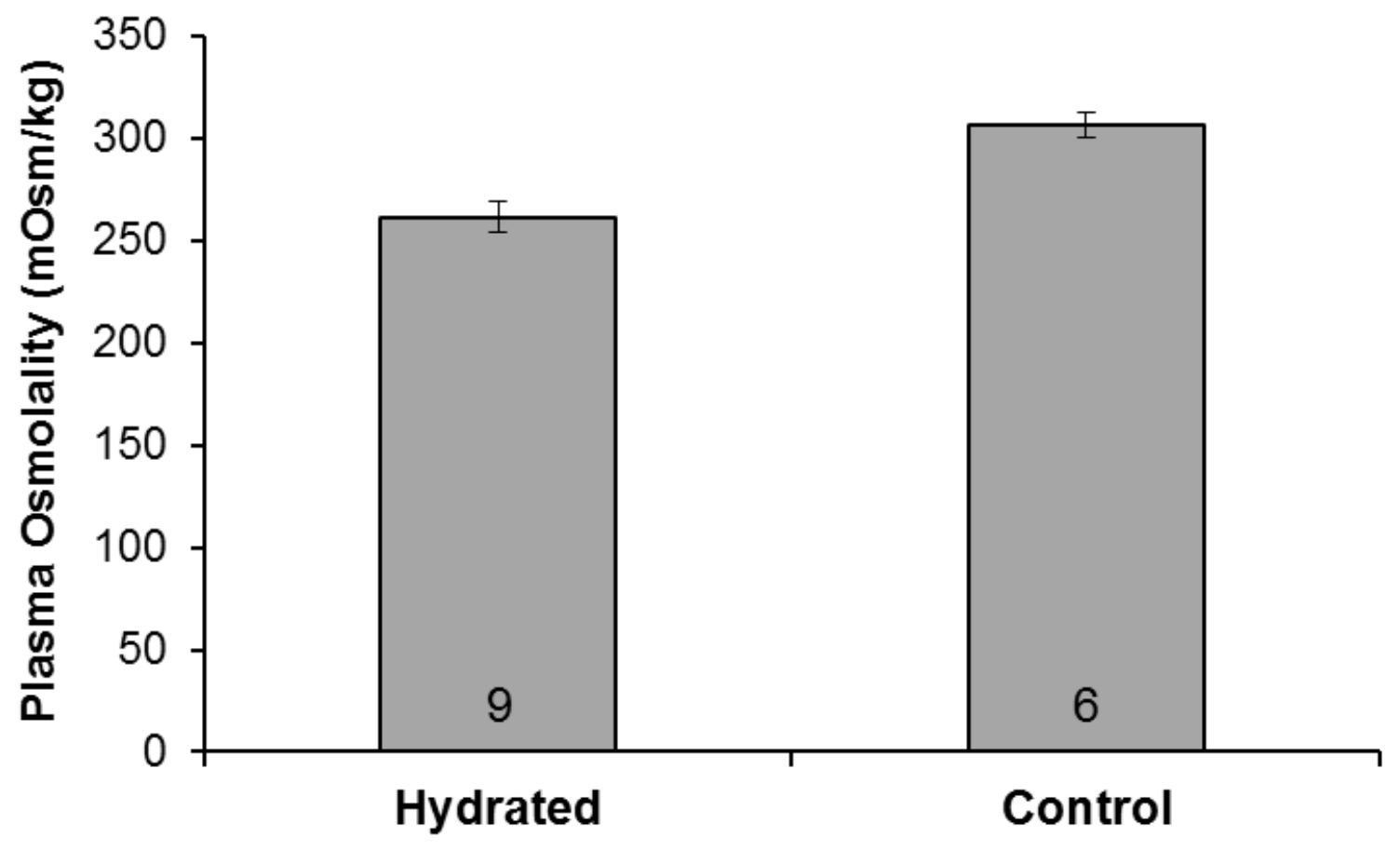

Figure 2. Plasma osmolality of hydrated (water-supplemented) Crotalus o. oreganus was significantly lower than in control snakes, indicating that experimental water supplementation was successful. Numbers in bars are sample sizes, and error bars represent 1 SEM. 


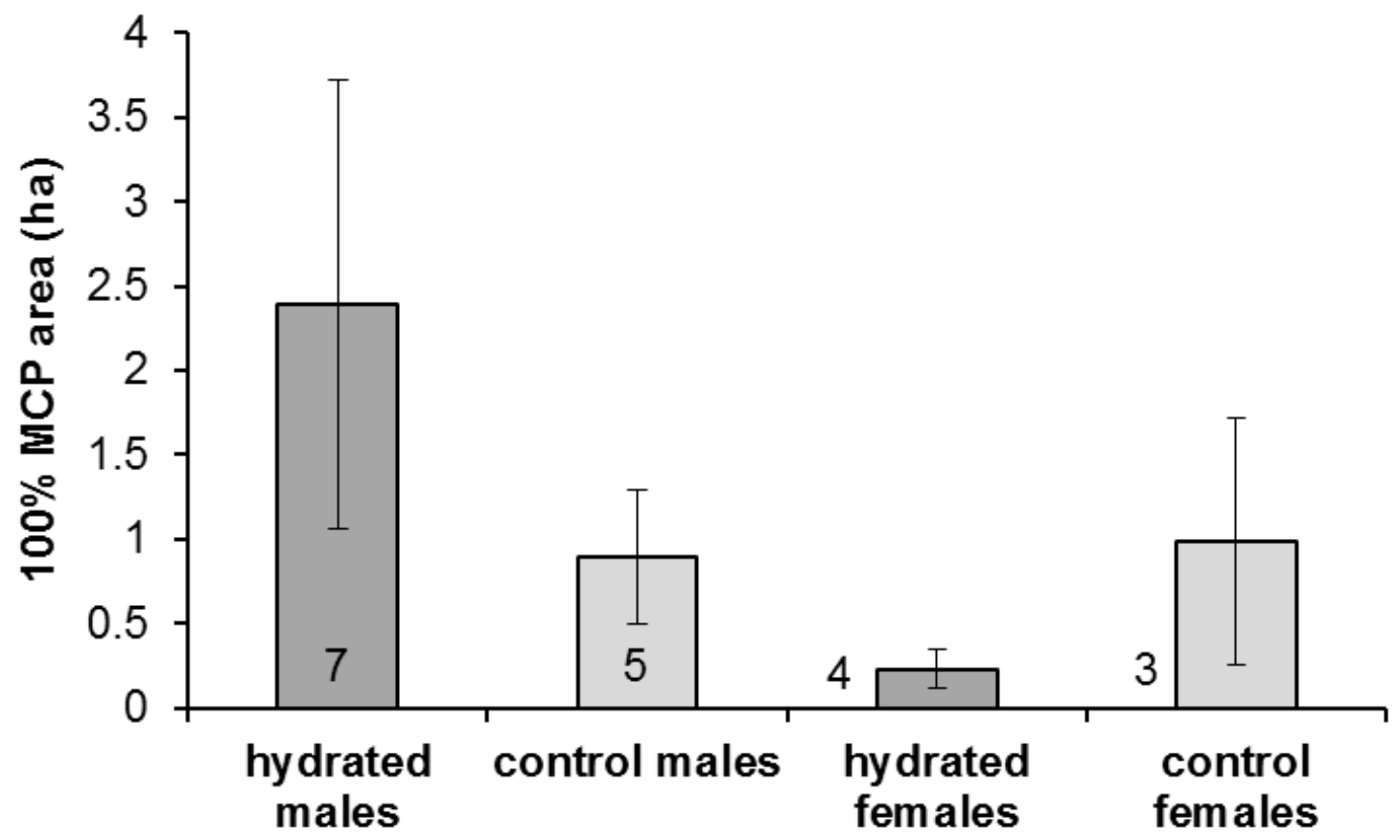

Additionally, a single female displayed an unusually large home range. A separate analysis was performed without these individuals which found no significant difference between the sexes. Note the variability in home range size. Numbers at the base of bars are sample sizes and error bars represent 1 SEM. 


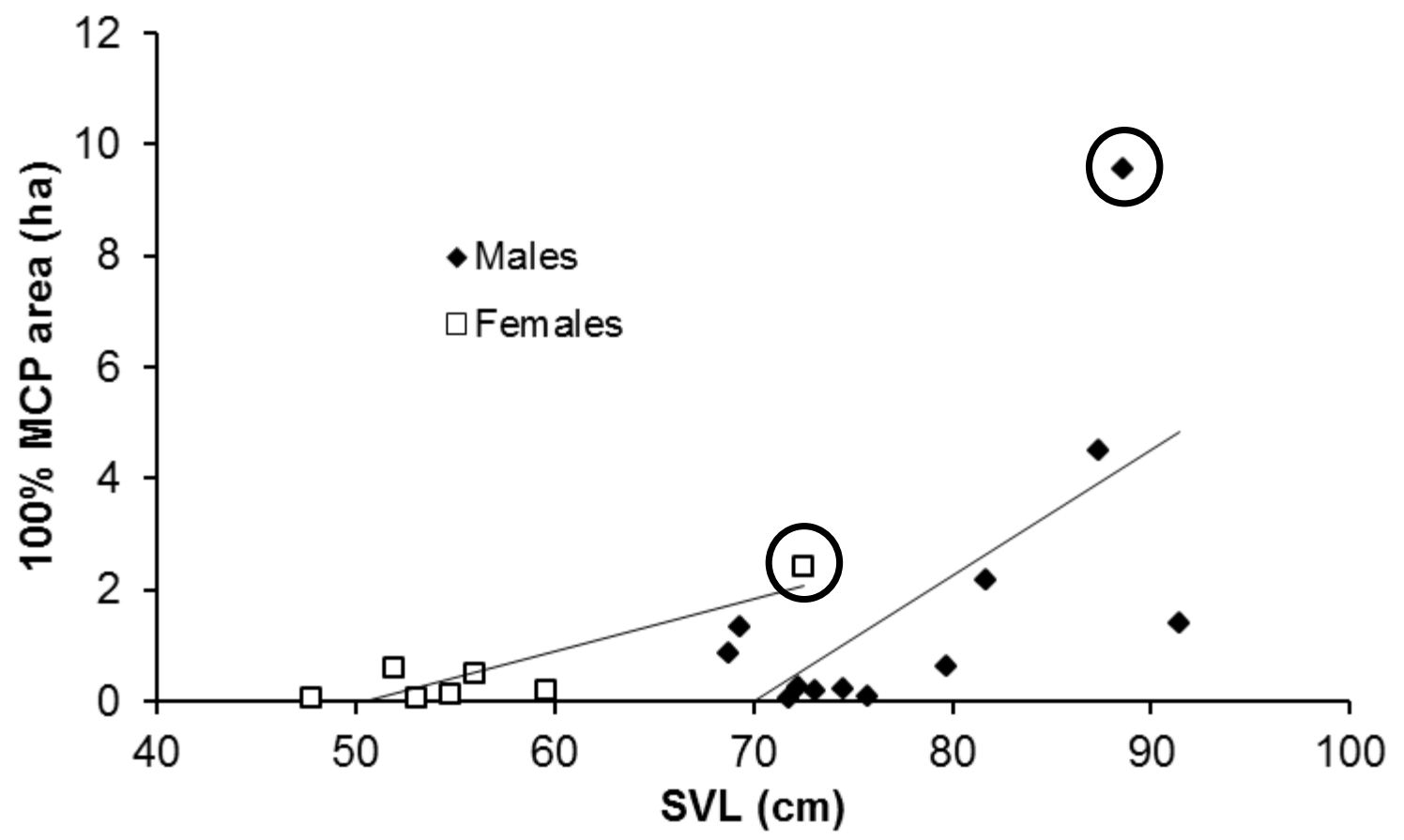

Figure 4. Snout-vent-length (SVL) of C. o. oreganus individuals is plotted against the area of the $100 \%$ Minimum Convex Polygon (MCP) area or home range. Larger snakes had larger home ranges. Note that male home ranges are very similar to female home ranges and that only a few males had extensive home range sizes. There are two obvious outliers: one female and one male (circled). These snakes exerted large leverage on the home range analysis. Removal of these individuals caused the difference in home range size between the sexes to disappear. There was no effect of hydration on home range size. 


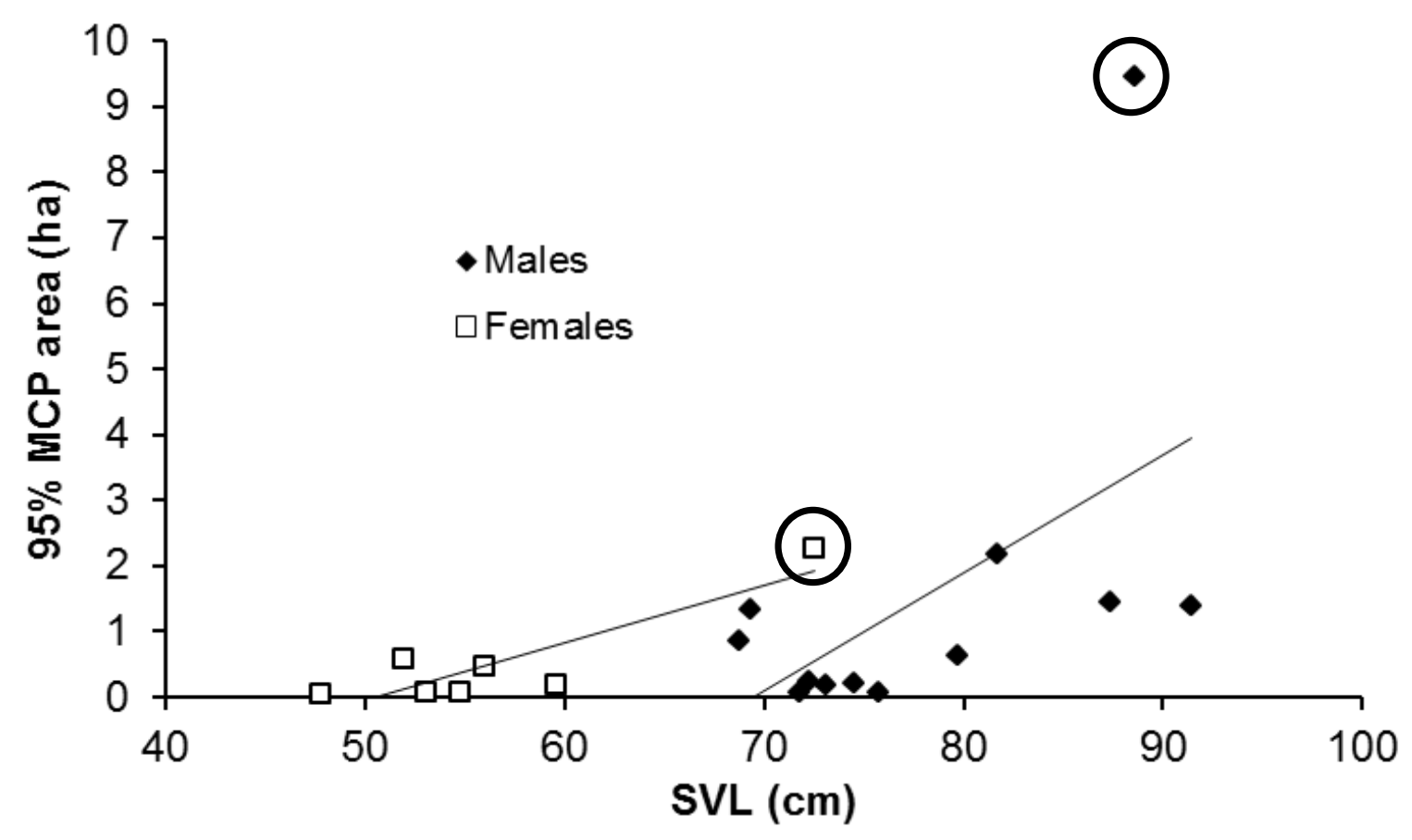

Figure 5. Snout-vent-length (SVL) of C. o. oreganus individuals is plotted against the area of the 95\% Minimum Convex Polygon (MCP) area or home range. Larger snakes had larger home ranges. Note that male home ranges are very similar to female home ranges and that only a few males had extensive home range sizes. There are two obvious outliers: one female and one male (circled). These snakes exerted large leverage on the home range analysis. Removal of these individuals caused the difference in home range size between the sexes to disappear. There was no effect of hydration on home range size. Only one snake experienced a large reduction in home range size from the calculation of $100 \% \mathrm{MCP}$ to $95 \% \mathrm{MCP}$. 


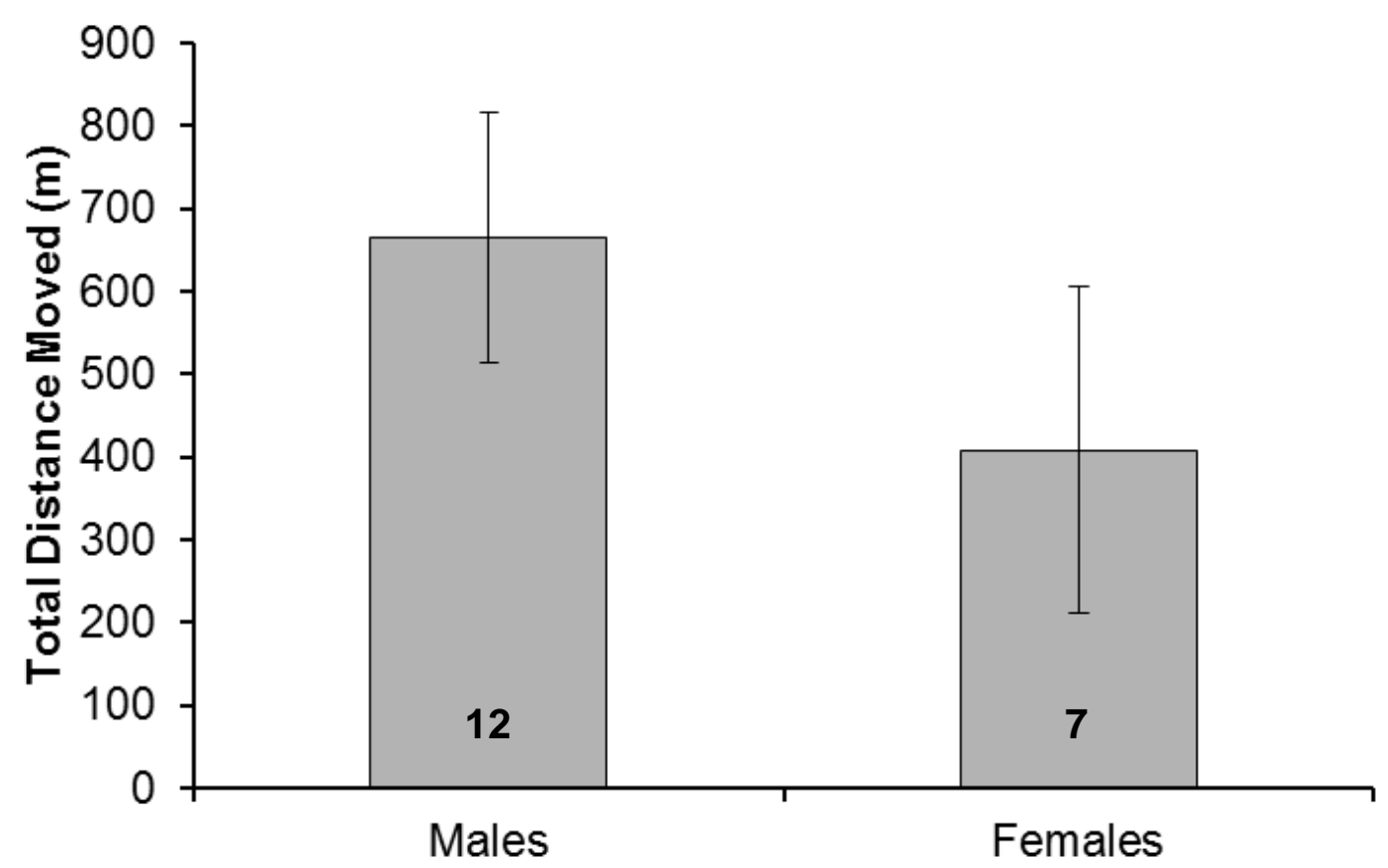

Figure 6. Total distance moved (TDM) of C. o. oreganus males and females. Males moved a significantly larger total distance than females. Males moved $257 \mathrm{~m}$ more than females on average. The removal of the outlier female which moved a greater total distance than all but one male did not influence the results. Numbers in bars are sample sizes and error bars are 1 SEM. 


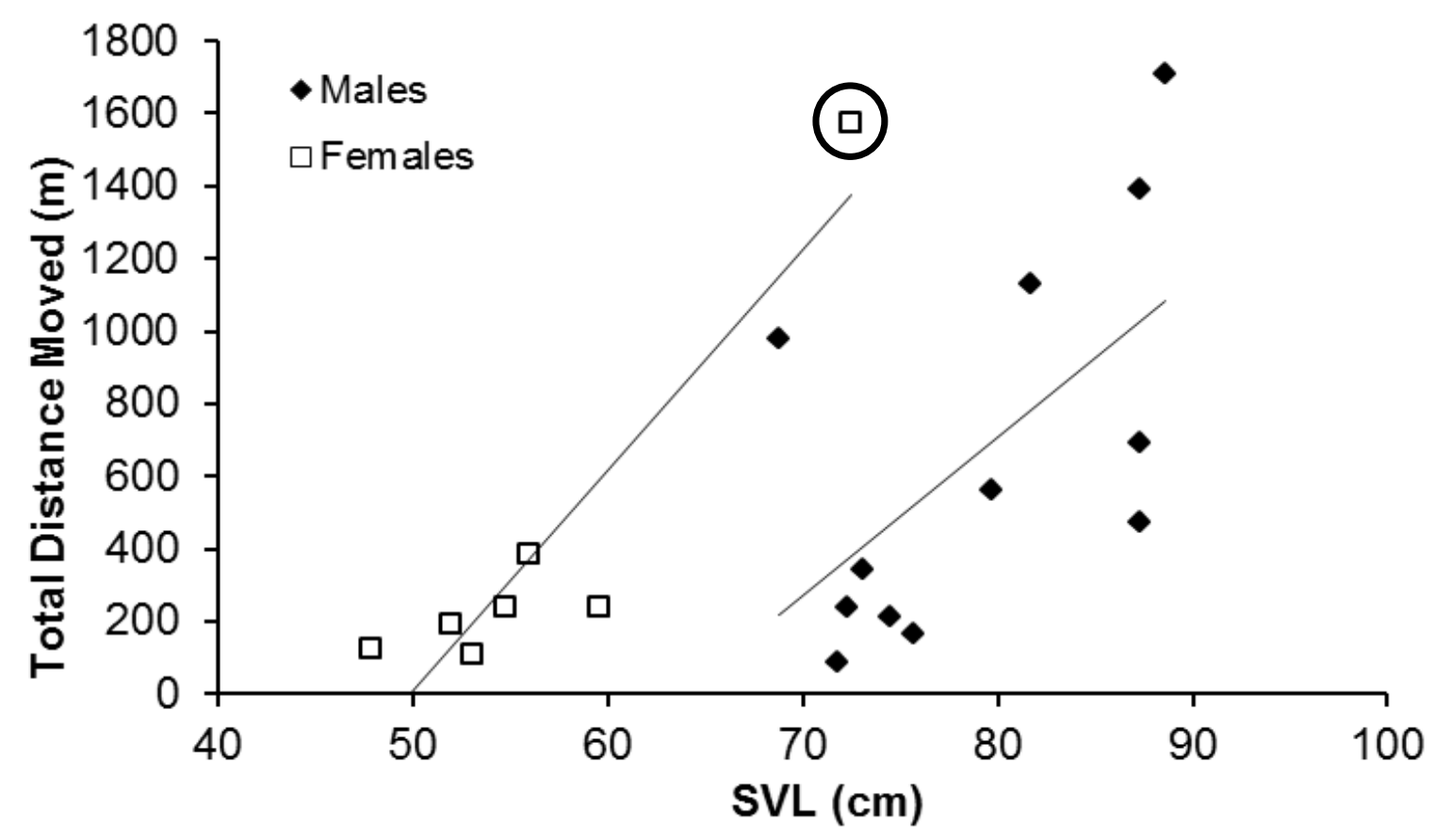

Figure 7. Snout-vent-length (SVL) of individual C. o. oreganus is plotted against its total distance moved. Longer snakes moved larger total distances. Note the female that moved a larger total distance than all but one male (circled). Despite this, males still moved a larger total distance, overall. 


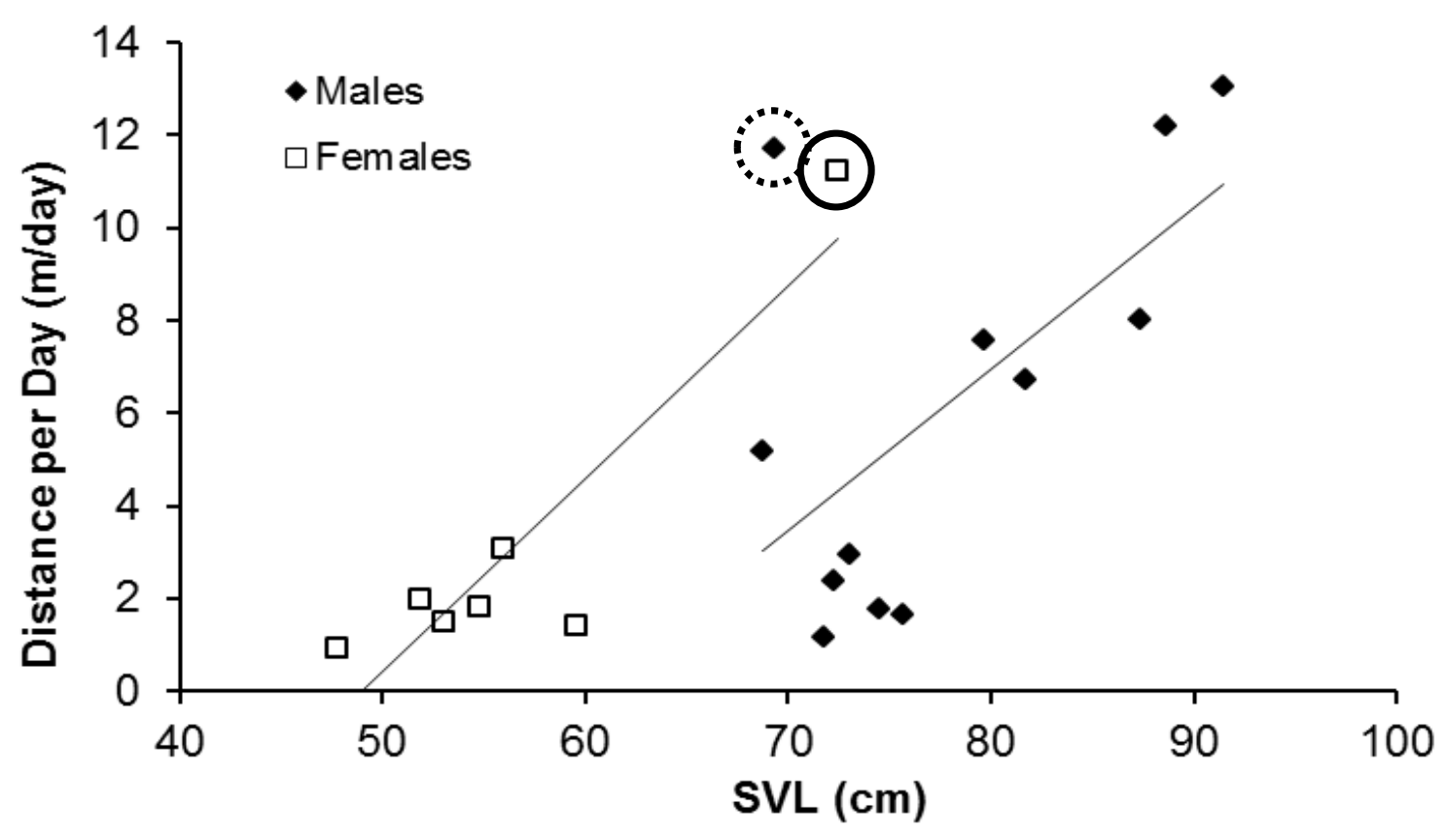

Figure 8. Snout-vent-length (SVL) of individual C. o. oreganus is plotted against the average distance moved per day. Longer snakes typically moved larger distances, with a few exceptions. The female with an abnormally large home range and total distance moved also had large daily movements (solid circle). Additionally, one smaller male $(\mathrm{SVL}=70)$ had larger movements than all but two males (dotted circle). 


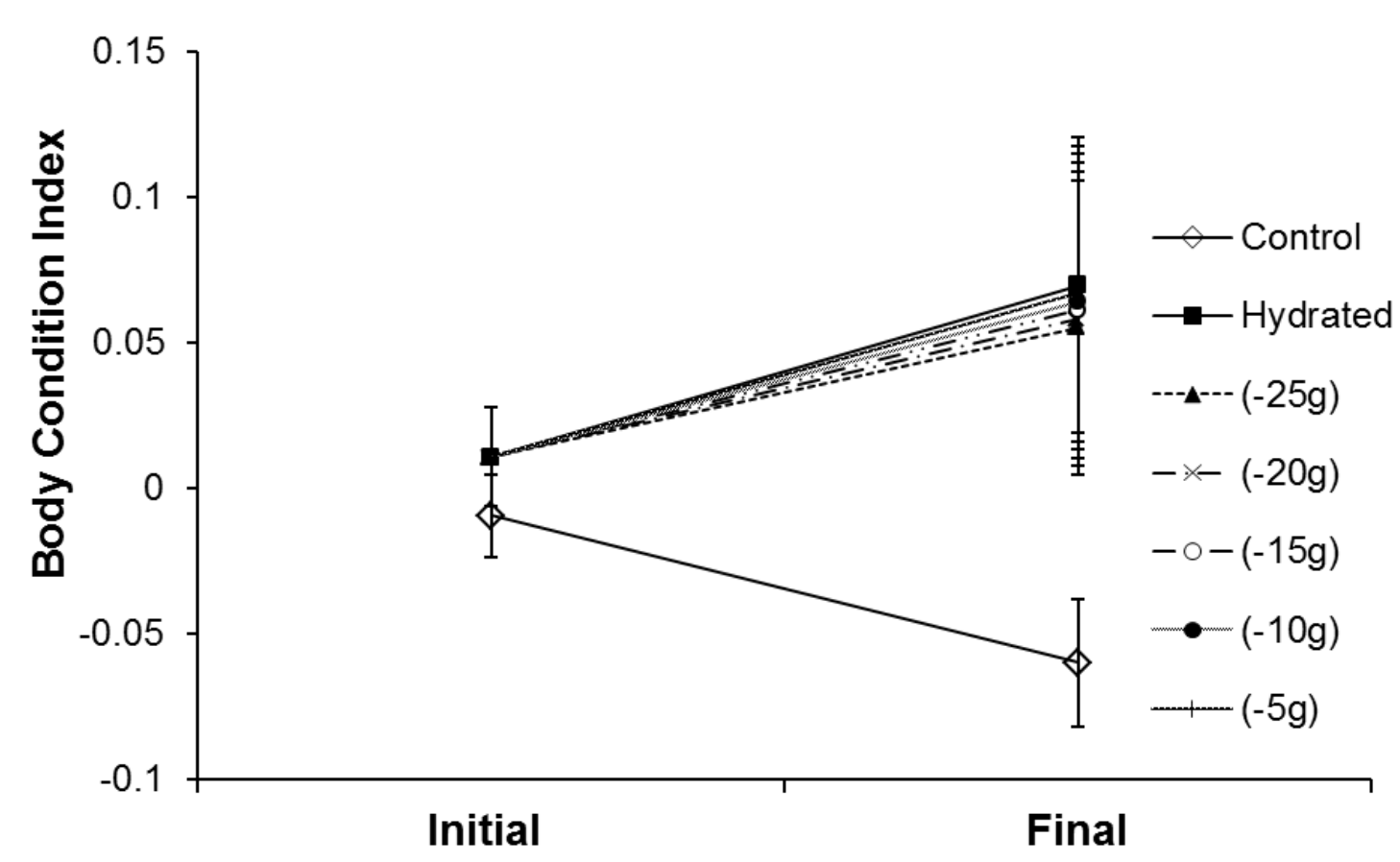

Figure 9. Body condition index (BCI) for C. o. oreganus taken at the beginning and end of the study period. There was a significant main effect of hydration where hydrated snakes had significantly higher BCI than control snakes. There was a marginally nonsignificant interaction between time (initial or final) and treatment group with hydrated snakes having higher final BCI than control snakes. After adjusting for water weight, this difference was non-significant. Hydrated snakes BCI was still significantly higher than control snakes. The overall difference between the treatment groups appears to be driven by the increased $\mathrm{BCI}$ in hydrated snakes and the decrease in $\mathrm{BCI}$ in control snakes at the end of the study. Note the similarity in initial BCI. 


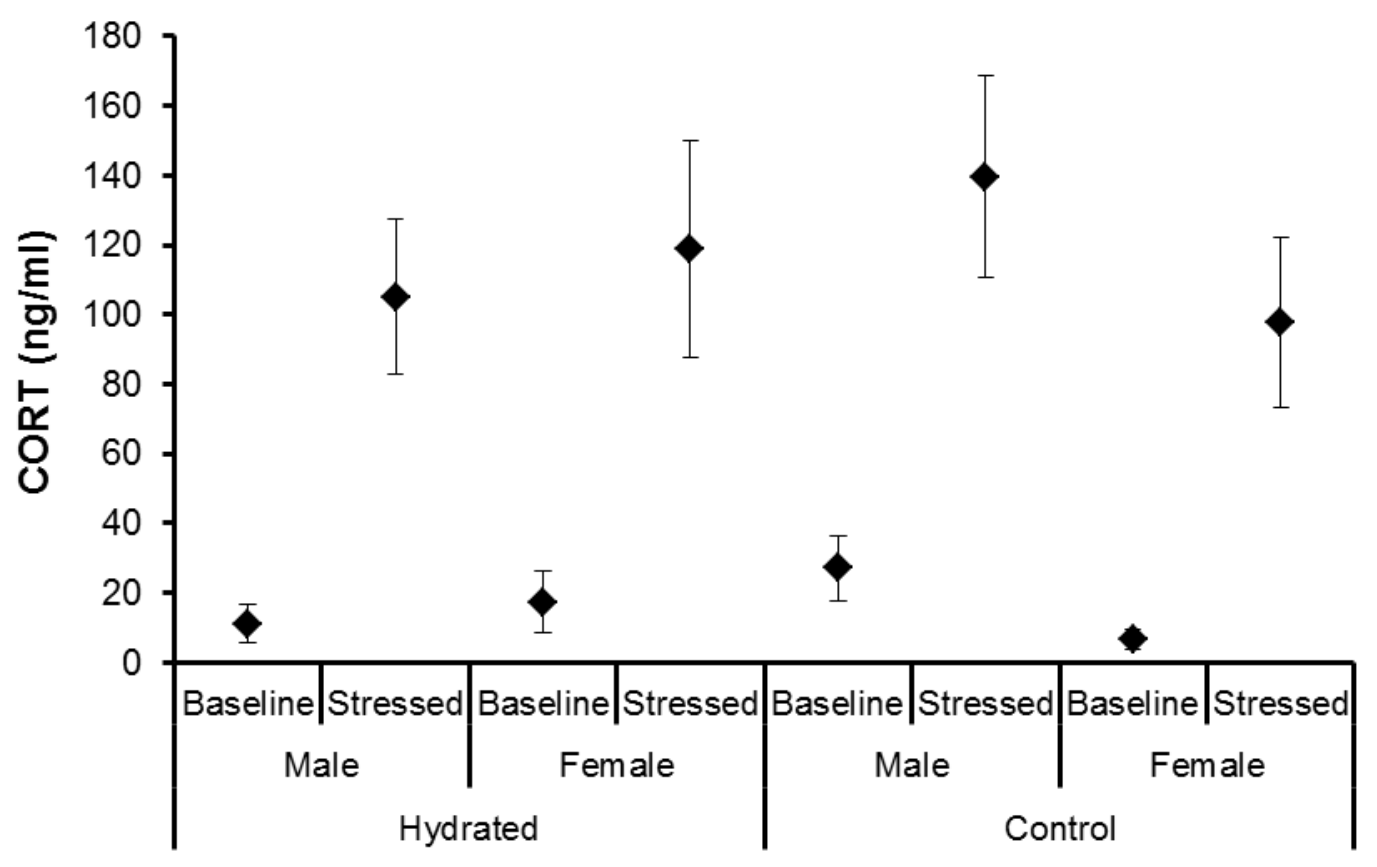

Figure 10. Mean corticosterone (CORT) concentrations of C. o. oreganus for baseline or stressed samples, sex, and treatment groups (control or hydrated). Stressed CORT concentration was consistently higher than baseline CORT regardless of treatment group or sex. There were no effects of hydration or sex on CORT physiology. Error bars are 1 SEM. 


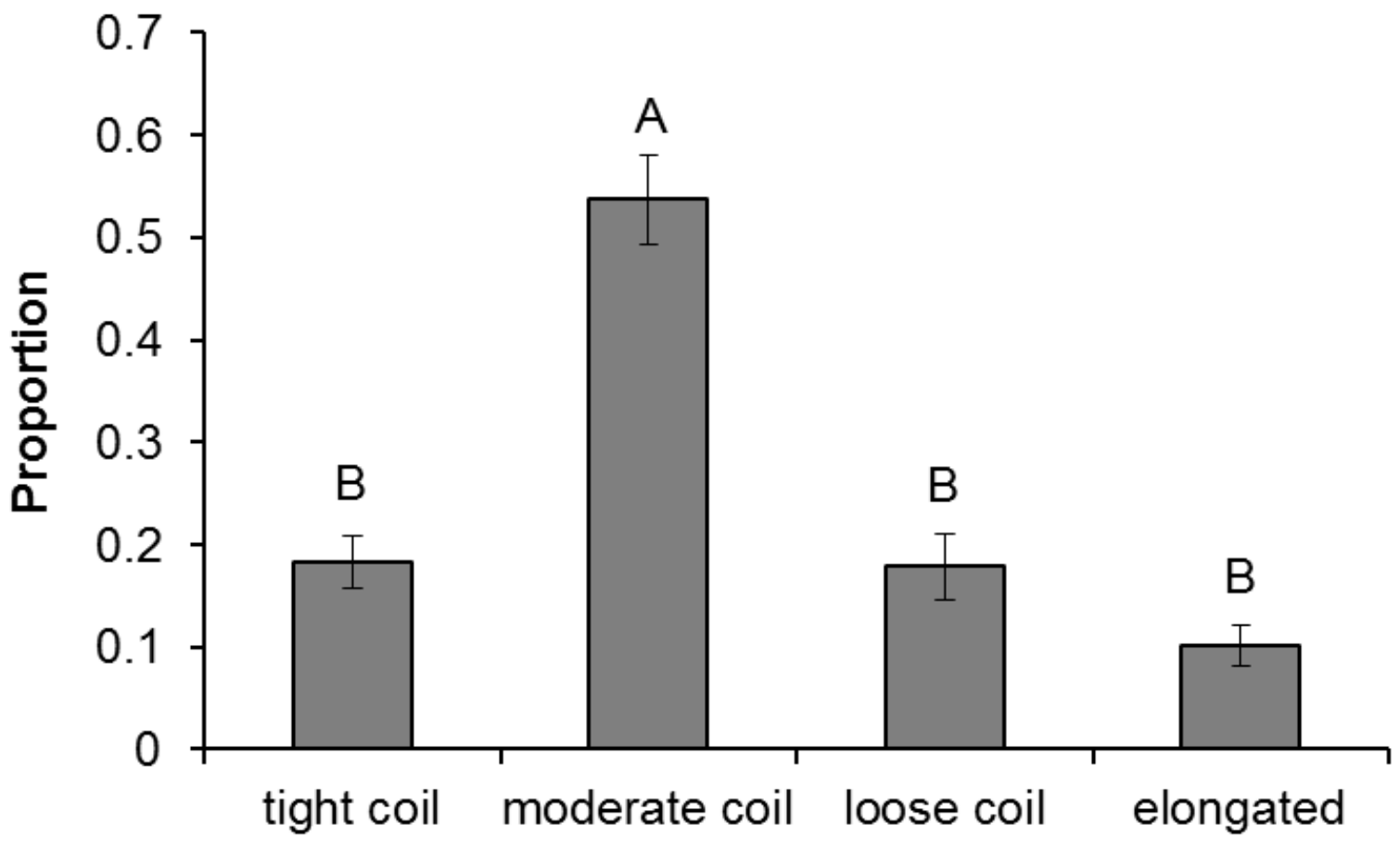

Figure 11. Frequency of time spent by $C$. o. oreganus in different body positions. Snakes spent a significantly larger amount of time in a moderate coil than in any other body position. This is expected in an ambush forager that does not make frequent movements. Bars that do not share a letter are significantly different. Error bars are 1 SEM. 


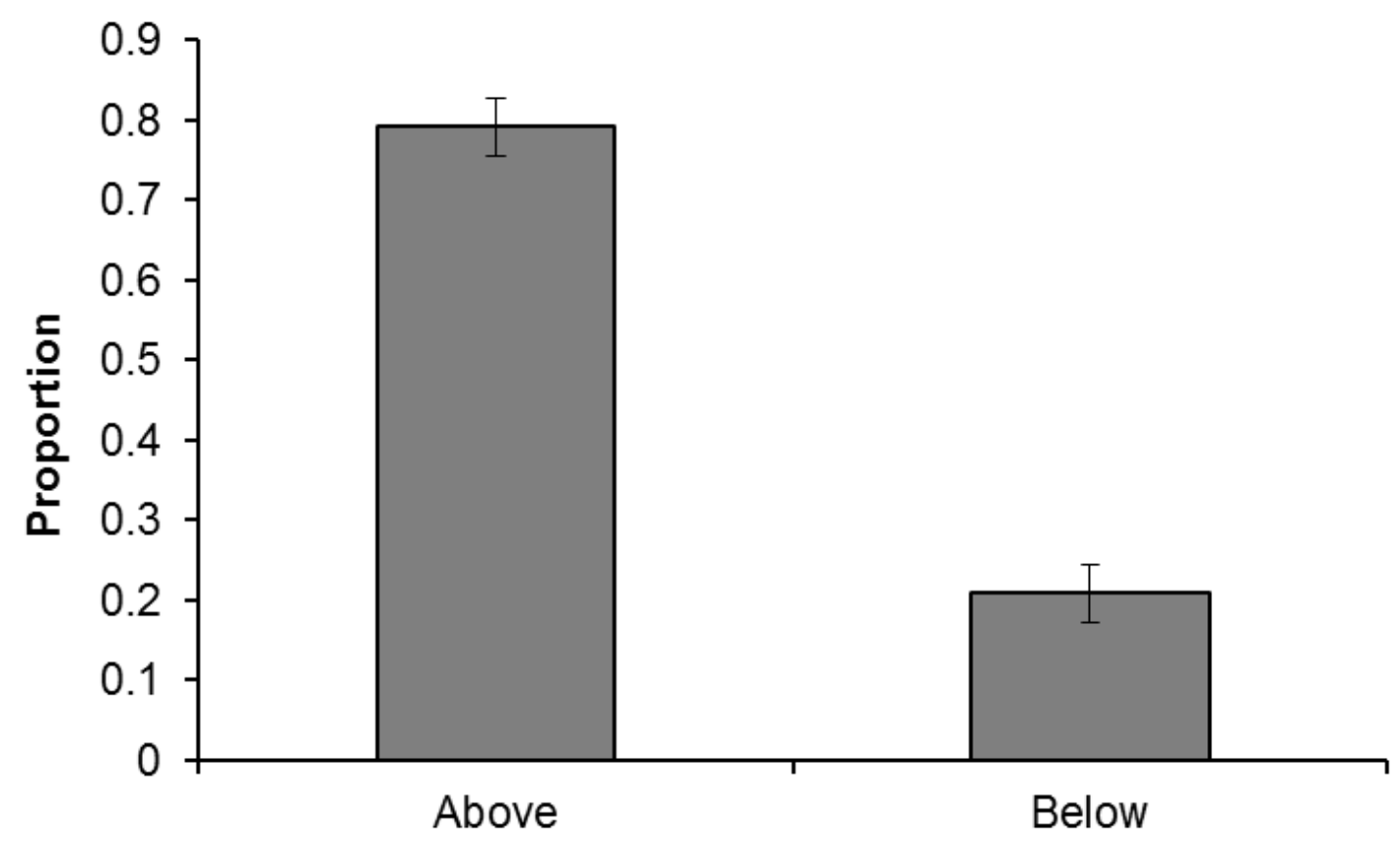

Figure 12. Frequency of time spent above or below ground by C. o. oreganus. Snakes spent a significantly larger portion of time on the surface than below ground. There were no effects of treatment group or sex on time spent on the surface. Error bars are 1 SEM. 


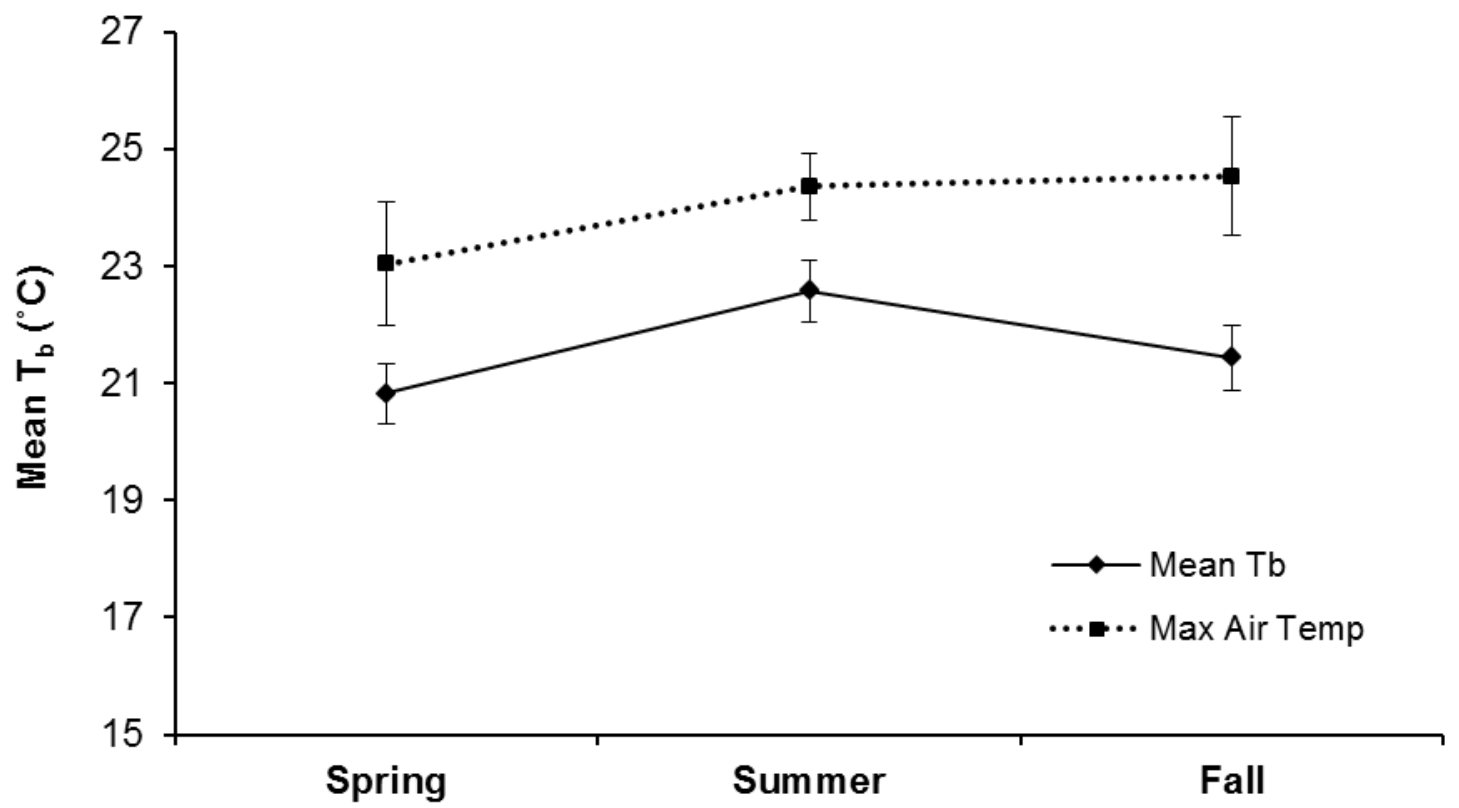

Figure 13. Mean $\mathrm{T}_{\mathrm{b}}$ of C. o. oreganus during spring, summer, and fall averaged across treatment groups and sexes $(\mathrm{N}=16)$. $\mathrm{T}_{\mathrm{b}}$ in the summer was significantly warmer than in the spring, but not from fall. Note that $\mathrm{T}_{\mathrm{b}}$ was always lower than the max air temperature. 


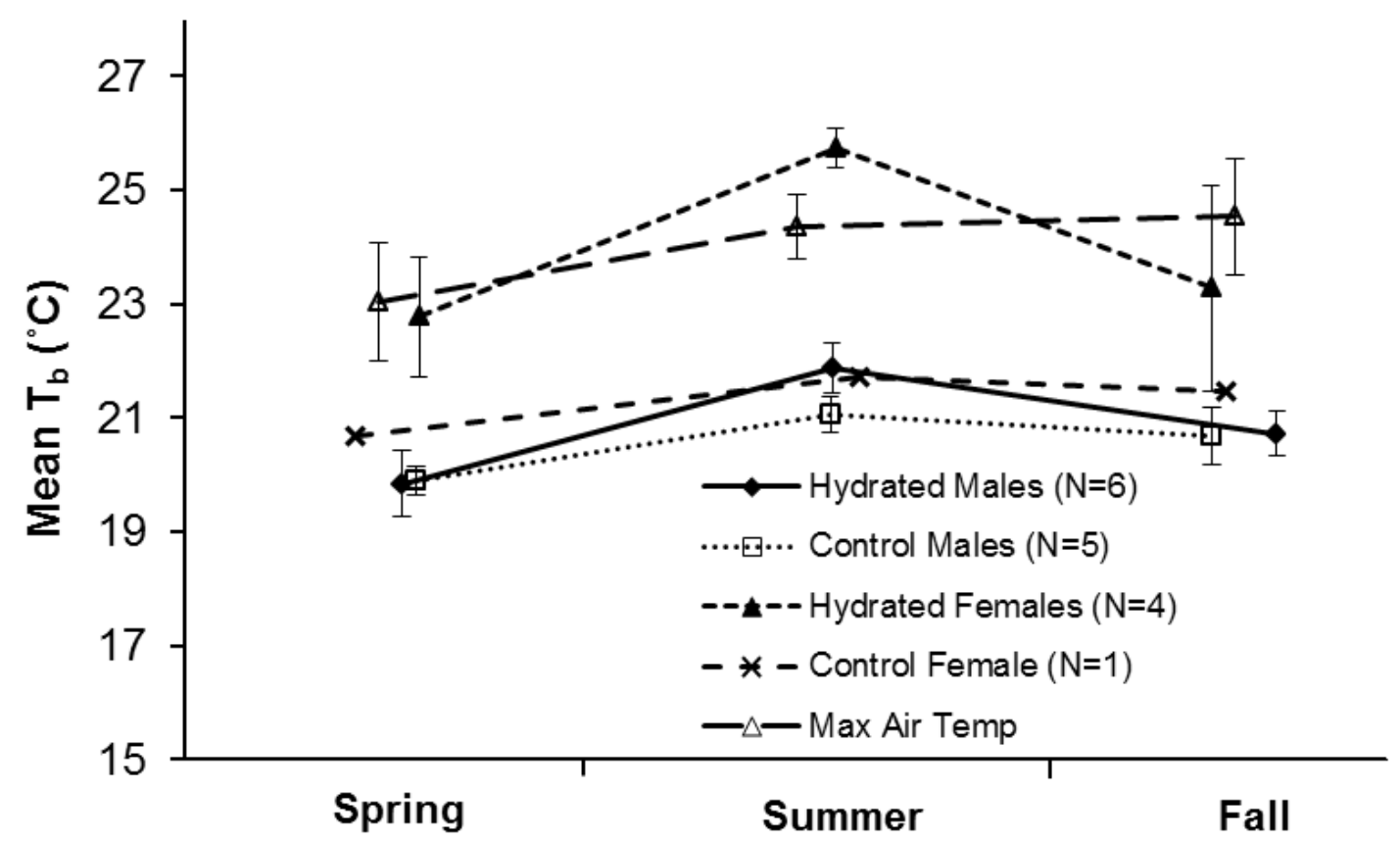

Figure 14. Mean $\mathrm{T}_{\mathrm{b}}$ of C. o. oreganus during spring, summer, and fall. Hydrated females had significantly higher mean $\mathrm{T}_{\mathrm{b}}$ than both hydrated and control males, but not control females. This is most likely due to the fact that all hydrated females were pregnant. Note the large variance in $\mathrm{T}_{\mathrm{b}}$ of hydrated females and that the control female clusters with males. 


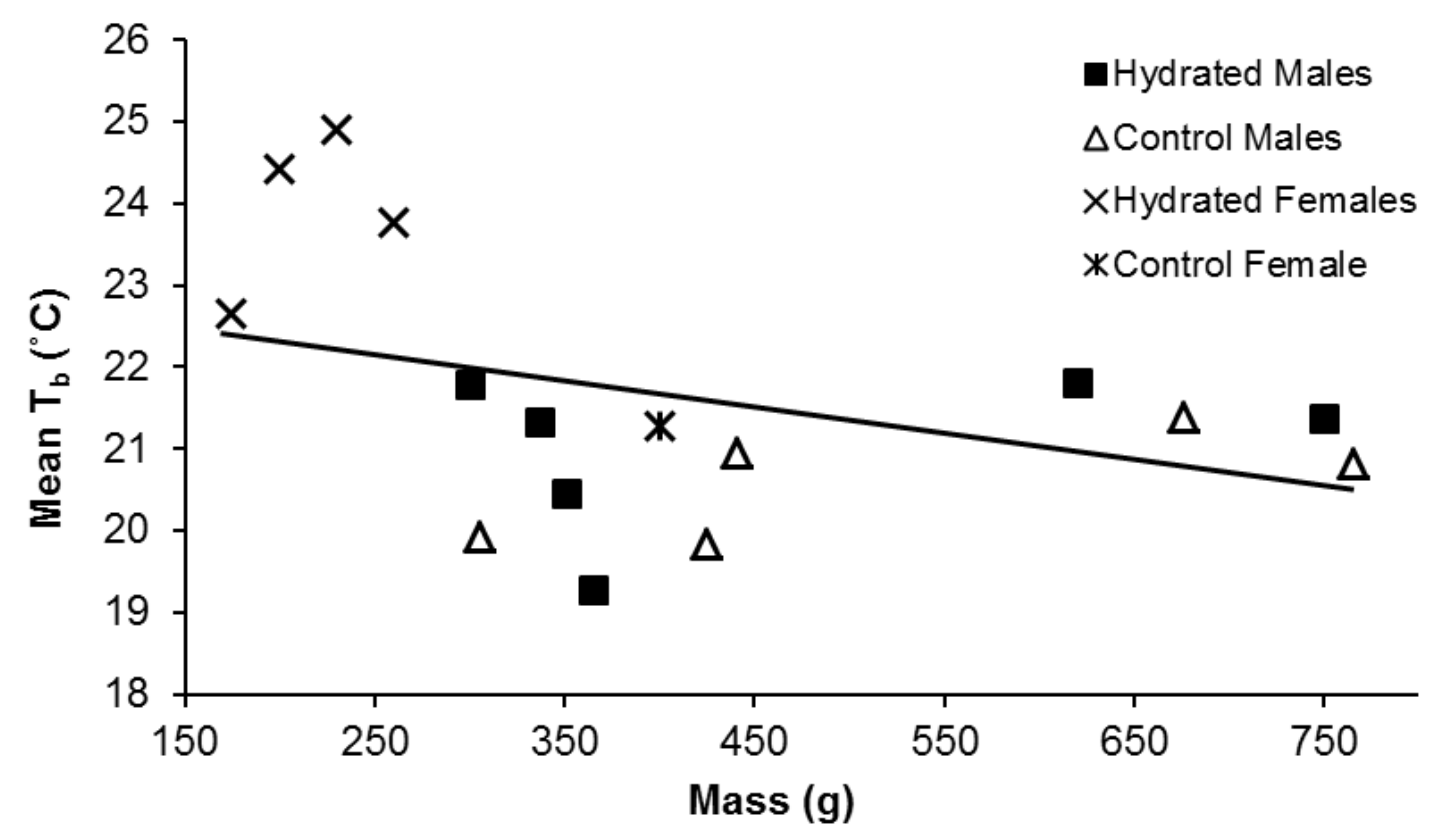

Figure 15. Mass of individual C. o. oreganus is plotted against mean $\mathrm{T}_{\mathrm{b}}$. Mass was significant as a covariate in the analysis of seasonal mean $\mathrm{T}_{\mathrm{b}}$ with larger snakes having lower mean $\mathrm{T}_{\mathrm{b}}$. 


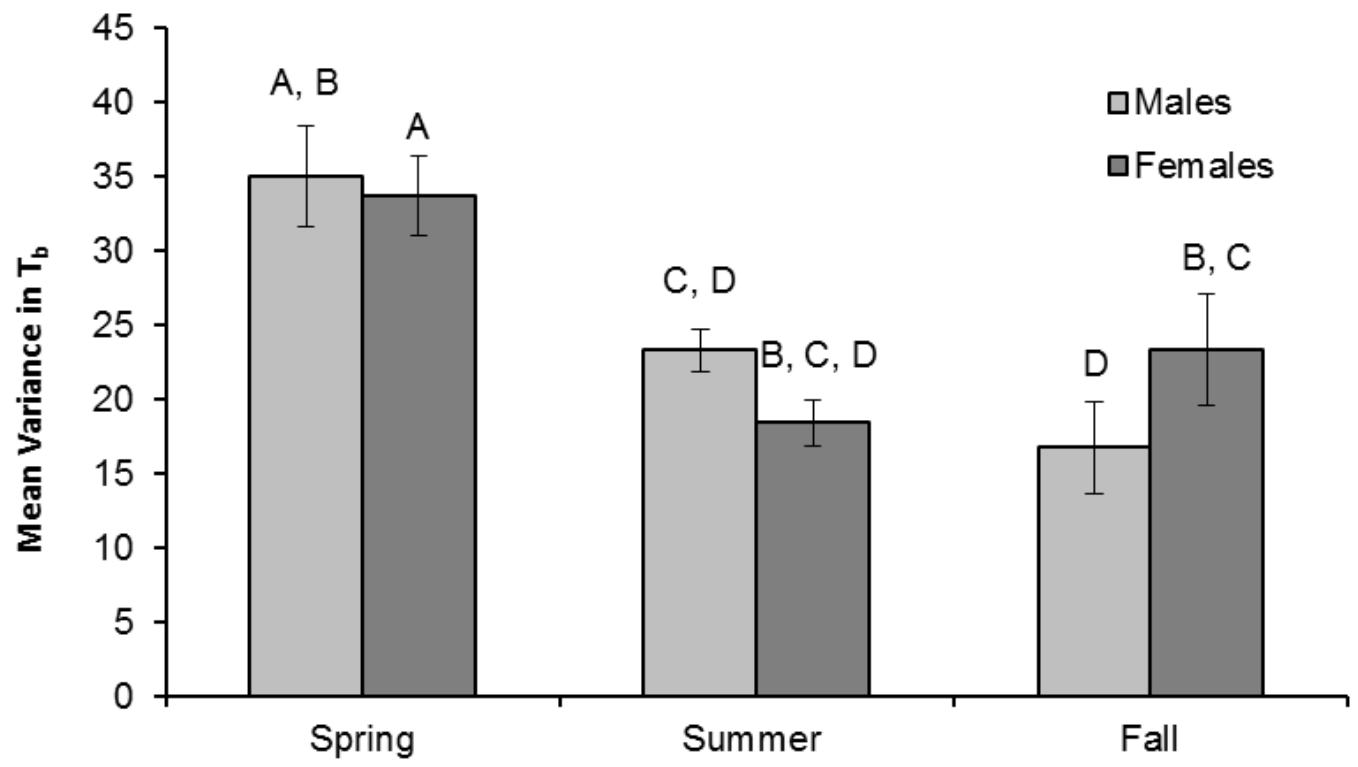

Figure 16. Mean variance in $\mathrm{T}_{\mathrm{b}}$ of male and female C. o. oreganus in spring, summer, and fall. Variance was significantly higher in spring, regardless of sex or treatment group. Bars that do not share a letter are significantly different from each other. Numbers in bars are sample sizes and error bars are 1 SEM. 


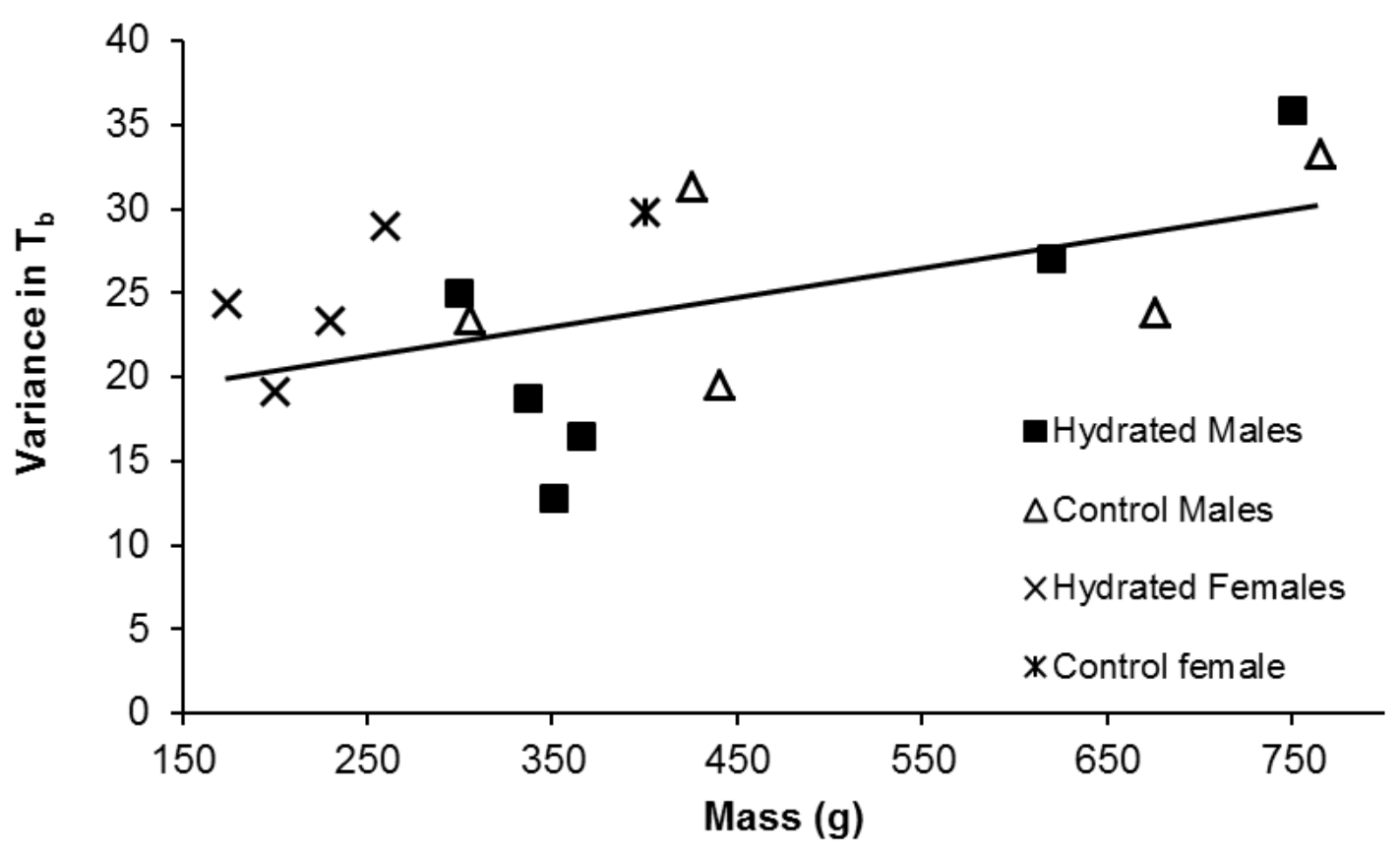

Figure 17. Mass of individual C. o. oreganus is plotted against variance in seasonal $\mathrm{T}_{\mathrm{b}}$. Mass was a significant covariate in the analysis of seasonal variance in $\mathrm{T}_{\mathrm{b}}$ with heavier snakes having more variance. 


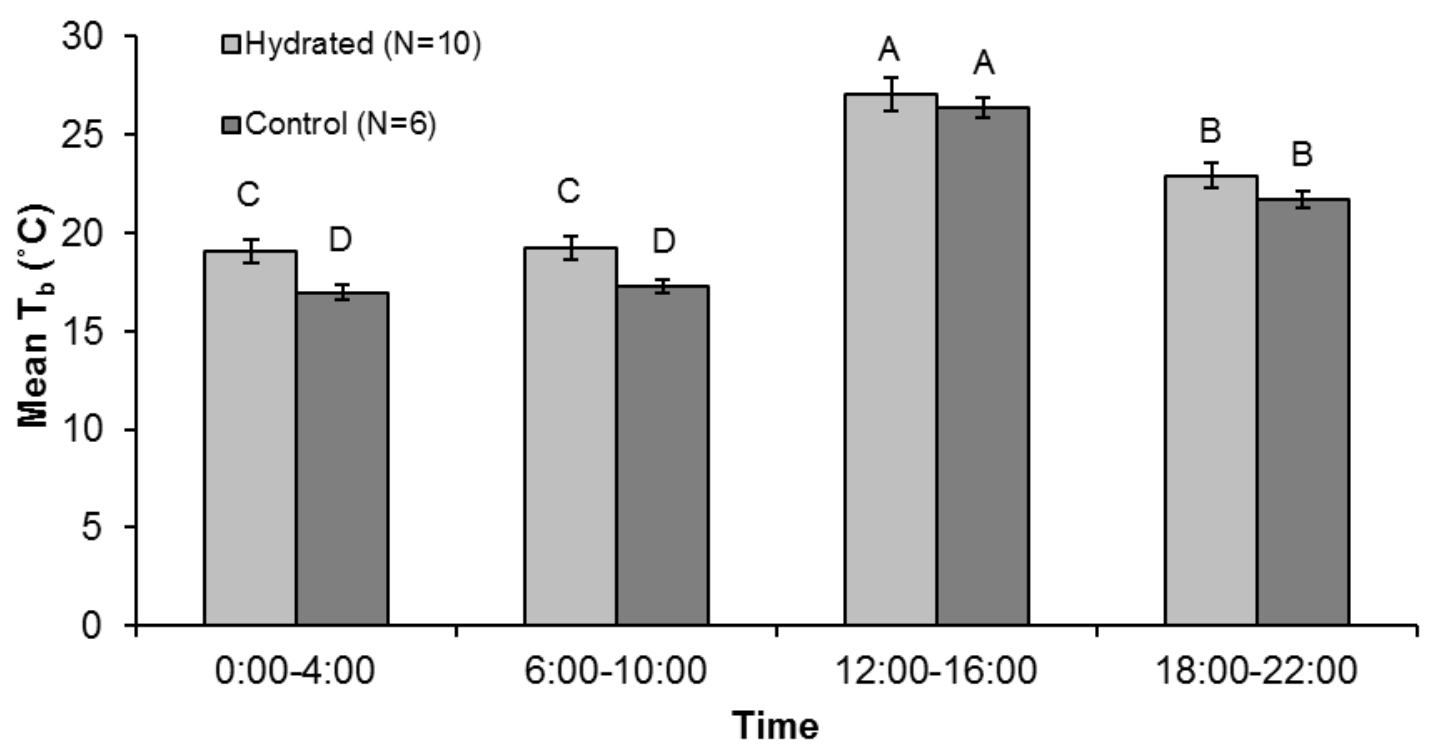

Figure 18. Mean $\mathrm{T}_{\mathrm{b}}$ of hydrated and control C. o. oreganus at four different times of day. The effect of hydration was dependent on the time of day. After noon, hydrated and control groups did not differ. However, between 0:00-10:00 hydrated and control groups differed in mean $\mathrm{T}_{\mathrm{b}}$. Bars that do not share a letter are significantly different. Error bars are 1 SEM. 


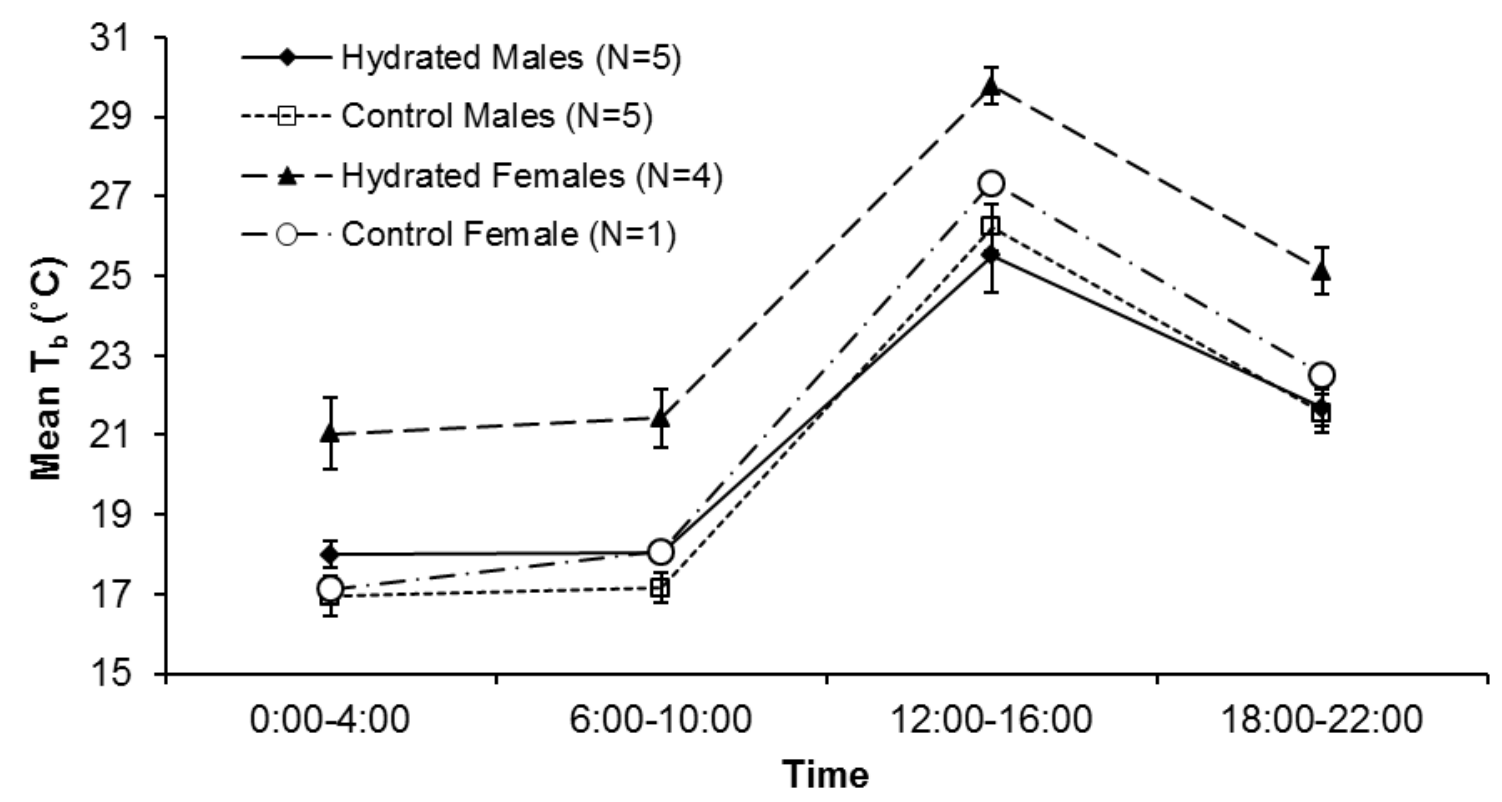

Figure 19. Mean $\mathrm{T}_{\mathrm{b}}$ of C. o. oreganus at four different times of day. Hydrated females show the highest mean $T_{b}$ regardless of time of day, but this was marginally nonsignificant. Note that all hydrated females were pregnant. Error bars are 1 SEM. 


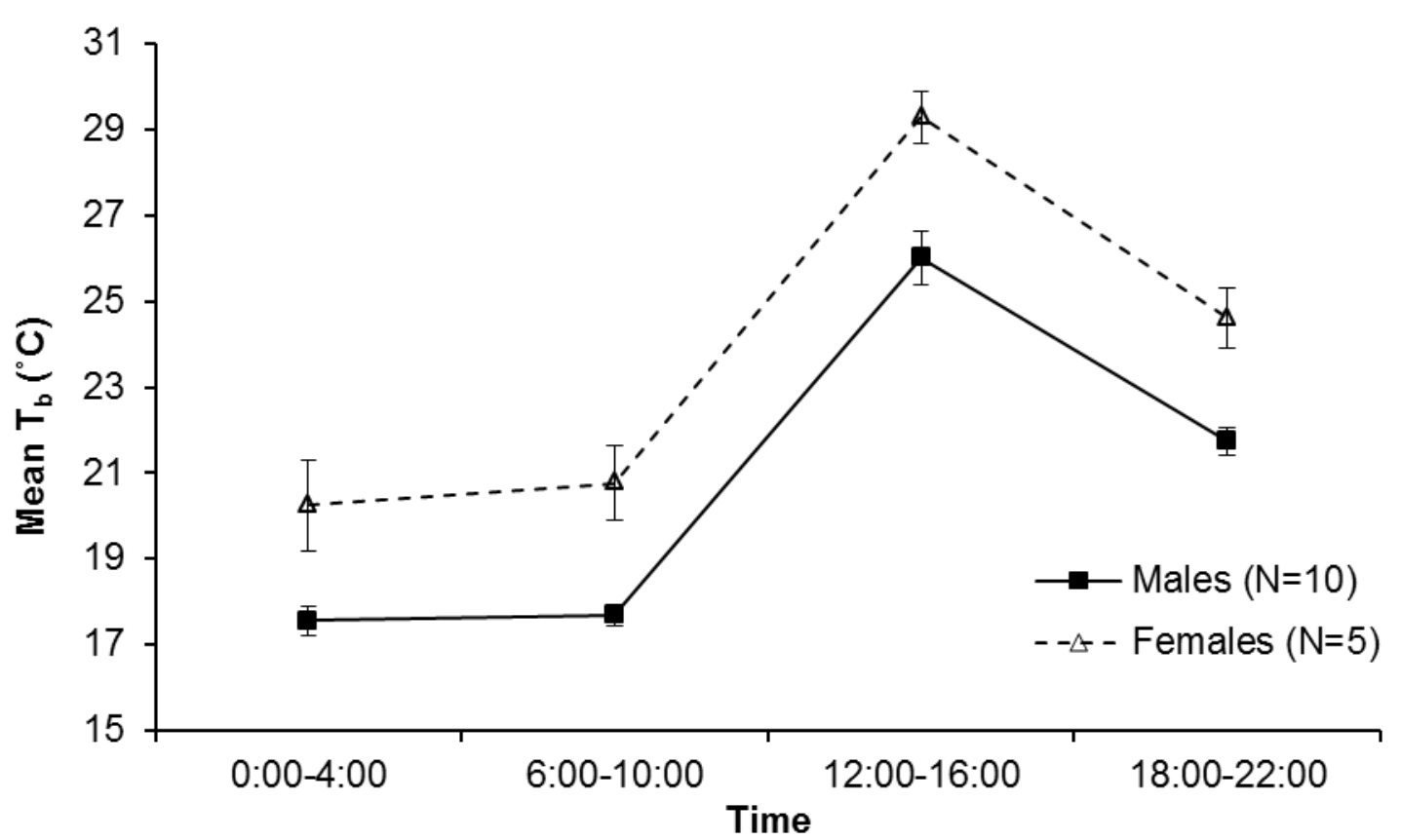

Figure 20. Mean $\mathrm{T}_{\mathrm{b}}$ of male and female C. o. oreganus at four different diel periods.

Females had significantly higher $\mathrm{T}_{\mathrm{b}}$, regardless of the time of day. Error bars are 1 SEM. 


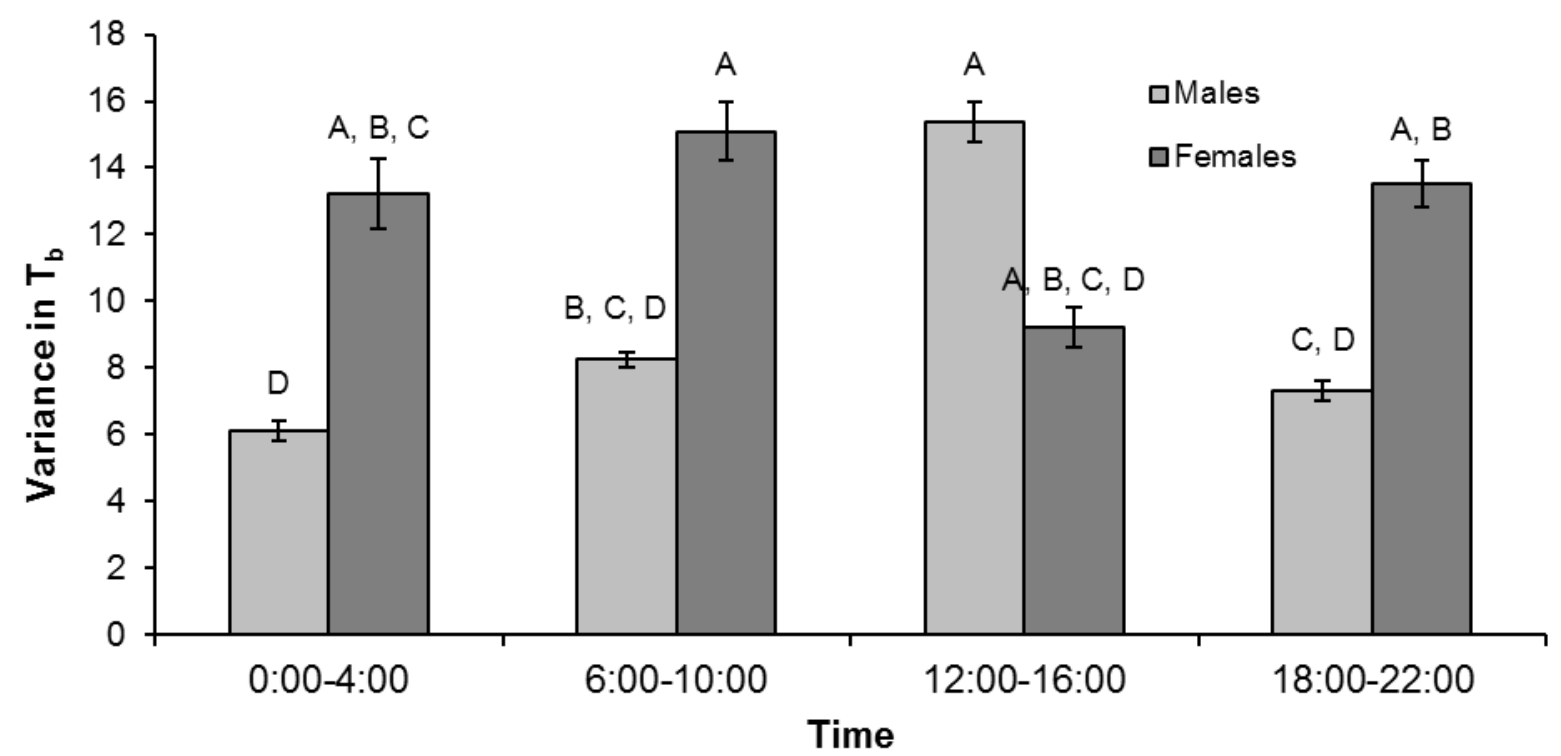

Figure 21. Variance in $\mathrm{T}_{\mathrm{b}}$ of male and female $C$. o. oreganus at four different times of day. The effect of sex on variance in $\mathrm{T}_{\mathrm{b}}$ was dependent on the time of day. Means that do not share a letter are significantly different. Variance for males spiked in the middle of the day, while for females it drops. This suggests that the pregnant females in this group were maintaining a narrow temperature range; however, this difference was not significant. Error bars are 1 SEM. 
Appendix C Supplementary Figures

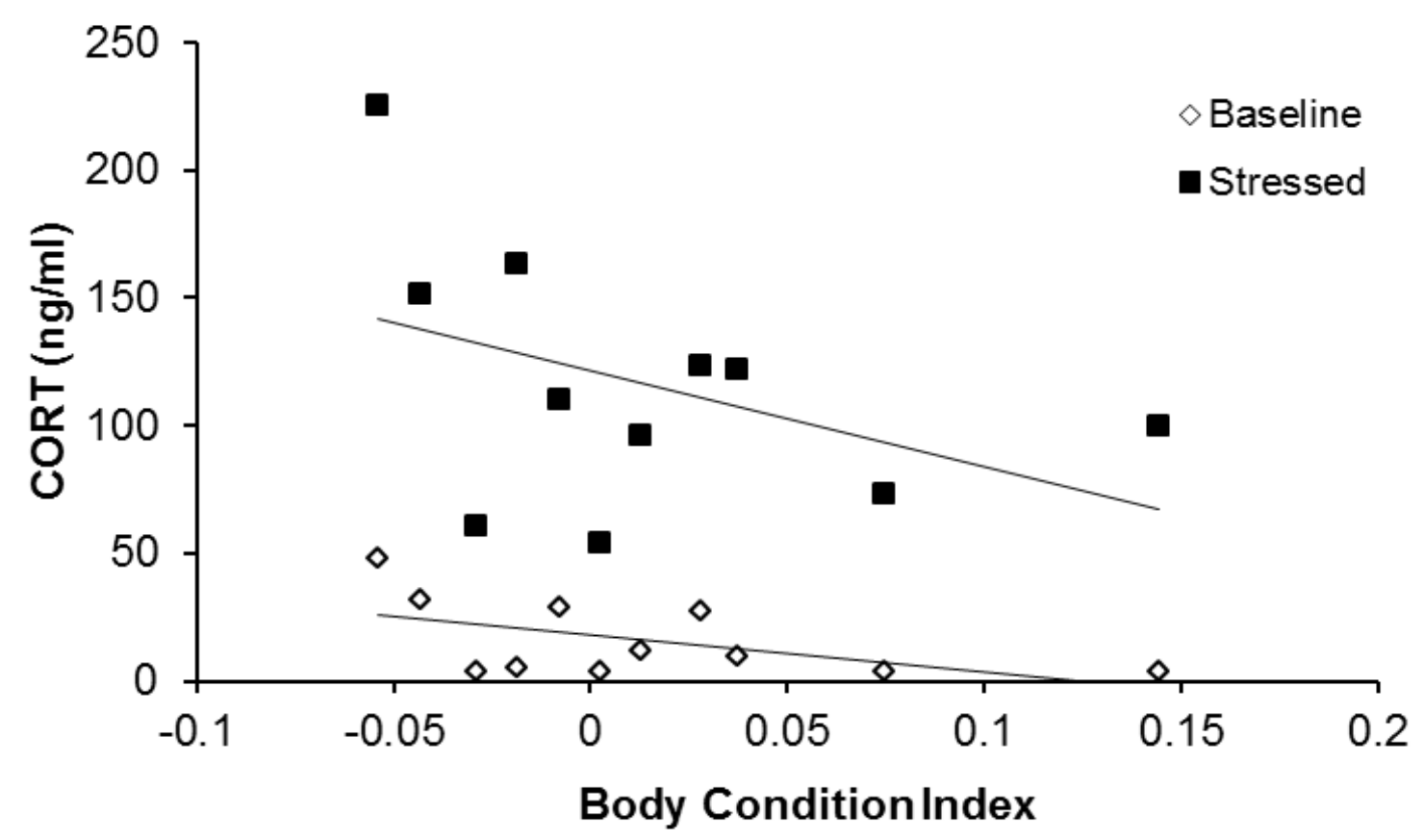

Figure 22. Initial BCI of individual C. o. oreganus is plotted against baseline and stressed CORT concentrations. Higher body conditions corresponded to lower CORT concentrations regardless of whether the sample came from before or after an acute stressor. Hydrated females are not included in this figure. ANCOVA: Sample $\mathrm{F}_{1,9.8}=$ 263.69, $\mathrm{p}<0.001$; Initial body condition $\mathrm{F}_{1,5.82}=17.83, \mathrm{p}=0.006$. 


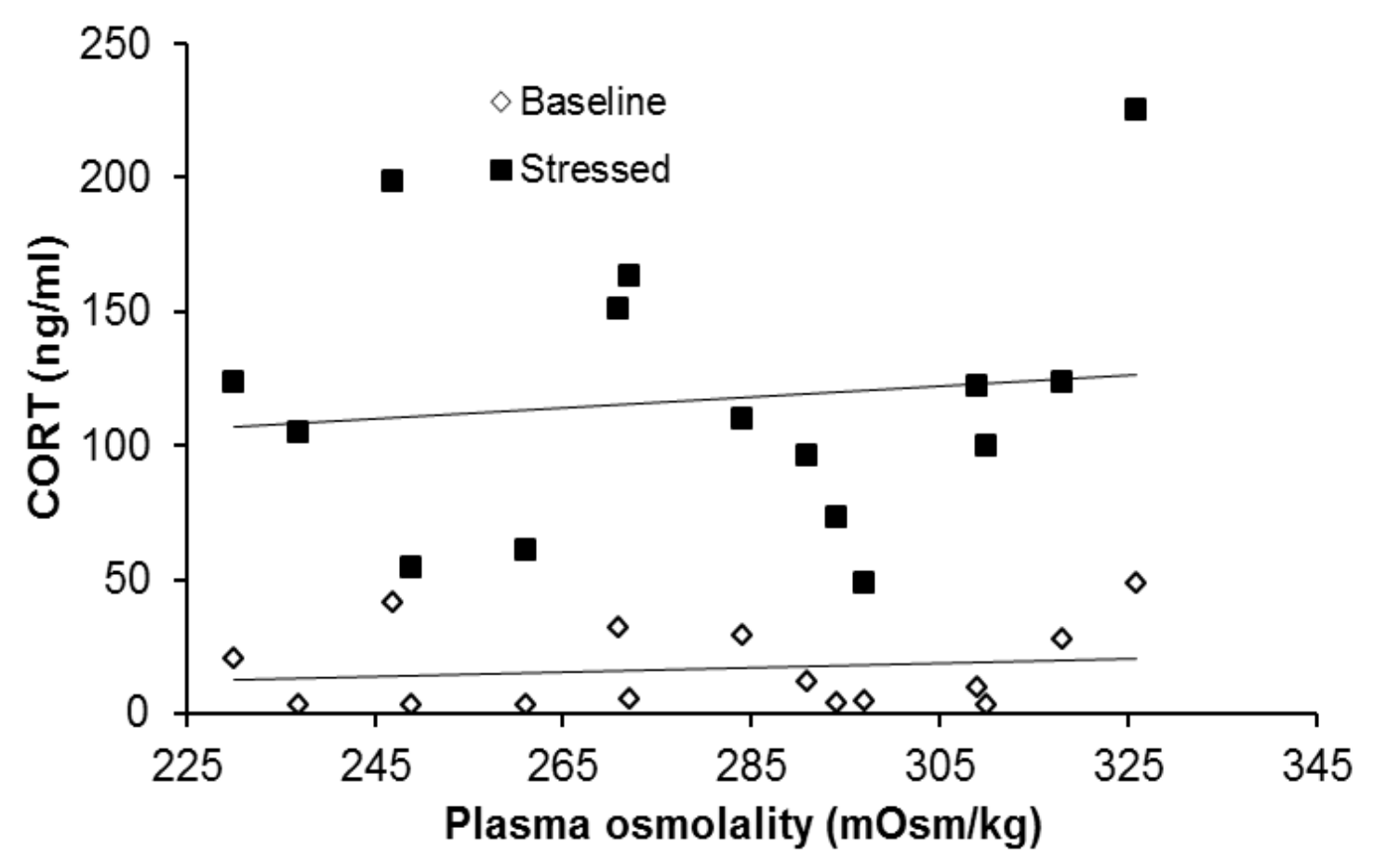

Figure 23. Plasma osmolality of individual C. o. oreganus is plotted against CORT concentration. There was a slight positive relationship and higher plasma osmolality corresponded to higher CORT concentrations. This relationship was not significant as a linear regression, but when included as a covariate with CORT as an ANCOVA it was significant $\left(\right.$ Sample $\mathrm{F}_{1,9.8}=263.69, \mathrm{p}<0.001$; plasma osmolality $\mathrm{F}_{1,5.81}=11.12, \mathrm{p}=$ 0.016). 


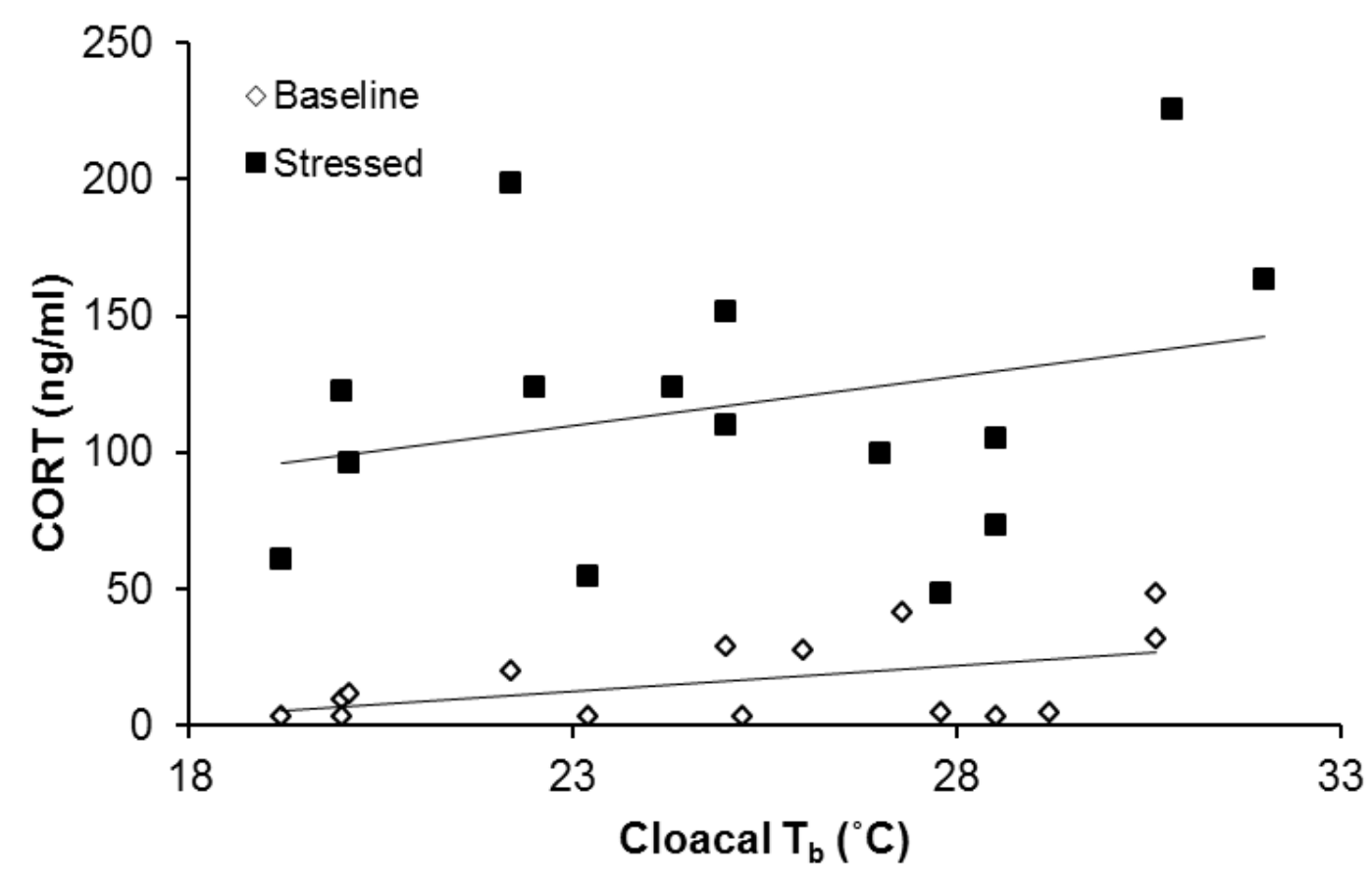

Figure 24. Cloacal $\mathrm{T}_{\mathrm{b}}$ of individual C. o. oreganus is plotted against baseline and stressed CORT concentration. As temperatures rose, so did CORT concentrations. This was not significant on its own as a linear regression but was significant as a covariate with CORT in an ANCOVA (Sample $\mathrm{F}_{1,9.8}=263.69, \mathrm{p}<0.001$; Cloacal $\mathrm{T}_{\mathrm{b}} \mathrm{F}_{1,6.1}=8.77, \mathrm{p}=0.025$ ). 